\title{
Competition And Performance in the Hungarian SECOND PILLAR
}

\author{
Gregorio Impavido and Roberto Rocha
}

\begin{abstract}
The performance of the Hungarian second pillar since inception has been mixed. This is partly due to a less than satisfactory support for the 1997 pension reform, conservative fund portfolio distributions, the hybrid nature of the mandatory pension fund system, the segmented nature of the market in terms of costs, and a less than aggressive commitment on the part of the Hungarian Financial Supervisory Authority to a low-cost, transparent, and competitive equilibrium. In the accumulation phase, the authorities would need to further promote transparency and comparability of information on costs and investment performance, facilitate migration to lower cost funds, and more generally promote competition. The regulatory framework of the payout phase needs to be overhauled before the first cohort of workers retires.
\end{abstract}

World Bank Policy Research Working Paper 3876, April 2006

The Policy Research Working Paper Series disseminates the findings of work in progress to encourage the exchange of ideas about development issues. An objective of the series is to get the findings out quickly, even if the presentations are less than fully polished. The papers carry the names of the authors and should be cited accordingly. The findings, interpretations, and conclusions expressed in this paper are entirely those of the authors. They do not necessarily represent the view of the World Bank, its Executive Directors, or the countries they represent. Policy Research Working Papers are available online at http://econ.worldbank.org.

$\dagger$ This paper was prepared by Gregorio Impavido (gimpavido@,worldbank.org) and Roberto R. Rocha (rrocha@worldbank.org), both in the Financial Sector Operations and Policy Department of the World Bank. The paper benefited from inputs by David J. Goldstein (dgoldstein1@,worldbank.org) in section VI dealing with capital markets. The usual caveat applies. 



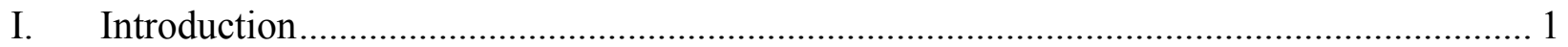

II. The structure of the Second Pillar............................................................................... 2

III. Performance of the Second Pillar: Growth ................................................................ 4

IV. Performance of the Second Pillar: Portfolios and Investment Return ............................. 7

V. Performance of the Second Pillar: Costs and Fees .................................................... 15

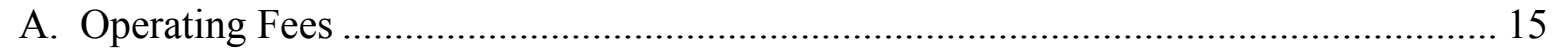

B. Asset Management Fees ...................................................................................... 17

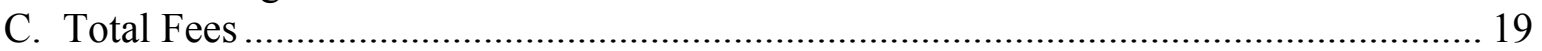

VI. Pension Reform and Capital Market Development .................................................... 26

VII. Regulation of the Accumulation and Payout Phases .................................................. 30

A. Main Regulatory Issues in the Accumulation Phase ............................................ 30

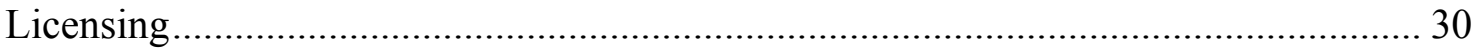

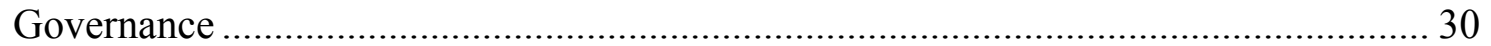

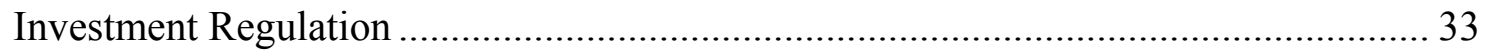

Minimum Return Guarantee .......................................................................... 35

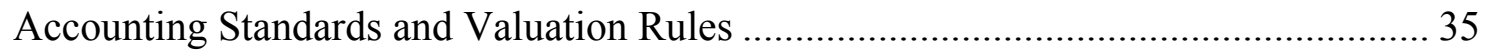

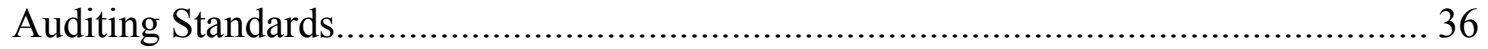

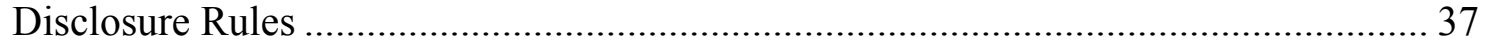

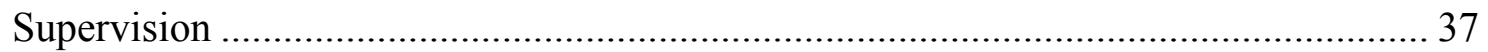

B. Main Regulatory Issues in the Payout Phase ........................................................... 39

Review of Main Payout Regulations ..................................................................... 39

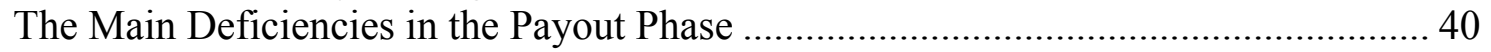

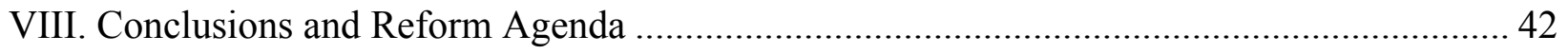

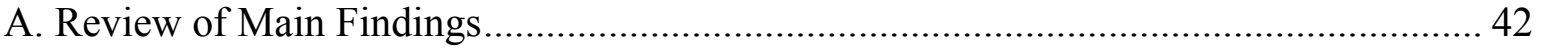

B. Improving the Regulatory Framework for the Accumulation Phase .......................... 44

C. Overhauling the Regulatory Framework for the Payout Phase ................................... 49

D. Promoting the Development of Financial Instruments ............................................ 50

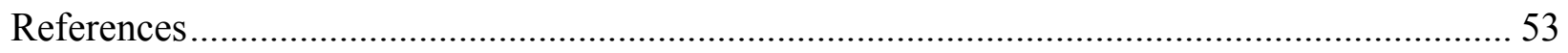

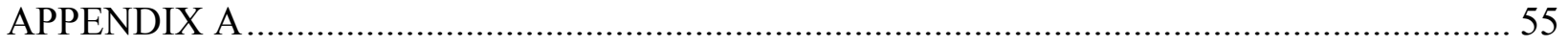

Methodology for Estimating the Sources of Growth of Pension Fund Assets. ................. 55

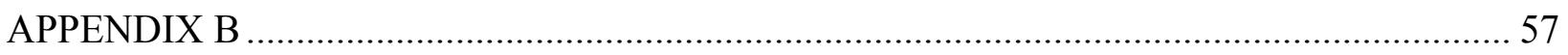

A General Framework for Comparing Fees During the Accumulation Phase ................... 57

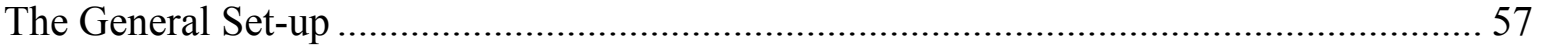

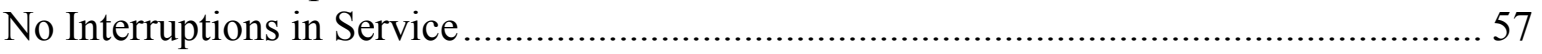


Total Differential of A(F,c,T) with no Interruption in Service.......................................... 58

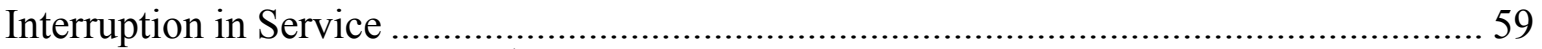

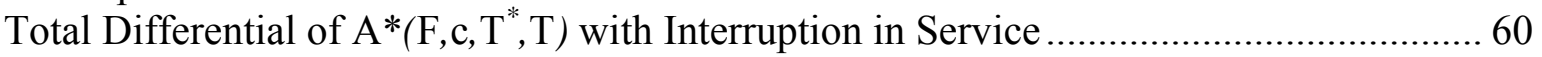

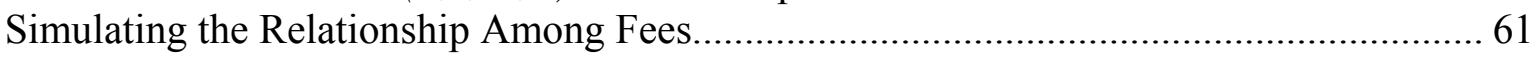

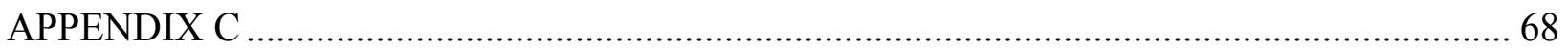

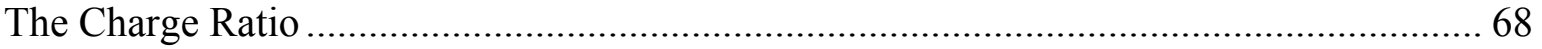

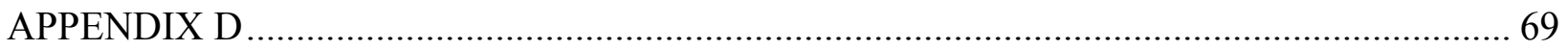

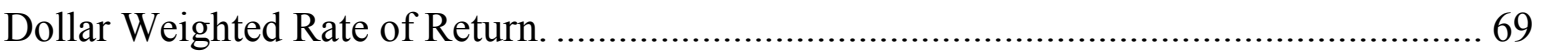

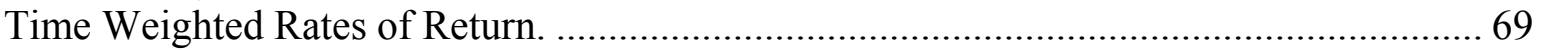

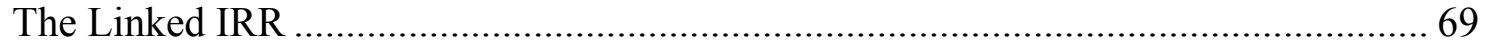

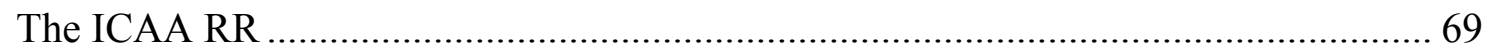

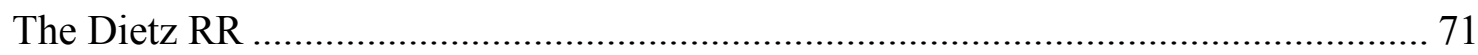

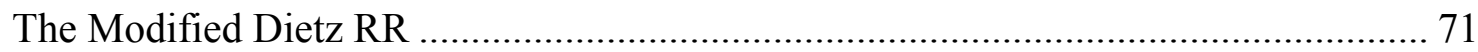

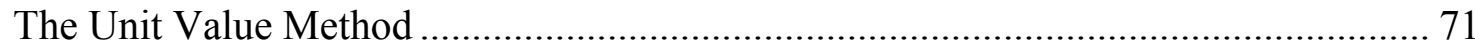

Comparing the Different Methodologies ......................................................................... 72

Tables

Table 1: Summary Data on the Structure of the Second and Third Pillars.................................. 2

Table 2: Number of Second Pillar Funds in Latin America and Central Europe, 2004 ................. 3

Table 3: Market Structure of the Hungarian Second Pillar, 2004.................................................. 3

Table 4: Second Pillar Market Structure by Type of Sponsor, 2004 ……………….................. 4

Table 5: Second Pillar Assets in Hungary and Other Reforming Countries (\% of GDP) .............. 6

Table 6: Sources of Growth of Pension Assets over GDP, 1998 - 2004 ...................................... 6

Table 7: Evolution of Second Pillar Contributions, 1998 - 2004 …….................................... 7

Table 8: Portfolio Composition of MPFs (\% of total), 1998 - 2004 .............................................. 9

Table 9: Portfolios of Pension Funds in Hungary and Other Reforming Countries (\%) .............. 9

Table 10: Fiscal Policy and National Savings in the Transition, 2000 - 2004 …….................... 10

Table 11: Net Rates of Return, Wage Growth, and Inflation Rates, 1998 - 2004 ........................ 12

Table 12: Average Gross and Net Real Rates of Return and Wage Growth, $1998-2005$......... 13

Table 13: Average Historical Rate of Return and Sovereign Risk ............................................ 13

Table 14: Annual Net Rate of Return by Type of MPF, 1998 - 2004 .......................................... 14

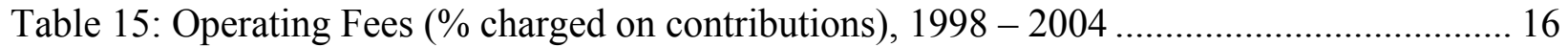

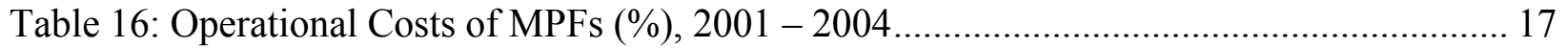

Table 17: Asset Management Fees (\% charged on average assets), 1998 - 2004 ......................... 18

Table 18: Total Fees as a Share of Contributions (\%), $1998-2004$............................................ 19

Table 19: Total Fees as a Share of Average Assets (\%), 1998 - 2004 ……............................... 20

Table 20: Charge ratios for the average MPF in Hungary, (\%) .................................................. 25

Table 21: Stocks of Major Financial Instruments (\% of GDP), 2000 and 2004............................ 26

Table 22: Statutory limits on asset holdings for MPFs............................................................ 34

Table 23: Comparative statics of fee relationship when net rate of return is allowed to change. 64

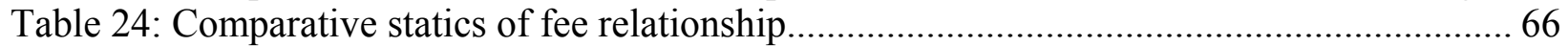

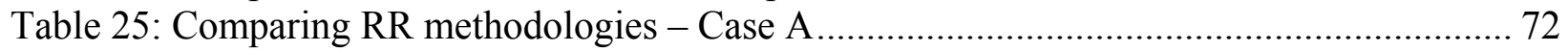


Table 26: Comparing RR methodologies - Case A.............................................................. 72

Table 27: Comparing RR methodologies - Case B .............................................................. 73

Table 28: Comparing RR methodologies - Case C ............................................................... 73

Table 29: Comparing RR methodologies - Case D............................................................... 73

Table 30: Comparing RR methodologies - Case E ............................................................ 74

Table 31: Comparing RR methodologies - Case B - E.................................................... 74

Figures

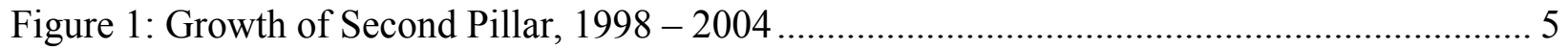

Figure 2: Size of public debt and share in pension funds portfolio - select countries ............... 10

Figure 3: Performance of Bonds and Stocks in Hungary, $1997-2004$................................... 11

Figure 4: Nominal and Real Annual Interest Rate on T-bills, 2000 - 2004 ............................ 12

Figure 5: Total Fees over Contributions - Hungary and Other Countries (\%).......................... 21

Figure 6: Total Fees over Assets - Hungary and Other Countries (\%) .................................. 21

Figure 7: Long Run Total Fees over Contributions for the Average MPF ............................... 22

Figure 8: Long Run Total Fees over Assets for the Average MPF ....................................... 22

Figure 9: Long-Run Fees over Contributions for Average, Highest and Lowest Cost MPF...... 23

Figure 10: Long-run Fees over Assets for Average, Highest and Lowest Cost MPF ............... 24

Figure 11: Long-Run Fees Over Contributions Equivalent to a 1\% Asset Management Fee..... 25

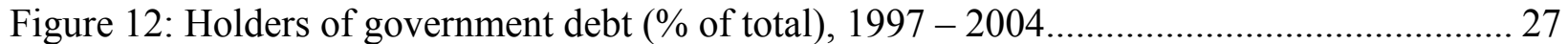

Figure 13: Stock Of government securities by maturity - HUF million, Dec. 2004 ................. 28

Figure 14: Average maturity and duration of government securities, 2002-2004 .................... 28

Figure 15: Decrease in Long-Run Average Fee over Assets in Mexico.................................... 47 



\section{INTRODUCTION}

1. In July 1997, the Hungarian Parliament approved the first systemic pension reform in Central and Eastern Europe. The reform involved several parametric changes to the old public pay-as-you-go scheme and the introduction of a mixed pension system comprising a downsized mandatory public scheme as a first pillar, a new system of mandatory and privately-managed schemes as a second pillar, and the old voluntary and privately managed schemes as a third pillar. ${ }^{1}$ The critical component of the systemic reform was the introduction of the mandatory pension funds (MPF) as second pillar.

2. Participation in the new second pillar was made mandatory for new entrants to the labor force after July 1, 1998, and voluntary for all remaining workers. The new second pillar started operating in January 1, 1998, and by 2004 MPF assets had increased to 4 percent of GDP. This compares with assets of 2.6 percent of GDP managed by the voluntary pension funds that had been operating since 1993 (the third pillar). ${ }^{2}$

3. This paper analyzes the structure and performance of the MPF system in Hungary, as well as its regulatory and supervisory framework. The analysis of the MPF system in Hungary is important for several reasons. The second pillar in Hungary is already larger than the third pillar, despite having been created five years later, and should become much larger in the coming decades when maturity is reached. Moreover, when the transition to the new system is completed, the second pillar should provide about 30 percent of the retirement income of all Hungary pensioners. In contrast, the third pillar plays only a complementary function in the Hungarian pension system. While this function is also important, the performance of the third pillar will not affect the welfare of the Hungarian retired population to the same extent as the second pillar.

4. Finally, a performance assessment of the Hungarian second pillar is also interesting due to the rather unique way in which the MPF system has been designed. The private pension sector of most countries is either based on closed occupational funds, legally structured as non-profit trusts or foundations with boards, or it is based on open funds, without boards, and managed by profit-oriented pension fund managers. The former model is prevalent in Western Europe while the latter model is prevalent in most reforming countries in Eastern Europe, as well as most Latin American countries. By contrast, MPFs in Hungary are open funds which operate as non-profit mutual associations with a board of directors and without minimum capital requirements.

5. The non-profit nature of the mutual association and the lack of a minimum capital requirement have meant that most MPFs had to be sponsored either by a large employer or by a financial group, in order to meet the high start-up costs. Today, the MPF sponsor controls de facto the board and therefore the fund policies. This has resulted in a segmented pension system with participating funds grouped in three main groups. The first and the largest group of funds is sponsored (and controlled) by financial institutions. The second group of funds is sponsored by large employers, mostly utility companies.

\footnotetext{
${ }^{1}$ The voluntary schemes had been introduced in 1993, long before the 1997 reform.

${ }^{2}$ Palacios and Rocha (1998) and Rocha and Vittas (2002) examine the Hungarian reform in detail. Matits (2002 and 2004) provide an analysis of the second and third pillars.
} 
The third group of funds seems to be composed of independent MPFs. The funds sponsored by financial institutions account for about 85 percent of total assets, despite charging higher fees. One of the main challenges faced by Hungarian regulators is to reduce the current degree of market segmentation, taking advantage of the presence of low-cost funds to improve competition and reduce costs and fees for all participants.

6. This paper is structured as follows. Section II analyzes the industrial organization of the Hungarian MPFs by type of sponsor. Section III, IV and V provide an analysis of the performance of the MPF system in terms of asset growth, portfolio composition and investment return, and fees, respectively. Section VI examines the links between pension reform and capital market development. Section VII examines the key regulatory issues in the accumulation and payout phases. Conclusions and policy recommendations follow.

\section{The STRUCTURE OF THE SEcond Pillar}

7. The second pillar started operating in January 1998, with 38 MPFs initially licensed by the Pension Fund Supervision Agency. The Pension Supervisor was integrated in the year 2000 into the Hungarian Financial Supervisory Authority (HFSA). ${ }^{3}$ Table 1 reports summary indicators of the evolution of the MPF system between 1998 and 2004. At the end of 2004, there were 18 MPFs operating in Hungary, managing the accounts of 2.4 million members (more than half of the labor force) and assets of 4 percent of GDP. The second pillar manages a larger portion of assets than the third pillar. It also covers more than twice as many members.

8. The second pillar has always been very concentrated, with the six largest MPFs accounting for more than 80 percent of total assets. Nevertheless, the reduction in the number of MPFs did not contribute to an increase in concentration since the MPFs that left the market (mostly through mergers or acquisitions) were very small. By contrast, the consolidation in the third pillar was accompanied by an increase in concentration. In 2004 there are still 75 voluntary pension funds in operation, from the 315 in 1998.

Table 1: Summary Data on the Structure of the Second and Third Pillars

\begin{tabular}{lrrrrrrr}
\hline & $\mathbf{1 9 9 8}$ & $\mathbf{1 9 9 9}$ & $\mathbf{2 0 0 0}$ & $\mathbf{2 0 0 1}$ & $\mathbf{2 0 0 2}$ & $\mathbf{2 0 0 3}$ & $\mathbf{2 0 0 4}$ \\
\hline Second Pillar & & & & & & & \\
Number of funds & 38 & 39 & - & 18 & 18 & 18 & 18 \\
Total Assets (\% of GDP) & 0.3 & 0.8 & 1.3 & 1.9 & 2.5 & 3.0 & 4.0 \\
Number of members (000) & 1,347 & 2,064 & 2,193 & 2,253 & 2,214 & 2,304 & 2,402 \\
Share of 6 largest funds (\%) & 83 & 84 & 84 & 86 & 87 & - & 83 \\
Third Pillar & & & & & & & \\
Number of funds & 315 & - & - & - & 82 & - & 75 \\
Total Assets (\% of GDP) & 1.0 & 1.4 & 1.7 & 2.0 & 2.2 & 2.4 & 2.6 \\
Number of members (000) & 940 & 1,008 & 1,081 & 1,153 & 1,179 & - & - \\
Share of 15 largest funds (\%) & 47 & 59 & 71 & 74 & 80 & - & - \\
\hline Source: HFSA & & & & & & &
\end{tabular}

9. The relatively small number of funds and the concentrated market structure are not features unique to the Hungarian second pillar. As a matter of fact, in other reforming

\footnotetext{
${ }^{3}$ See Section VII.
} 
countries in Central Europe and Latin America, the number of institutions operating in the second pillar is even smaller, as shown in Table 2.

Table 2: Number of Second Pillar Funds in Latin America and Central Europe, 2004

\begin{tabular}{cc|cc}
\hline Central Europe & & Latin America & \\
\hline Hungary & $\mathbf{1 8}$ & Argentina & 12 \\
Bulgaria & 8 & Bolivia & 2 \\
Croatia & 7 & Chile & 6 \\
Estonia & 6 & Colombia & 6 \\
Kazakhstan & 13 & Costa Rica & 8 \\
Latvia & 5 & El Salvador & 2 \\
Poland & 16 & Mexico & 13 \\
& & Peru & 4 \\
& & Uruguay & 4 \\
\hline
\end{tabular}

Source: HFSA, AIOS, FIAP

10. What are possibly unique in Hungary are the segmented nature of the second pillar and the continued existence of smaller institutions. Table 3 shows the large difference between the smallest and the largest institution in the Hungarian second pillar, whether the difference is measured in assets, members, or contributions.

Table 3: Market Structure of the Hungarian Second Pillar, 2004

\begin{tabular}{lccc}
\hline & $\begin{array}{c}\text { Assets } \\
\text { (HUF 000,000) }\end{array}$ & $\begin{array}{c}\text { Members } \\
\text { (unit) }\end{array}$ & $\begin{array}{c}\text { Contributions } \\
\text { (HUF 000,000) }\end{array}$ \\
\hline Smallest MPF & 1,003 & 2,840 & 320.3 \\
Largest MPF & 224,161 & 681,231 & $57,267.8$ \\
Average MPF & 48,997 & 133,456 & $11,851.4$ \\
Market Total & 881,944 & $2,402,210$ & $213,324.9$ \\
Share of Largest Six MPFs & $83 \%$ & $87 \%$ & $83 \%$ \\
Herfindahl Index & 1,491 & 1,638 & 1,510 \\
\hline
\end{tabular}

Source: HFSA raw data.

11. The co-existence of large and small institutions is to a large extent due to the diversified nature MPF sponsors. Table 4 shows how the ten MPFs sponsored by financial institutions tend to be much larger. Average assets, contributions and members in this first group are much higher than for the other two groups. ${ }^{4}$ The five MPFs sponsored by large employers have between 8,000 and 20,000 members, mostly employees of the sponsoring company or the group of companies in the sector (i.e., the electricity sector). The three MPFs in the third group have on average 60,000 members, although there is a large difference between the smallest and the largest MPF in this group.

12. The MPFs in the first group account for 87 percent of the market, however measured, reflecting the profit oriented nature of the sponsor and the more aggressive marketing tactics. The MPFs sponsored by employers or considered to be independent represent only around 5 and 8 percent of the market, respectively. These MPFs are open to members who are not employees of the sponsor(s), and most of them would actually welcome an increase in membership as a means to reduce average operating costs.

\footnotetext{
${ }^{4}$ However, the smallest MPF belongs to this group.
} 
However, the sponsorship in these cases does not have a profit motive, and therefore neither the MPFs nor the sponsors maintain a sales force designed to attract more members.

Table 4: Second Pillar Market Structure by Type of Sponsor, 2004

\begin{tabular}{|c|c|c|c|c|}
\hline $\begin{array}{l}\text { Type of } \\
\text { Sponsor }\end{array}$ & & $\begin{array}{c}\text { Assets } \\
\text { HUF 000 } \\
\end{array}$ & $\begin{array}{c}\text { Members } \\
\text { (unit) }\end{array}$ & $\begin{array}{c}\text { Contributions } \\
\text { HUF 000 } \\
\end{array}$ \\
\hline \multirow{5}{*}{ 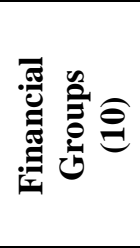 } & Min & $1,003,353$ & 9,141 & 347,000 \\
\hline & Max & $224,161,495$ & 681,231 & $57,267,822$ \\
\hline & Average & $76,904,851$ & 214,356 & $18,605,398$ \\
\hline & Total Financial & $769,048,517$ & $2,143,569$ & $186,053,986$ \\
\hline & $\%$ of Market & $87 \%$ & $89 \%$ & $87 \%$ \\
\hline \multirow{5}{*}{ 旁国 } & Min & $4,410,819$ & 8,195 & 986,141 \\
\hline & Max & $16,081,593$ & 21,622 & $3,836,397$ \\
\hline & Average & $9,201,794$ & 13,746 & $2,097,909$ \\
\hline & Total Employer & $46,008,972$ & 68,733 & $10,489,545$ \\
\hline & $\%$ of Market & $5 \%$ & $3 \%$ & $5 \%$ \\
\hline \multirow{5}{*}{ 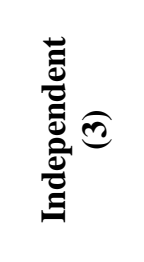 } & Min & $1,523,589$ & 2,840 & 320,274 \\
\hline & Max & $34,102,743$ & 106,596 & $8,348,993$ \\
\hline & Average & $22,295,590$ & 63,303 & $5,593,792$ \\
\hline & Total Independent & $66,886,770$ & 189,908 & $16,781,376$ \\
\hline & $\%$ of Market & $8 \%$ & $8 \%$ & $8 \%$ \\
\hline
\end{tabular}

Source: HFSA raw data.

13. The MPFs sponsored by financial institutions typically outsource asset management and administration to other specialized companies within the same financial group. The other MPFs usually outsource these services as well, sometimes to the same companies, although there are MPFs sponsored by employers that manage their assets internally. When asset management is outsourced, the asset management company typically charges much lower fees to MPFs outside the financial group. There is a marked segmentation in terms of fees that has not translated into increased switching by members from high fee funds to low fee funds. As noted below, this is due in part to the lack of readily comparable information on returns and fees until recently.

14. Finally, arrangements for revenue collection have remained deficient. Individual MPFs deal with many employers, including thousands of small and medium enterprises. As a result, the industry has been considering the creation of a single company specialized in revenue collection, and owned by all the MPFs.

\section{Performance Of The Second Pillar: GroWth}

15. Membership in the second pillar grew rapidly in the first years of operation, as shown in Figure 1. The initial jump in membership reflected the high rate of voluntary switching of younger workers which had already rights under the old system, especially workers under 40 years of age. In the following years, membership was expected to increase at lower but steady rates, in line with the flow of new entrants to the labor force. 
However, in 2001 and 2002, membership stagnated and even declined a little, as result of the lack of official support to the reform. The 1998/2002 Fidesz administration did not support the 1997 pension reform and reverted some of the transition rules - the contribution rate was not increased from 6 to 8 percent as planned, membership of new entrants became voluntary and workers were allowed to switch back to the pure PAYG system. The original rules were restored with the return of the Socialist Government in mid-2002, leading to a slow but steady increase in membership since that time, in line with the original reform plans. ${ }^{5}$

16. In 2004, second pillar assets amounted to about 4 percent of GDP, as previously shown in Table 1. Although the second pillar has surpassed the third pillar in size, it is still small by international comparison. As shown in Table 5, the ratio of second pillar assets to GDP in Hungary is lower than other countries in Latin America and Central Europe with the same period of implementation, and even lower than younger pension systems. Second pillar assets in Hungary have grown at a modest rate of about 0.5 percent of GDP per year, as shown in Table 6, a slower pace of growth than the one projected at the time of the reform.

Figure 1: Growth of Second Pillar, 1998 - 2004

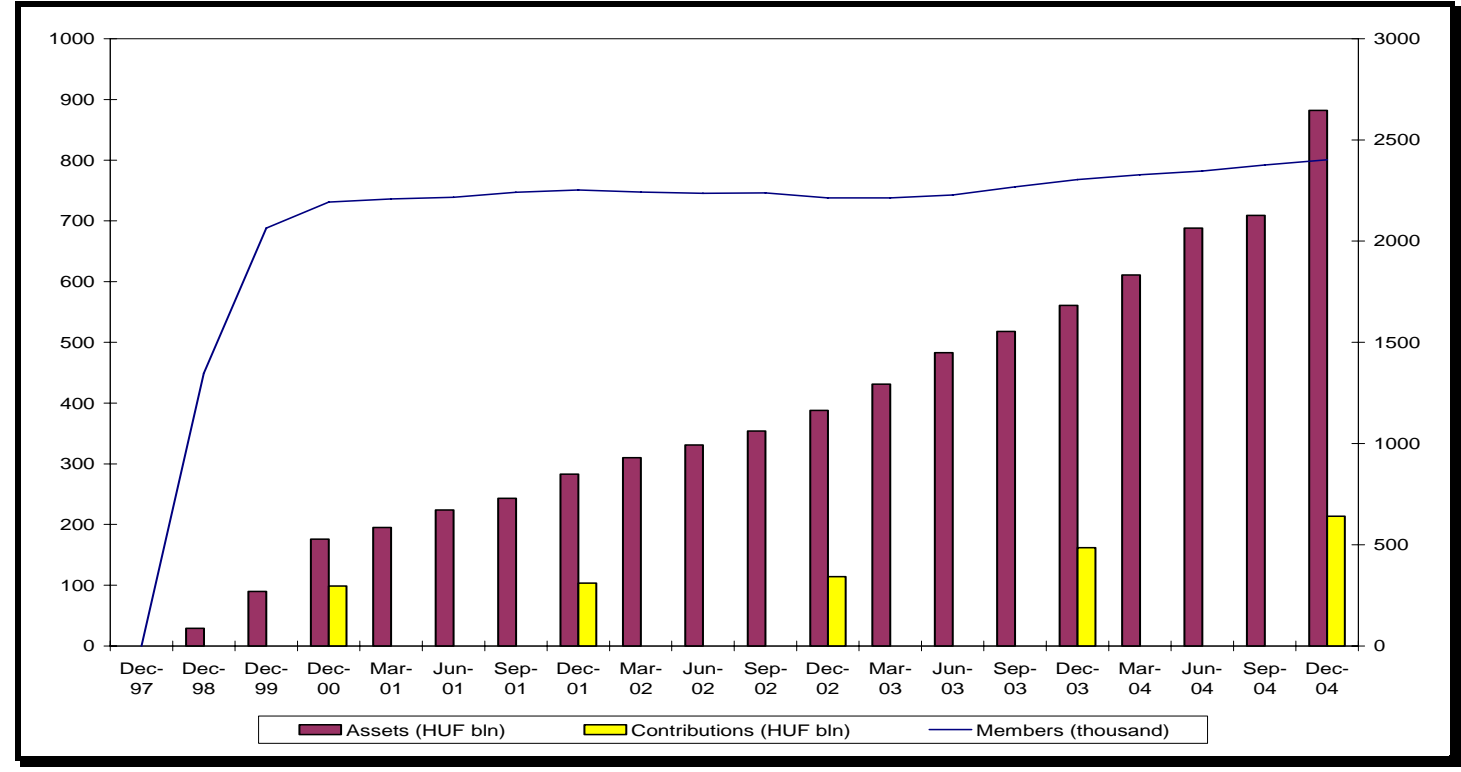

Source: HFSA

17. In order to gain further insights into the causes of the slow growth of assets, the changes in the ratio of pension assets of GDP were tracked by estimating each of its four components: the flow of contributions, asset returns, fees charged, and the growth of GDP. The first two components increase the ratio by increasing the stock of assets, while the third and fourth components decrease the ratio by decreasing the stock of assets and increasing the denominator, respectively. Appendix A describes the methodology used for estimating these components in the absence of flow of funds data.

\footnotetext{
${ }^{5}$ Reform reversals also affected the PAYG component of the pension system. The rate of contribution to the PAYG is 4.5 percentage points lower than the levels envisaged by the reform and may be lowered further by 2 percentage points in 2007 and 2009. The government also granted a $13^{\text {th }}$ monthly pension to retirees to compensate for the Swiss indexation introduced with the reform (Orbán and Palotai, 2005).
} 
Table 5: Second Pillar Assets in Hungary and Other Reforming Countries (\% of GDP)

\begin{tabular}{lccc}
\hline Country & First Year of Operation & At $\mathbf{7}^{\text {th }}$ Year & $\mathbf{2 0 0 4}$ \\
\hline Hungary & 1998 & 4.0 & 4.0 \\
Argentina & 1994 & 7.1 & 12.0 \\
Bolivia & 1997 & 20.9 & 20.5 \\
Chile & 1981 & 13.5 & 59.1 \\
Colombia & 1994 & - & 10.3 \\
Costa Rica & 2001 & - & 2.7 \\
El Salvador & 1998 & 13.7 & 13.7 \\
Mexico & 1997 & 5.7 & 5.8 \\
Peru & 1993 & 4.1 & 11.0 \\
Poland & 1999 & - & 8.0 \\
Uruguay & 1996 & 9.3 & 16.1 \\
\hline
\end{tabular}

Source: HFSA, AIOS

18. As shown in Table 6, the slow growth of the ratio of pension assets to GDP in Hungary has been primarily due to the slow initial growth of contributions and the poor return performance in the first years of implementation. The flow of contributions remained basically stagnant in 2000 - 2002, and only started accelerating in 2003 and 2004 , especially the latter year. The contribution of asset returns should also have increased during the whole period of implementation, in line with the increase in assets, but also remained small and stagnant during most of the period due to low rates of return in most years, as examined in more detail in Section IV. Operating fees did not subtract too much value from assets but have been increasing steadily. This is a trend that is cause for concern, as noted in Section V.

Table 6: Sources of Growth of Pension Assets over GDP, 1998 - 2004

\begin{tabular}{lrrrrrrr}
\hline & $\mathbf{1 9 9 8}$ & $\mathbf{1 9 9 9}$ & $\mathbf{2 0 0 0}$ & $\mathbf{2 0 0 1}$ & $\mathbf{2 0 0 2}$ & $\mathbf{2 0 0 3}$ & $\mathbf{2 0 0 4}$ \\
\hline Assets (\% of GDP) & 0.29 & 0.79 & 1.33 & 1.91 & 2.47 & 3.02 & 3.97 \\
Change (\% of GDP) & - & 0.50 & 0.54 & 0.57 & 0.56 & 0.56 & 0.95 \\
& & & & & & & \\
Sources (\% of GDP): & - & 0.47 & 0.52 & 0.53 & 0.51 & 0.63 & 0.94 \\
Contributions & 0.27 & 0.49 & 0.61 & 0.66 & 0.68 & 0.87 & 1.06 \\
Asset returns & - & 0.08 & 0.11 & 0.12 & 0.16 & 0.12 & 0.27 \\
Fees and charges & - & -0.03 & -0.04 & -0.06 & -0.07 & -0.08 & -0.10 \\
GDP growth & - & -0.06 & -0.15 & -0.19 & -0.26 & -0.28 & -0.30 \\
\hline
\end{tabular}

Source: Appendix A.

19. The slow growth of contributions to the second pillar was due to several factors, including the failure to increase the contribution rate according to the original plans, the stagnation of second pillar membership in $2000-2002$, the decrease in the contribution ceiling relative to the average covered wage, and the relatively low covered wage bill in Hungary. As shown in Table 7, the contribution rate was maintained at 6 percent until 2001 , and only increased with the return of the socialist government in 2002. The base of the contribution to the second pillar stagnated at about $10-11$ percent of GDP in the same period, reflecting not only the stagnant membership in 2000 - 2002, but also the failure to increase the contribution ceiling in line with the increase in the covered wage. Finally, the 
covered wage bill in Hungary (the total base of contributions to the pension system, including the first and second pillars) decreased sharply during the late 1980s and early 1990 s due to evasion, and has recovered only slightly in recent years. ${ }^{6}$

20. The second pillar grew at a faster rate in 2004, due to the increase in contributions and a much better rate of return. The increase in contributions was in turn due to the increase in the contribution rate, the continued increase in membership and the increase in the contribution ceiling. The future growth of the second pillar will be influenced to a large extent by government policies. Sustaining a high growth of assets will require maintaining the contribution rate at the current levels, keeping the contribution ceiling at the current level of 2.5 times the average wage, maintaining the rules of transition to the new pension system, contributing to adequate returns through the development of new financial instruments, and containing costs and fees.

Table 7: Evolution of Second Pillar Contributions, 1998 - 2004

\begin{tabular}{lrrrrrrr}
\hline & $\mathbf{1 9 9 8}$ & $\mathbf{1 9 9 9}$ & $\mathbf{2 0 0 0}$ & $\mathbf{2 0 0 1}$ & $\mathbf{2 0 0 2}$ & $\mathbf{2 0 0 3}$ & $\mathbf{2 0 0 4}$ \\
\hline Contributions (\% of GDP) & 0.27 & 0.49 & 0.61 & 0.66 & 0.68 & 0.87 & 1.06 \\
& & & & & & & \\
& 6.0 & 6.0 & 6.0 & 6.0 & 7.0 & 7.0 & 8.0 \\
Contribution rate (\%) & 4.6 & 8.1 & 10.1 & 11.0 & 11.4 & 12.4 & 13.2 \\
Contribution base (\% of GDP) & & & & & & & \\
& & & & & & & \\
Determinants of contribution base: & 1,347 & 2,064 & 2,193 & 2,253 & 2,214 & 2,304 & 2,402 \\
Membership (thousands) & - & 2.0 & 1.9 & 1.8 & 1.6 & - & 2.5 \\
Contribution ceiling/Average covered wage & 22.1 & 22.4 & 22.2 & 23.5 & 23.9 & 24.2 & - \\
Covered wage bill (\% of GDP) & & & & & & & \\
Memo item: & 20.7 & 36.1 & 45.7 & 46.9 & 47.5 & 52.4 & - \\
Contribution base/Covered Wage Bill & & & & & &
\end{tabular}
Source: HFSA raw data.

21. A recovery of the covered wage bill would also contribute to larger contributions and more rapid growth of the second pillar. As shown in Table 7, the base of contributions to the second pillar has been growing in line with the increase in membership, and is now more than half of the covered wage bill. At the end of the transition, when all contributors are enrolled in the new pension system, the base of contributions to the second pillar will be the same as the covered wage bill, and the growth of the second pillar will depend on the growth of the covered wage bill itself. It is possible that the covered wage bill will recover to the levels prevailing in the late 1980s (about $33-34$ percent of GDP) because these are the levels consistent with Hungary's per capita income and the ones observed in neighboring countries, but this will require more efforts to address tax evasion and may take a decade or more to be achieved.

\section{Performance of the Second Pillar: Portfolios and Investment Return}

MPFs have maintained a conservative investment policy since the start of the second pillar in 1998. As shown in

\footnotetext{
${ }^{6}$ The covered wage bill in Hungary declined from 32 percent of GDP in the 1980s to 22 percent of GDP in the mid-1990s (Palacios and Rocha (1998) and Rocha and Vittas (2002)). By comparison, the covered wage bill is 33 percent of GDP in Slovakia and the Czech Republic and 42 percent of GDP in Slovenia.
} 
22. Table 8, Government securities accounted for 73 percent of the portfolio in 2004, a high share considering that the system has been operating for seven years already. Direct equity holdings account for less than 10 percent of the total, and holdings of bonds issued by corporations and financial institutions are extremely small. The only noticeable change in the portfolio is the increase in the holdings of investment notes and other assets. Investment notes are actually mutual fund shares, 80 percent of which are invested in equity. Therefore, direct and indirect equity holdings amount to 15 percent of the total, which is still a modest share.

23. Other assets amount to about 8 percent of the portfolio and are dominated by mortgage bonds. The share of mortgage bonds in the portfolio is also low by comparison with other OECD countries - this is a popular asset class for pension funds in most OECD countries, due to its attractive return-risk characteristics, good liquidity, and relatively long durations. However, the prospects in this area look somewhat brighter, because the rapid development of the market for mortgage bonds has been one of the most encouraging and promising developments in the Hungarian capital market since the start of the pension reform. Finally, the share of foreign assets looks small, considering the openness and the relatively small size of the Hungarian economy.

Note that this type of conservative portfolio has also been observed in most other reforming countries. As shown in

24. Table 8, the share of Government bonds in pension fund portfolios exceeds 60 percent in most cases, and the share of equity and foreign assets tend to be very small. The experience of most countries tends to be very different from the well known Chilean case, where pension funds started investing in private sector instruments in the early stages, firstly through holdings of mortgage bonds and other mortgage-backed securities, and subsequently through investments in equity, corporate and infrastructure bonds, and also some private equity. More recently, Chilean funds started holding large amounts of foreign assets, mostly foreign equity.

25. The lack of fiscal support during the transition to the new system may explain the different experiences of Hungary on the one side, and Chile and many reforming countries on the other side. Chile undertook a fiscal adjustment that largely offset the revenue losses to the second pillar, promoting an increase in national savings and opening room for investments in private instruments already in the first years of reform implementation. ${ }^{7}$ By contrast, in most other countries fiscal policy has not been supportive, resulting to a large extent on a debt-financed transition and relatively large issues of Government bonds, which ended up in the portfolios of pension funds. The importance of this fiscal/macro factor explaining portfolio compositions is illustrated in Figure 2, which shows the high correlation between the share of Government bonds in portfolios and the ratio of Government debt to GDP in several Latin American countries.

\footnotetext{
${ }^{7}$ Corbo and Schmidt-Hebbel (2003) provide an analysis of the macroeconomic effects of the Chilean pension reform. Rocha (2006) examines the structure and performance of Chile's second pillar.
} 
Table 8: Portfolio Composition of MPFs (\% of total), 1998 - 2004

\begin{tabular}{lrrrrrrr}
\hline & $\mathbf{1 9 9 8}$ & \multicolumn{1}{c}{$\mathbf{1 9 9 9}$} & \multicolumn{1}{c}{$\mathbf{2 0 0 0}$} & \multicolumn{1}{c}{$\mathbf{2 0 0 1}$} & \multicolumn{1}{c}{$\mathbf{2 0 0 2}$} & \multicolumn{1}{c}{$\mathbf{2 0 0 3}$} & $\mathbf{2 0 0 4}$ \\
\hline Cash & 10.8 & 2.8 & 1.3 & 1.1 & 3.3 & 0.7 & 0.6 \\
Time Deposits/CDs & 3.5 & 0.3 & 0.1 & 0.1 & 0.7 & 0.4 & 0.5 \\
Government securities & 76.7 & 83.4 & 77.6 & 80.0 & 68.0 & 69.9 & 72.7 \\
Direct Equity & 6.6 & 9.8 & 14.8 & 11.6 & 8.9 & 9.3 & 7.8 \\
Corporate and FI Bonds & 1.7 & 1.7 & 2.3 & 3.0 & 4.2 & 3.0 & 1.7 \\
Investment notes & 0.3 & 1.7 & 2.6 & 2.3 & 7.1 & 7.2 & 8.2 \\
Other & 0.4 & 0.3 & 1.3 & 1.9 & 7.8 & 9.5 & 8.5 \\
Total & 100.0 & 100.0 & 100.0 & 100.0 & 100.0 & 100.0 & 100.0 \\
\hline Memo: & & & & & & & \\
Est. Total Equity & 6.8 & 11.2 & 16.7 & 13.4 & 14.6 & 15.1 & 14.4 \\
Est. Foreign Assets & 3.5 & 5.6 & 8.3 & 6.7 & 7.3 & 7.5 & 7.9 \\
\hline Source: HFSA & & & & & & &
\end{tabular}

Table 9: Portfolios of Pension Funds in Hungary and Other Reforming Countries (\%)

\begin{tabular}{|c|c|c|c|c|c|c|c|c|c|}
\hline \multirow[t]{2}{*}{ Country } & \multirow[t]{2}{*}{$\begin{array}{c}\text { First } \\
\text { Year of } \\
\text { Operation }\end{array}$} & \multicolumn{2}{|c|}{$\begin{array}{l}\text { Govt. } \\
\text { Bonds }\end{array}$} & \multicolumn{2}{|c|}{$\begin{array}{c}\text { Financial } \\
\text { Institutions }\end{array}$} & \multicolumn{2}{|c|}{ Equity } & \multicolumn{2}{|c|}{$\begin{array}{c}\text { Foreign } \\
\text { Assets }\end{array}$} \\
\hline & & $\begin{array}{c}7^{\text {th }} \\
\text { Year }\end{array}$ & 2004 & $\begin{array}{c}7^{\text {th }} \\
\text { Year }\end{array}$ & 2004 & $\begin{array}{c}7^{\text {th }} \\
\text { Year }\end{array}$ & 2004 & $\begin{array}{c}7^{\text {th }} \\
\text { Year }\end{array}$ & 2004 \\
\hline Hungary & 1998 & 72.7 & 72.7 & 2.2 & 2.2 & 14.4 & 14.4 & 7.9 & 7.9 \\
\hline Argentina & 1994 & 56.0 & 62.0 & 15.6 & 6.6 & 12.3 & 12.7 & 4.5 & 10.3 \\
\hline Bolivia & 1997 & 64.1 & 67.5 & 7.3 & 5.6 & 8.6 & 7.5 & 1.7 & 1.5 \\
\hline Chile & 1981 & 41.4 & 18.7 & 49.4 & 29.5 & 6.2 & 42.8 & 0.0 & 27.2 \\
\hline Colombia & 1994 & - & 48.5 & - & 16.6 & - & 6.2 & - & 6.7 \\
\hline Costa Rica & 2001 & - & 73.1 & - & 14.2 & - & 0.1 & - & 0.0 \\
\hline El Salvador & 1998 & 83.5 & 83.5 & 10.5 & 10.5 & 0.2 & 0.2 & 0.0 & 0.0 \\
\hline Mexico & 1997 & 82.3 & 85.5 & 4.5 & 4.9 & 0.0 & 0.0 & 0.0 & 0.0 \\
\hline Peru & 1993 & 7.1 & 24.2 & 39.3 & 11.4 & 37.1 & 37.7 & 0.0 & 10.2 \\
\hline Poland & 1999 & - & 59.6 & - & - & - & 32.8 & - & 2.2 \\
\hline Uruguay & 1996 & 55.5 & 57.9 & 39.6 & 36.9 & 0.0 & 0.0 & 0.0 & 0.0 \\
\hline
\end{tabular}


Figure 2: Size of public debt and share in pension funds portfolio - select countries

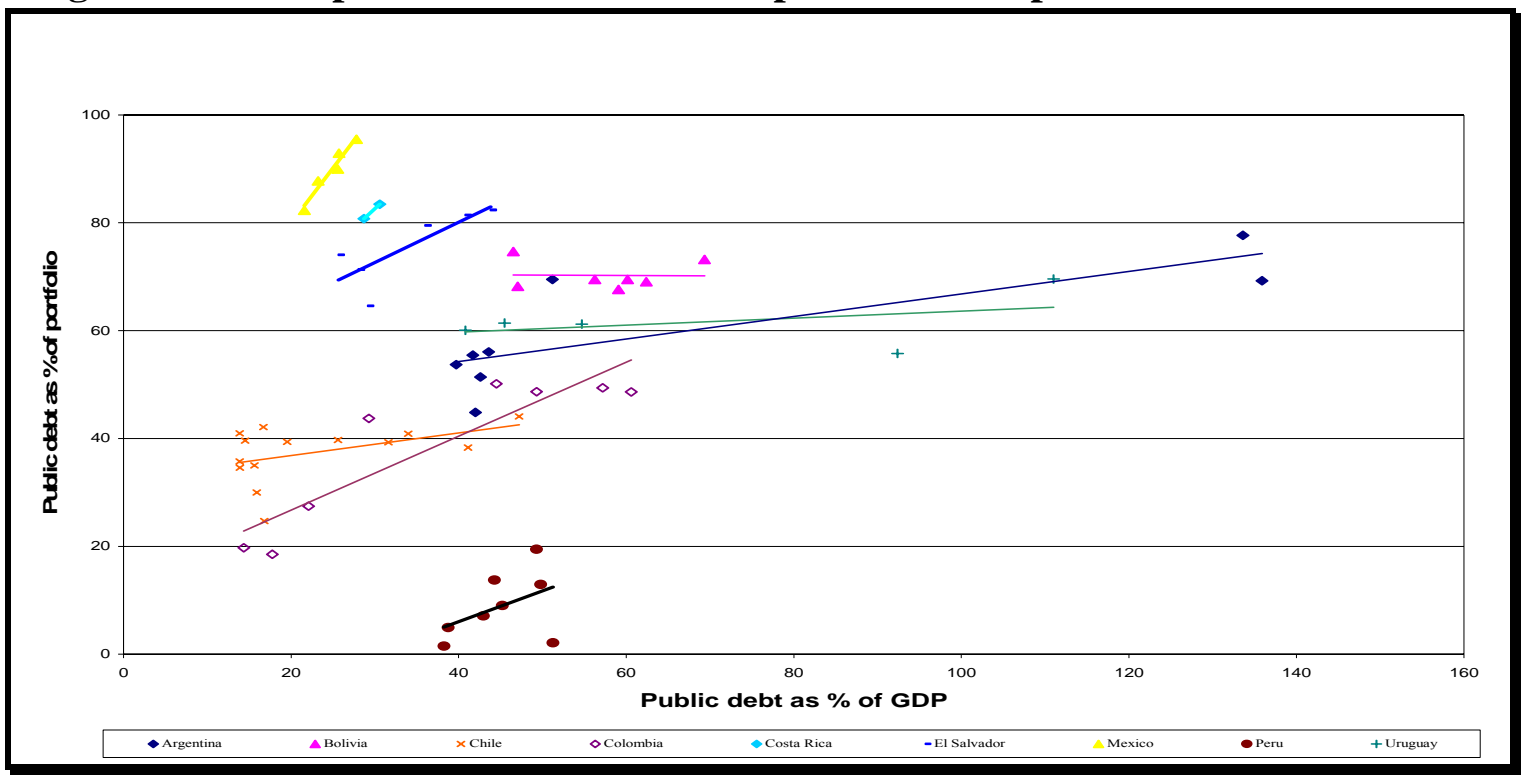

Source: Otermin (2004).

26. At the start of the reform, Hungary was expected to follow a mixed financing strategy that would result in some increase in national savings and open more room for investment in private instruments. This would be achieved through parametric reforms to the PAYG system, and observance of the Maastricht ceiling of 3 percent of GDP on fiscal deficits during the whole period of reform implementation. ${ }^{8}$ However, fiscal deficits increased significantly during the early 2000 s, as shown in Table 10 . This increase in the fiscal deficit was due in good part to a sharp increase in public sector wages, and exceeded by a wide margin the revenue losses to the second pillar. As shown in Table 10, between 2000 and 2004, the annual losses to the second pillar increased by about 0.5 percent of GDP, while the primary balance worsened by 3 percent of GDP. In the intermediate years the difference was much larger. This increase in deficits led to an increase in the ratio of public debt to GDP above and beyond the increase that would result from a debt-financed transition with a neutral fiscal policy in other areas, and also contributed to the decline in national savings in the same period. Under these conditions, a large share of Government bonds in pension fund portfolios is not a surprising outcome.

Table 10: Fiscal Policy and National Savings in the Transition, 2000 - 2004

\begin{tabular}{|c|c|c|c|c|c|c|}
\hline & Unit & 2000 & 2001 & 2002 & 2003 & 2004 \\
\hline General Government Balance & $\%$ GDP & -2.8 & -4.5 & -9.4 & -7.2 & -5.4 \\
\hline Primary Balance & $\%$ GDP & 2.1 & -0.3 & -5.6 & -3.4 & -1.2 \\
\hline Losses to the Second Pillar & $\%$ GDP & 0.6 & 0.7 & 0.7 & 0.9 & 1.1 \\
\hline Government Debt & $\%$ GDP & 55.4 & 53.5 & 57.1 & 59.1 & 60.7 \\
\hline Gross National Savings ${ }^{1}$ & $\%$ GDP & 22.3 & 20.6 & 18.1 & 16.6 & 15.3 \\
\hline Gross Domestic Investment $^{2}$ & $\%$ GDP & 30.9 & 26.8 & 25.2 & 25.3 & 24.1 \\
\hline
\end{tabular}

Notes: 1) consistent with the external current account; 2) includes changes in inventories.

Source: Ministry of Finance, HFSA, IMF

\footnotetext{
${ }^{8}$ Rocha and Vittas (2002).
} 
27. In addition to fiscal policy, there are also other factors that may have contributed to the observed portfolio composition, particularly the high share of Government bonds. Firstly, alternative financial instruments have not been developed, with the exception of the very recent and promising development of the mortgage bond market. The lack of development of financial instruments such as corporate bonds, infrastructure bonds and private equity has been due in part to the expansion of lending by a very competitive banking sector, after a period of contraction in the 1990s due to restructuring and privatization. However, some residual regulatory obstacles may also have hindered the development of these markets, as discussed in Section VII.

28. Secondly, asset managers may have become wary of equity investments, as a result of the very poor performance of equity markets in the early years of the reform. As shown in Figure 3, the second pillar started operating in 1998, the year when the Hungarian equity market (measured by the BUX index) was severely hit by the Russian crisis. Equity prices recovered in 1999 but declined sharply again in 2000 and 2001, in line with the overall decline in international equity markets. During this whole period bond returns (measured by the MAX index) were higher and less volatile. The situation only reverted in 2003, when equity prices initiated a steady recovery, and bond prices faltered due to an increase in interest rates (Figure 4).

Figure 3: Performance of Bonds and Stocks in Hungary, 1997 - 2004

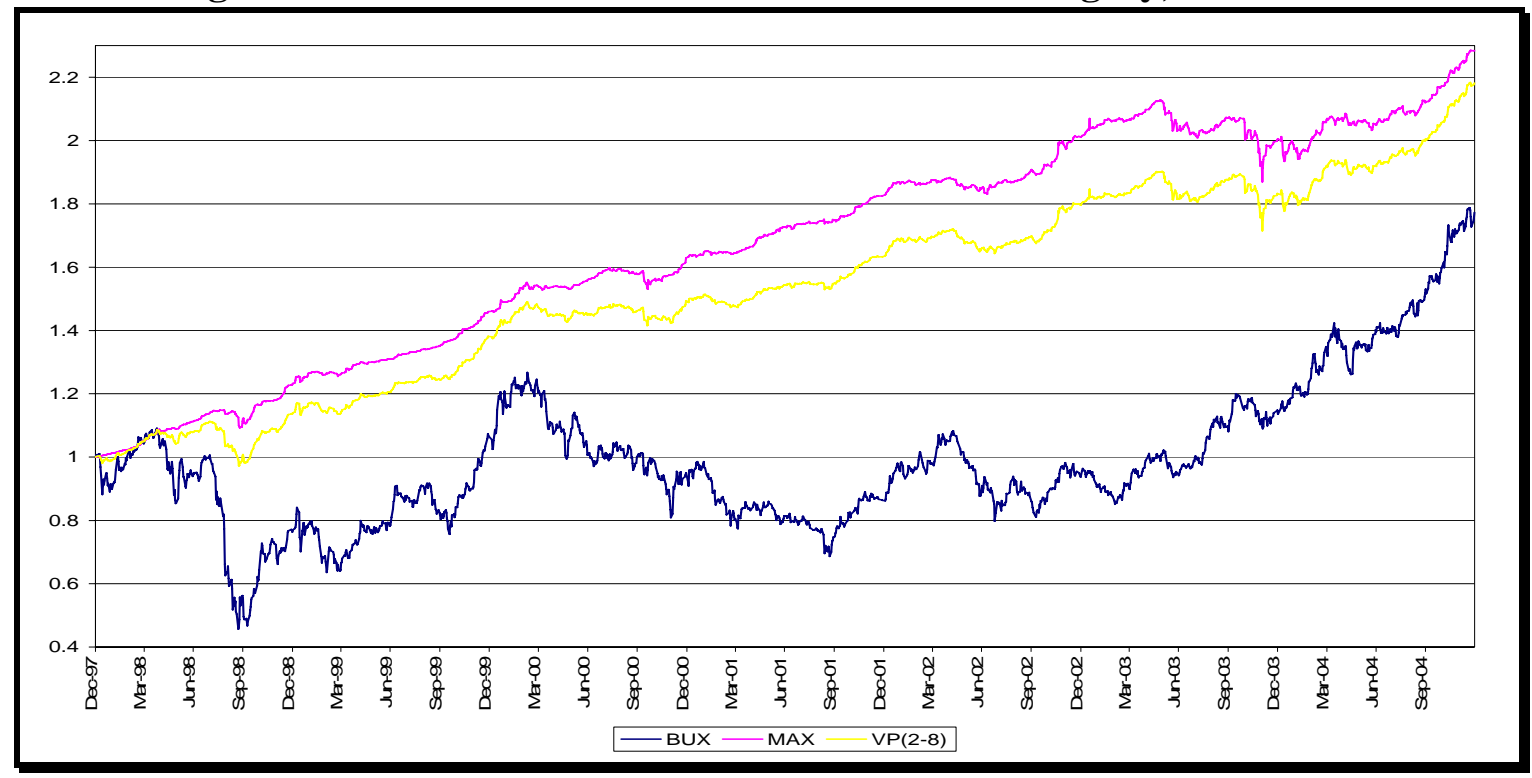

Source: $\mathrm{AKK}$ and MNB data.

29. Thirdly, there is a prevalent view among market participants and regulators that pension fund portfolios in Hungary are conservative because most asset management companies are subsidiaries of mother companies in Continental Europe, i.e., from countries that do not have an "equity culture". According to this view, the presence of a larger number of subsidiaries of Anglo-Saxon companies in Poland would also explain the larger holdings of equity in the Polish second pillar, relatively to Hungary's. Finally, members of the few voluntary pension funds that provide portfolio choices have favored more conservative portfolios, made up almost exclusively of Government bonds (OECD 2005). Although the experience with multiple portfolios is very recent and limited (only 5 
out of the 75 voluntary pension funds offer more than one portfolio), some asset managers may have extrapolated this revealed preference for conservative portfolios to the much wider universe of second pillar members.

Figure 4: Nominal and Real Annual Interest Rate on T-bills, 2000 - 2004

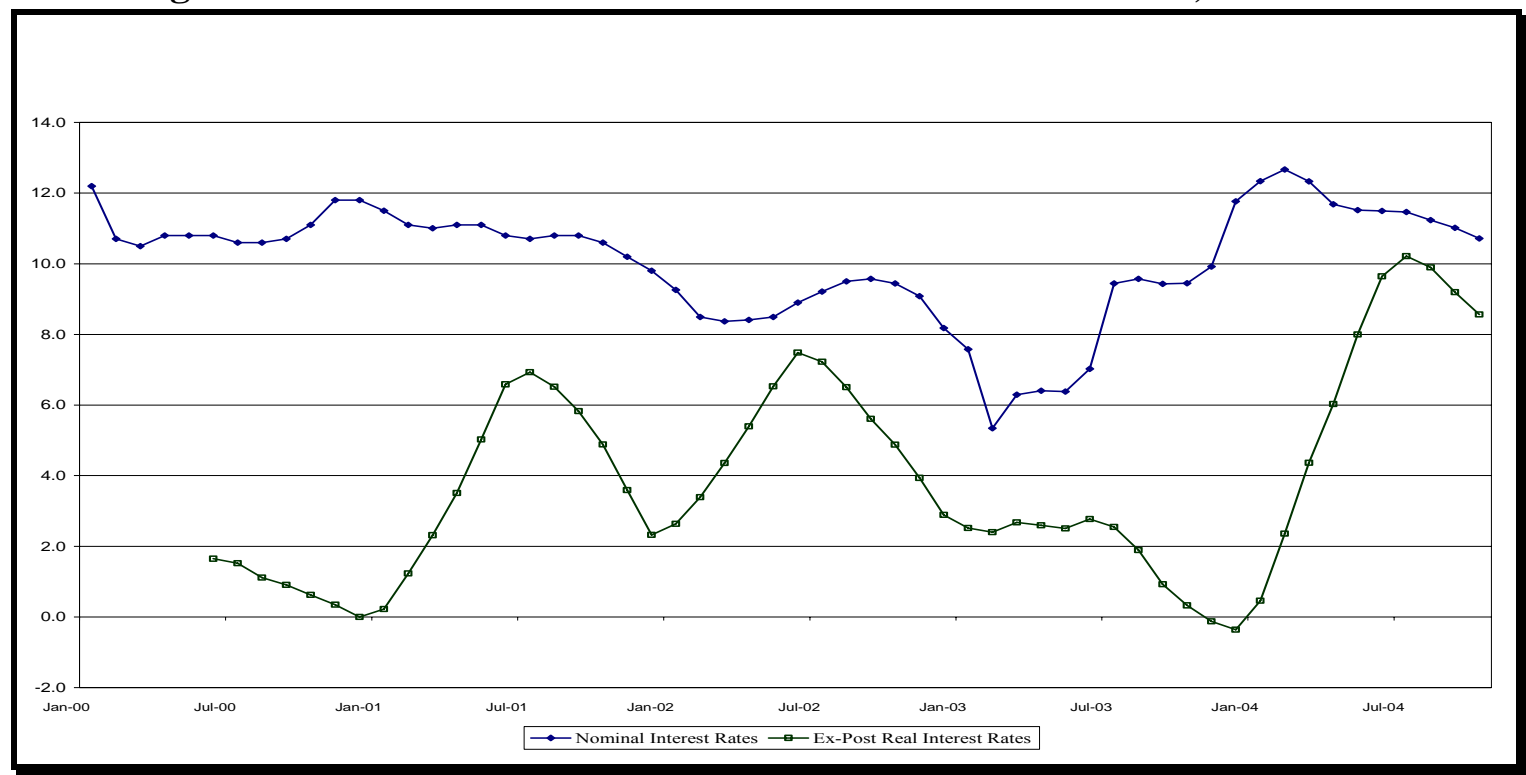

Source: AKK

30. The average return performance of MPFs has been rather disappointing. As shown in Table 11 and Table 12, the real rate of return net of fees was negative in some years and the annualized average net real rate return in the $1998-2005$ period amounted to only 3.9 percent p.a., lower than the average real wage growth of 5.3 percent in the same period. ${ }^{9}$ This last measure is a measure of the implicit return in a balanced PAYG system and commonly used as a benchmark for assessing the performance of a second pillar. Wage growth in this period was unusually high and was in good part driven by a large increase in public sector wages. For this reason, it may not be a good benchmark for measuring second pillar performance in Hungary during this period. However, the average real rate of return in Hungary has also been low by comparison with other reforming countries, as shown in Table 13. ${ }^{10}$

Table 11: Net Rates of Return, Wage Growth, and Inflation Rates, 1998 - 2004

\begin{tabular}{lccrrrrrr}
\hline & $\mathbf{1 9 9 8}$ & $\mathbf{1 9 9 9}$ & $\mathbf{2 0 0 0}$ & $\mathbf{2 0 0 1}$ & $\mathbf{2 0 0 2}$ & $\mathbf{2 0 0 3}$ & $\mathbf{2 0 0 4}$ & $\mathbf{2 0 0 5}$ \\
\hline Net Nominal Rate of Return & 15.7 & 17.1 & 7.9 & 8.0 & 7.4 & 3.4 & 16.3 & 13.0 \\
Wage Growth & 16.8 & 12.1 & 12.7 & 13.2 & 15.0 & 12.7 & 6.3 & 6.2 \\
Inflation Rate (Aver) & 14.2 & 10.0 & 9.8 & 9.2 & 5.3 & 4.6 & 6.8 & 3.9 \\
Inflation Rate (Dec) & 10.3 & 11.2 & 10.1 & 6.8 & 4.8 & 5.7 & 5.5 & 3.0 \\
\hline
\end{tabular}

Notes: /1 estimates

Source: NBH and HFSA raw data (wage and return), and IMF (inflation).

\footnotetext{
${ }^{9}$ We use December inflation to calculate the real rate of return and average inflation to calculate the real wage growth as the rate of return is realized in December of each year while wages are a flow over the year.

${ }^{10}$ Rates of return in Hungary are reported net of asset management fees, while in other countries rates of return are usually reported in gross terms. The average gross rate of return shown in Table 12 and Table 13 was estimated by adding asset management fees of 1 percent of assets.
} 
Table 12: Average Gross and Net Real Rates of Return and Wage Growth, 1998 - 2005

\begin{tabular}{ccc}
\hline $\begin{array}{c}\text { Average Weighted Real } \\
\text { Net Rate of Return }\end{array}$ & $\begin{array}{c}\text { Average Weighted Real } \\
\text { Gross Rate of Return }\end{array}$ & $\begin{array}{c}{ }^{2} \\
\text { Average Real Wage }_{\text {Growth }^{3}}\end{array}$ \\
\hline $3.85 \%$ & $4.85 \%$ & $5.27 \%$ \\
\hline
\end{tabular}

Notes: 1/ Difference between the Average Net Rate of Return (weighted by 2003 - 2004 average assets) in Table 14 and the Average Inflation Rate (Dec); 2/ 100 basis points spread have been assumed between the net and gross rates; 3/ Difference between the Average Wage Growth and the Average Inflation Rate (Aver).

Source: NBH and HFSA raw data, IMF

31. The lower average rate return of Hungarian pension funds begs an explanation, as pension funds in other reforming countries also invested conservatively during this period. One possible explanation for the lower returns in Hungary is the lower risk premium of Hungarian Government securities that translated, ceteris paribus, into lower real interest rates on these securities. As shown in Table 13, Hungarian sovereign issues had one of the best credit ratings and paid the lowest spreads among other reforming countries, with the possible exception of Chile. For this reason, it is not surprising that real rates of interest on Government securities were one of the lowest among other reforming countries, and that pension fund returns were also relatively low. ${ }^{11}$ Chilean funds would also have generated low returns if they had invested primarily in Government securities. Their higher returns were generated fundamentally by a much more diversified portfolio, consisting not only of domestic and international equity, but also of mortgage, corporate, and infrastructure bonds paying a premium over Government bonds.

Table 13: Average Historical Rate of Return and Sovereign Risk

\begin{tabular}{|c|c|c|c|c|c|}
\hline Country & $\begin{array}{c}\text { Average } \\
\text { Accumulated } \\
\text { Real Gross } \\
\text { Rate of Return } \\
\text { (\% p.a.) }\end{array}$ & $\begin{array}{l}\text { Average Real } \\
\text { Int. Rate on } \\
\text { Government } \\
\text { Securities } \\
\text { (\% p.a.) } \\
\text { (2000 - 2004) }\end{array}$ & $\begin{array}{c}\text { Average } \\
\text { Sovereign } \\
\text { Spread } \\
(\%) \\
\\
(2000-2004) \\
\end{array}$ & $\begin{array}{c}\text { S\&P } \\
\text { Sovereign } \\
\text { Rating }\end{array}$ & $\begin{array}{c}\text { S\&P } \\
\text { Sovereign } \\
\text { Rating }\end{array}$ \\
\hline Hungary & 3.9 & 3.9 & 59 & BBB+ & A- \\
\hline Argentina & 9.9 & - & 3,574 & $\mathrm{BB}$ & SD \\
\hline Bolivia & 10.4 & 7.7 & - & $\mathrm{B}+$ & B- \\
\hline Chile & 10.2 & 4.0 & 156 & A- & $\mathrm{A}$ \\
\hline Colombia & 6.9 & $11.61 /$ & 579 & $\mathrm{BB}$ & $\mathrm{BB}$ \\
\hline Costa Rica & 6.7 & - & 327 & $\mathrm{BB}$ & $\mathrm{BB}$ \\
\hline El Salvador & 9.9 & - & 315 & $\mathrm{BB}+$ & $\mathrm{BB}^{+}$ \\
\hline Mexico & 7.7 & 4.2 & 299 & $\mathrm{BB}+$ & BBB- \\
\hline Peru & 7.6 & - & 531 & - & - \\
\hline Poland & 8.6 & 8.1 & 165 & $\mathrm{BBB}+$ & $\mathrm{BBB}+$ \\
\hline Uruguay & 12.9 & - & 723 & BBB- & B \\
\hline
\end{tabular}

Notes: 1/ 2001-2004 arithmetic average of coupon of gross internal debt.

Sources: HFSA, AIOS, World Bank, S\&P, and IMF

32. In addition to the lower risk premium on Government securities, the return performance of MPFs was also affected by factors specific to Hungary, such as the drop in equity prices that resulted from the Russian crisis, and the steep increase in interest rates in recent years that produced a capital loss on the portfolio of fixed income assets. The

\footnotetext{
${ }^{11}$ Ex-post real interest rates were computed for only a sub-set of reforming countries due to data limitations.
} 
recovery of bond and equity prices in 2004 and 2005 indicates that these were temporary factors and suggests that the average return performance should continue improving in coming years. However, the improvement in performance will only be sustained in the longer-run if MPFs diversify further their portfolios, holding larger amounts of higher yield securities issued in Hungary, the EU, and in other markets.

33. Net rates of return have been generally similar across MPFs, reflecting their fairly similar portfolios. This is due to herding and the fact that some asset management companies manage the assets of more than one MPF. However, there are also some noteworthy differences. As shown in Table 14, the average net rate of return of MPFs sponsored by employers and independent MPFs was slightly higher than the return of MPFs sponsored by financial institutions, and the standard deviations and coefficients of variation were smaller. The larger standard deviation of the returns of MPFs sponsored by financial institutions reveals that some of these MPFs performed significantly below the average during the period.

Table 14: Annual Net Rate of Return by Type of MPF, 1998 - 2004 $\begin{array}{lllllllll}1998 & 1999 & 2000 & 2001 & 2002 & 2003 & 2004 & \text { Av. }\end{array}$

\begin{tabular}{|c|c|c|c|c|c|c|c|c|}
\hline \multicolumn{9}{|l|}{ Total MPF Market } \\
\hline Average Rate of Return & 15.7 & 17.1 & 7.9 & 8.0 & 7.4 & 3.4 & 16.3 & 10.8 \\
\hline Average Rate of Return (weighted) & 13.2 & 17.4 & 6.6 & 6.8 & 6.7 & 3.6 & 17.0 & 10.2 \\
\hline Standard Deviation & 3.9 & 2.6 & 2.7 & 2.0 & 1.9 & 1.5 & 1.9 & 2.4 \\
\hline Coefficient of Variation & 0.30 & 0.15 & 0.42 & 0.29 & 0.29 & 0.41 & 0.11 & 0.28 \\
\hline Corr. Coeff. (Contribution fee) & -0.13 & -0.52 & -0.17 & -0.21 & -0.08 & 0.37 & 0.21 & -0.08 \\
\hline Corr. Coeff. (AM fee) & -0.42 & 0.00 & -0.27 & -0.41 & -0.51 & -0.19 & 0.05 & -0.25 \\
\hline \multicolumn{9}{|l|}{ Sponsored by Employers } \\
\hline Average Rate of Return & 16.4 & 16.3 & 8.7 & 9.0 & 8.0 & 3.0 & 16.2 & 11.1 \\
\hline Average Rate of Return (weighted) & 17.0 & 16.2 & 8.8 & 9.0 & 8.0 & 3.1 & 16.3 & 11.2 \\
\hline Standard Deviation & 2.0 & 1.7 & 1.7 & 1.1 & 1.8 & 2.2 & 2.3 & 1.8 \\
\hline Coefficient of Variation & 0.12 & 0.10 & 0.19 & 0.12 & 0.23 & 0.71 & 0.14 & 0.23 \\
\hline Corr. Coeff. (Contribution fee) & -0.31 & -0.64 & -0.16 & -0.29 & 0.16 & -0.03 & 0.00 & -0.18 \\
\hline Corr. Coeff. (AM fee) & 0.79 & 0.07 & -0.44 & -0.56 & 0.20 & 0.35 & 0.65 & 0.15 \\
\hline \multicolumn{9}{|l|}{ Sponsored by Financial Institutions } \\
\hline Average Rate of Return & 14.8 & 17.5 & 8.0 & 7.6 & 6.8 & 3.2 & 16.1 & 10.6 \\
\hline Average Rate of Return (weighted) & 12.6 & 17.4 & 6.6 & 6.6 & 6.6 & 3.5 & 17.1 & 10.0 \\
\hline Standard Deviation & 5.3 & 3.4 & 2.8 & 2.4 & 2.0 & 1.1 & 2.0 & 2.7 \\
\hline Coefficient of Variation & 0.42 & 0.20 & 0.42 & 0.36 & 0.31 & 0.32 & 0.12 & 0.31 \\
\hline Corr. Coeff. (Contribution fee) & -0.36 & -0.52 & 0.04 & -0.28 & -0.27 & 0.74 & 0.47 & -0.02 \\
\hline Corr. Coeff. (AM fee) & -0.43 & -0.09 & -0.43 & -0.25 & -0.52 & -0.59 & 0.15 & -0.31 \\
\hline \multicolumn{9}{|l|}{ Independent } \\
\hline Average Rate of Return & 16.9 & 17.4 & 6.1 & 7.5 & 8.3 & 4.5 & 16.9 & 11.1 \\
\hline Average Rate of Return (weighted) & 17.2 & 18.0 & 4.8 & 7.0 & 7.4 & 4.7 & 16.4 & 10.8 \\
\hline Standard Deviation & 1.9 & 1.0 & 4.2 & 1.0 & 1.7 & 0.5 & 0.8 & 1.6 \\
\hline Coefficient of Variation & 0.11 & 0.06 & 0.86 & 0.15 & 0.23 & 0.10 & 0.05 & 0.22 \\
\hline Corr. Coeff. (Contribution fee) & -0.33 & -0.39 & -0.75 & -0.71 & -0.90 & 0.92 & -0.97 & -0.45 \\
\hline Corr. Coeff. (AM fee) & 0.77 & 0.64 & 0.74 & -0.87 & -0.72 & 1.00 & -0.97 & 0.09 \\
\hline
\end{tabular}

Source: HFSA raw data

34. The MPFs sponsored by financial institutions charge on average higher asset management fees, as shown in the next section. Moreover, there is a negative correlation between net rates of return and asset management fees, driven precisely by this group of 
MPFs. This implies that members of some of these MPFs have been paying higher asset management fees without benefiting from a commensurately better asset management performance. The fact that these MPFs have been able to retain market share reflects the weak response of members to prices (i.e., returns and fees). This inertia and the resulting market segmentation are due, at least to some extent, to weak disclosure rules. This issue will be further examined in the sections below.

\section{Performance of the Second Pillar: Costs And Fees}

35. MPFs charge two main types of fees, an operational fee which is charged on contributions and an asset management fee which is charged on assets. The operational fee covers the wages of the small staff of the MPFs and expenditures related to revenue collection, record keeping, and marketing. These activities are usually outsourced to separate administration companies, but some MPFs sponsored by large employers and independent MPFs perform these functions internally. The asset management fee is paid by the MPF to the independent asset management company and usually covers not only asset management but also brokerage and custodian fees. Very few MPFs perform asset management internally. The asset management fee is usually defined as a fixed fraction of assets under management, but in a few cases it also includes a variable component linked to return performance. In either case, the asset management fee is effectively charged to members, because their accounts are credited on a net basis. ${ }^{12}$

\section{A. Operating Fees}

36. Hungarian accounting standards require MPFs to divide contributions into three separate reserves: (i) a "coverage" reserve for the individual accounts; (ii) an "operational" reserve to cover operational costs; and (iii) a "liquidity" reserve to smooth rates of return and to relax eventual liquidity constraints in paying benefits. In 2004, MPFs allocated an average of 92.5 percent of contributions to the coverage reserve, 6.5 percent to the operational reserve and 1 percent to the liquidity reserve.

37. Average operating fees increased from about 5.5 percent of contributions in the early years of operation to about 6.5 percent of contributions in 2004, as shown in Table 15. Independent MPFs and MPFs sponsored by large employers have charged higher operating fees than MPFs sponsored by financial institutions, possibly reflecting the fact that some functions are performed internally. However, this is compensated by much lower asset management fees, as noted below.

\footnotetext{
${ }^{12}$ Market participants indicate that performance fees are negligible. An exit fee of no more that 0.1 percent of the balance can be charged by the MPF to members switching to other funds but this fee has also been negligible, since very few members have switched funds since the reform.
} 
Table 15: Operating Fees (\% charged on contributions), $1998-2004$

\begin{tabular}{lcccccccc}
\hline Fund & Sponsor & $\begin{array}{c}\mathbf{1 9 9 8} \\
\mathbf{( \% )}\end{array}$ & $\begin{array}{c}\mathbf{1 9 9 9} \\
\mathbf{( \% )}\end{array}$ & $\begin{array}{c}\mathbf{2 0 0 0} \\
\mathbf{( \% )}\end{array}$ & $\begin{array}{c}\mathbf{2 0 0 1} \\
\mathbf{( \% )}\end{array}$ & $\begin{array}{c}\mathbf{2 0 0 2} \\
\mathbf{( \% )}\end{array}$ & $\begin{array}{c}\mathbf{2 0 0 3} \\
\mathbf{( \% )}\end{array}$ & $\begin{array}{c}\mathbf{2 0 0 4} \\
\mathbf{( \% )}\end{array}$ \\
\hline Dimenzió & EMP & 6.0 & 6.0 & 5.9 & 5.9 & 6.0 & 5.9 & 6.0 \\
HONVÉD & EMP & 6.0 & 6.0 & 6.0 & 7.4 & 7.5 & 7.5 & 7.5 \\
Postás & EMP & 5.8 & 5.0 & 5.0 & 5.0 & 5.0 & 5.0 & 5.0 \\
Vasustas & EMP & 8.0 & 7.1 & 6.3 & 7.0 & 7.0 & 7.0 & 6.9 \\
VIT & EMP & 6.0 & 6.0 & 6.0 & 6.0 & 7.0 & 7.0 & 7.0 \\
AEGON & FIN & 6.0 & 6.5 & 5.4 & 5.6 & 6.0 & 6.0 & 5.9 \\
AH & FIN & 5.0 & 5.0 & 4.7 & 6.9 & 7.0 & 7.0 & 6.5 \\
Budapest & FIN & 4.0 & 4.0 & 4.2 & 5.0 & 6.0 & 6.0 & 5.9 \\
CS & FIN & 5.5 & 5.1 & 5.1 & 5.5 & 7.0 & 7.0 & 6.6 \\
ERSTE & FIN & 5.4 & 5.5 & 6.7 & 5.8 & 6.0 & 6.6 & 6.9 \\
ING & FIN & 5.6 & 6.2 & 6.0 & 6.8 & 7.0 & 7.0 & 7.0 \\
MKB & FIN & 6.1 & 5.7 & 5.4 & 5.5 & 5.5 & 5.5 & 5.5 \\
OTP & FIN & 5.1 & 5.0 & 5.9 & 6.9 & 7.0 & 7.0 & 6.5 \\
Quaestor & FIN & 5.0 & 5.0 & 4.9 & 5.0 & 5.0 & 7.4 & 7.0 \\
UNIQA & FIN & - & 10.0 & 4.2 & 5.3 & 5.5 & 5.3 & 5.5 \\
Aryankor & INDEP & 5.6 & 5.2 & 4.9 & 6.4 & 7.0 & 7.0 & 6.8 \\
Életút & INDEP & 4.7 & 6.2 & 5.9 & 6.0 & 6.0 & 6.0 & 6.0 \\
Évgyürúk & INDEP & 7.0 & 6.3 & 6.6 & 7.7 & 8.0 & 7.6 & 7.1 \\
\hline Weighted Average & MKT & 5.6 & 5.7 & 5.5 & 6.4 & 6.8 & 6.8 & 6.5 \\
Weighted Average & EMP & 6.1 & 5.9 & 5.8 & 6.4 & 6.6 & 6.6 & 6.6 \\
Weighted Average & FIN & 5.5 & 5.6 & 5.5 & 6.4 & 6.7 & 6.7 & 6.5 \\
Weighted Average & INDEP & 6.3 & 6.0 & 6.0 & 7.2 & 7.5 & 7.3 & 6.9 \\
\hline Sorn & & & & & & &
\end{tabular}

Source: HFSA raw data

38. Administration and record keeping account for the largest share of operational costs, as shown in Table 16. This is followed by wages of MPF personnel, the supervisory fee paid to the HFSA, and the guarantee fee. In contrast to most systems in Latin America, the share of marketing-related costs in total costs has been extremely small, although it is possible that some marketing activities are performed by other companies in the same financial group (i.e., the asset manager or the insurance company) and the associated costs are hidden in the asset management fee. It is also possible that the costs associated with contribution collection are not fully reflected in administration costs, because they are partly shifted to employers. In Hungary, arrangements for collecting contributions are not efficient and employers can be required to submit contributions to up to 18 different funds and spend substantial resources in this activity. 
Table 16: Operational Costs of MPFs (\%), $2001-2004$

\begin{tabular}{lrrrr}
\hline & $\mathbf{2 0 0 1}$ & $\mathbf{2 0 0 2}$ & $\mathbf{2 0 0 3}$ & $\mathbf{2 0 0 4}$ \\
\hline Material expenses & 0.9 & 0.6 & 0.6 & 0.4 \\
Wages and social security contributions & 6.8 & 8.2 & 7.9 & 8.0 \\
Compensations for pension fund officers & 1.7 & 1.4 & 1.4 & 1.4 \\
Agent fees related to member recruitment & 5.0 & 3.7 & 3.5 & 2.0 \\
Administration and record keeping fees & 54.5 & 61.0 & 60.3 & 65.5 \\
Audit fees & 0.8 & 0.7 & 0.6 & 0.3 \\
Actuarial fees & 0.3 & 0.4 & 0.3 & 0.4 \\
Consulting fees & 0.3 & 0.9 & 0.5 & 0.4 \\
Marketing expenses & 0.5 & 1.4 & 2.0 & 2.1 \\
Supervision fees & 5.1 & 8.0 & 8.6 & 4.7 \\
Guarantee fees & 5.9 & 5.7 & 6.1 & 6.4 \\
Other & 18.1 & 7.9 & 8.2 & 8.3 \\
\hline TOTAL (HUF millions) & $6,763.8$ & $7,141.3$ & $9,352.5$ & $12,651.5$ \\
\% of contributions (weighted average) & N.A. & 6.8 & 6.8 & 6.5 \\
\hline Sort HFSA
\end{tabular}

Source: HFSA

\section{B. Asset Management Fees}

39. As mentioned before, asset management fees are typically expressed as a share of total assets managed, although some asset management companies also charge a performance fee that depends on the rate of return. The asset management fee usually covers brokerage and custodian fees as well. As shown in Table 17, average asset management fees have declined slightly since the start of the system and have been around 100 basis points or 1 percent of total assets managed. Asset management fees have been very different across the different types of funds, with MPFs sponsored by financial institutions typically paying much higher fees than the other two types of MPFs. The MPFs sponsored by employers have paid the lowest fees, and it is noteworthy that some asset management companies change much lower fees to these MPFs than to MPFs within the same financial group. ${ }^{13}$

\footnotetext{
${ }^{13}$ For instance, in 2004, the AEGON asset management company charged a management fee of 1.3 percent to the AEGON pension fund and a fee of 0.3 percent to the Dimenzió pension fund.
} 
Table 17: Asset Management Fees (\% charged on average assets), 1998 - 2004

\begin{tabular}{lcccccccc}
\hline Fund & Sponsor & $\begin{array}{c}\mathbf{1 9 9 8} \\
\mathbf{( \% )}\end{array}$ & $\begin{array}{c}\mathbf{1 9 9 9} \\
\mathbf{( \% )}\end{array}$ & $\begin{array}{c}\mathbf{2 0 0 0} \\
\mathbf{( \% )}\end{array}$ & $\begin{array}{c}\mathbf{2 0 0 1} \\
\mathbf{( \% )}\end{array}$ & $\begin{array}{c}\mathbf{2 0 0 2} \\
\mathbf{( \% )}\end{array}$ & $\begin{array}{c}\mathbf{2 0 0 3} \\
\mathbf{( \% )}\end{array}$ & $\begin{array}{c}\mathbf{2 0 0 4} \\
\mathbf{( \% )}\end{array}$ \\
\hline Dimenzió & EMP & 0.00 & 0.93 & 0.71 & 0.37 & 0.27 & 0.29 & 0.30 \\
HONVÉD & EMP & 0.11 & 0.70 & 0.56 & 0.54 & 0.49 & 0.24 & 0.34 \\
Postás & EMP & 0.09 & 0.52 & 0.33 & 0.37 & 0.36 & 0.33 & 0.33 \\
Vasustas & EMP & 0.03 & 0.95 & 0.40 & 0.35 & 0.22 & 0.17 & 0.25 \\
VIT & EMP & 0.00 & 0.00 & 0.00 & 0.00 & 0.00 & 0.00 & 0.05 \\
AEGON & FIN & 2.25 & 2.93 & 1.68 & 1.68 & 1.36 & 1.43 & 1.37 \\
AH & FIN & 0.93 & 0.99 & 1.41 & 0.91 & 1.18 & 0.78 & 1.19 \\
Budapest & FIN & 1.15 & 1.34 & 1.21 & 1.16 & 1.17 & 1.02 & 1.00 \\
CS & FIN & 0.79 & 0.96 & 1.09 & 1.08 & 0.97 & 1.28 & 1.06 \\
ERSTE & FIN & 0.17 & 0.71 & 0.71 & 0.72 & 0.98 & 1.41 & 1.44 \\
ING & FIN & 1.03 & 0.90 & 0.94 & 0.82 & 0.90 & 0.86 & 0.98 \\
MKB & FIN & 0.00 & 0.00 & 0.68 & 0.53 & 0.53 & 0.65 & 0.64 \\
OTP & FIN & 1.12 & 1.50 & 0.78 & 0.94 & 0.71 & 0.79 & 0.87 \\
Quaestor & FIN & 0.00 & 0.00 & 0.01 & 0.00 & 0.01 & 0.01 & 0.09 \\
UNIQA & FIN & - & 0.80 & 1.90 & 1.86 & 1.83 & 1.34 & 1.21 \\
Aryankor & INDEP & 0.34 & 0.59 & 0.62 & 1.05 & 1.19 & 0.58 & 0.57 \\
Életút & INDEP & 0.00 & 0.53 & 0.74 & 0.25 & 0.20 & 0.21 & 0.29 \\
Évgyürük & INDEP & 0.16 & 1.15 & 0.58 & 0.65 & 0.54 & 0.57 & 0.50 \\
\hline Weighted Average & MKT & 1.13 & 1.42 & 1.06 & 1.03 & 0.95 & 0.92 & 0.97 \\
Weighted Average & EMP & 0.05 & 0.62 & 0.44 & 0.37 & 0.32 & 0.23 & 0.28 \\
Weighted Average & FIN & 1.29 & 1.51 & 1.14 & 1.09 & 1.00 & 1.00 & 1.05 \\
Weighted Average & INDEP & 0.21 & 0.94 & 0.60 & 0.81 & 0.84 & 0.57 & 0.53 \\
\hline Soure HFSA ras & & & & & & & &
\end{tabular}

Source: HFSA raw data

40. This segmentation in asset management fees can be ascribed to the governance structure of MPFs and weak transparency provisions in the regulation of the second pillar. As previously mentioned, MPF boards are de facto controlled by their sponsors, which define the fees that will be charged by the service providers within the group. Members do not de facto vote with their voices, as they typically do not go to general assemblies and vote for the boards, but could "vote with their feet", i.e., switch to the funds generating higher rates of return and charging lower fees. However, the lack of information on critical data on rates of returns and fees have limited competition and promoted the segmentation previously discussed. The potential advantages of a hybrid pension system that includes low cost institutions have not been effectively explored.

41. The lack of transparency in the Hungarian second pillar has been due not only to the insufficient disclosure of returns and fees but also to the mixed fee structure that creates problems of comparability (i.e., operating fees charged on contributions and asset management fees charged on assets). In 2004, MPFs were required for the first time to publish net and gross rates of return, but operational fees and asset management fees are still disclosed as a function of two different numerators. This does not facilitate comparability of fees across funds for the average consumer. 


\section{Total Fees}

42. Table 18 and Table 19 show total fees expressed as a share of contributions and assets, respectively, for each MPF over the 1998-2004 period. Average total fees as a share of contributions increased from 6 percent to about 10 percent in recent years, as shown in Table 19. This increase in total fees on contributions reflects primarily the increasing fees associated with asset management, and which results fundamentally from a fixed asset management fee per unit of assets and larger assets. Total fees charged by independent MPFs and MPFs sponsored by employers are on average significantly lower than the fees charged by MPFs sponsored by financial institutions, reflecting fundamentally their lower asset management fees. The differences in total fees over contributions charged by individual MPFs have increased over time, and in 2004 amounted frequently to 4 percent. Members comparing simply the operating fees (Table 15) would not be able to appreciate the differences across MPFs.

Table 18: Total Fees as a Share of Contributions (\%), 1998 - 2004

\begin{tabular}{lcccccccc}
\hline Fund & Sponsor & $\begin{array}{c}\mathbf{1 9 9 8} \\
\mathbf{( \% )}\end{array}$ & $\begin{array}{c}\mathbf{1 9 9 9} \\
\mathbf{( \% )}\end{array}$ & $\begin{array}{c}\mathbf{2 0 0 0} \\
\mathbf{( \% )}\end{array}$ & $\begin{array}{c}\mathbf{2 0 0 1} \\
\mathbf{( \% )}\end{array}$ & $\begin{array}{c}\mathbf{2 0 0 2} \\
\mathbf{( \% )}\end{array}$ & $\begin{array}{c}\mathbf{2 0 0 3} \\
\mathbf{( \% )}\end{array}$ & $\begin{array}{c}\mathbf{2 0 0 4} \\
\mathbf{( \% )}\end{array}$ \\
\hline Dimenzió & EMP & 6.0 & 7.2 & 7.3 & 7.0 & 7.0 & 7.0 & 7.1 \\
HONVÉD & EMP & 6.1 & 6.6 & 6.8 & 8.5 & 8.8 & 8.2 & 8.7 \\
Postás & EMP & 5.9 & 5.5 & 5.6 & 6.0 & 6.2 & 6.2 & 6.3 \\
Vasustas & EMP & 8.0 & 8.0 & 6.8 & 7.8 & 7.7 & 7.6 & 7.8 \\
VIT & EMP & 6.0 & 6.0 & 6.1 & 6.0 & 7.0 & 7.0 & 7.1 \\
AEGON & FIN & 7.0 & 9.9 & 8.4 & 9.5 & 10.6 & 10.8 & 10.8 \\
AH & FIN & 5.4 & 6.0 & 6.8 & 8.9 & 10.6 & 9.4 & 10.5 \\
Budapest & FIN & 4.6 & 5.5 & 6.2 & 7.8 & 9.7 & 8.8 & 9.2 \\
CS & FIN & 5.9 & 6.0 & 7.0 & 8.2 & 10.1 & 11.0 & 10.4 \\
ERSTE & FIN & 5.4 & 6.1 & 7.9 & 7.5 & 8.7 & 10.6 & 10.9 \\
ING & FIN & 6.0 & 7.1 & 7.6 & 8.7 & 9.7 & 9.6 & 10.4 \\
MKB & FIN & 6.1 & 5.7 & 6.4 & 6.9 & 7.4 & 7.5 & 7.8 \\
OTP & FIN & 5.7 & 6.4 & 7.0 & 8.9 & 8.9 & 9.3 & 9.3 \\
Quaestor & FIN & 5.0 & 5.0 & 5.0 & 5.0 & 5.0 & 7.4 & 7.2 \\
UNIQA & FIN & - & 11.6 & 6.5 & 8.7 & 10.6 & 8.9 & 9.4 \\
Aryankor & INDEP & 5.8 & 5.8 & 5.8 & 9.1 & 10.7 & 8.7 & 8.6 \\
Életút & INDEP & 4.7 & 6.8 & 7.4 & 6.7 & 6.7 & 6.8 & 7.1 \\
Évgyürük & INDEP & 7.1 & 7.2 & 7.5 & 9.1 & 9.6 & 9.3 & 8.8 \\
\hline Weighted Average & MKT & 6.1 & 7.1 & 7.2 & 8.8 & 9.7 & 9.6 & 9.8 \\
Weighted Average & EMP & 6.1 & 6.5 & 6.5 & 7.3 & 7.6 & 7.3 & 7.6 \\
Weighted Average & FIN & 6.1 & 7.2 & 7.3 & 8.8 & 9.7 & 9.7 & 10.0 \\
Weighted Average & INDEP & 6.0 & 6.7 & 7.0 & 8.4 & 9.1 & 8.4 & 8.2 \\
\hline Source: HFSA raw data & & & & & & & &
\end{tabular}

Source: HFSA raw data

43. Average total fees expressed as a share of assets have decreased significantly, from 13 percent in 1998 to 3 percent in 2004. This sharp decrease is typical of young pension systems and reflects the rapid growth of assets relative to contributions. Again, total fees expressed as a share of assets were lower for the MPFs sponsored by employers (2.1 percent), followed by independent MPFs (2.6 percent) and MPFs sponsored by financial 
groups (2.9 percent). The relative differences in fees charged by different types of MPFs have increased over time, reflecting the increasing weight of the asset management fee.

Table 19: Total Fees as a Share of Average Assets (\%), 1998 - 2004

\begin{tabular}{lcccccccc}
\hline Fund & Sponsor & $\begin{array}{c}\mathbf{1 9 9 8} \\
\mathbf{( \% )}\end{array}$ & $\begin{array}{c}\mathbf{1 9 9 9} \\
\mathbf{( \% )}\end{array}$ & $\begin{array}{c}\mathbf{2 0 0 0} \\
\mathbf{( \% )}\end{array}$ & $\begin{array}{c}\mathbf{2 0 0 1} \\
\mathbf{( \% )}\end{array}$ & $\begin{array}{c}\mathbf{2 0 0 2} \\
\mathbf{( \% )}\end{array}$ & $\begin{array}{c}\mathbf{2 0 0 3} \\
\mathbf{( \% )}\end{array}$ & $\begin{array}{c}\mathbf{2 0 0 4} \\
\mathbf{( \% )}\end{array}$ \\
\hline Dimenzió & EMP & 12.5 & 5.8 & 3.6 & 2.4 & 1.9 & 2.0 & 2.0 \\
HONVÉD & EMP & 11.8 & 7.3 & 4.8 & 4.2 & 3.4 & 2.9 & 2.6 \\
Postás & EMP & 12.7 & 5.3 & 3.2 & 2.3 & 1.8 & 1.7 & 1.6 \\
Vasustas & EMP & 17.7 & 8.6 & 4.8 & 3.4 & 2.5 & 2.2 & 2.1 \\
VIT & EMP & 11.4 & 4.9 & 2.9 & 2.1 & 1.9 & 2.0 & 2.0 \\
AEGON & FIN & 15.7 & 8.4 & 4.8 & 4.1 & 3.1 & 3.2 & 3.0 \\
AH & FIN & 11.5 & 6.1 & 4.6 & 3.9 & 3.5 & 3.0 & 3.1 \\
Budapest & FIN & 9.3 & 5.0 & 3.7 & 3.2 & 3.0 & 3.0 & 2.8 \\
CS & FIN & 11.4 & 6.0 & 4.0 & 3.3 & 3.1 & 3.5 & 2.9 \\
ERSTE & FIN & 11.0 & 6.4 & 4.4 & 3.3 & 3.1 & 3.8 & 3.9 \\
ING & FIN & 13.6 & 6.9 & 4.4 & 3.7 & 3.2 & 3.1 & 2.9 \\
MKB & FIN & 12.4 & 5.3 & 4.0 & 2.6 & 2.0 & 2.5 & 2.2 \\
OTP & FIN & 11.1 & 7.0 & 4.9 & 4.2 & 3.2 & 3.3 & 2.9 \\
Quaestor & FIN & 10.2 & 4.5 & 4.2 & 3.1 & 2.5 & 3.5 & 3.5 \\
UNIQA & FIN & & 5.9 & 5.4 & 4.8 & 3.8 & 3.3 & 2.9 \\
Aryankor & INDEP & 11.0 & 5.8 & 3.8 & 3.6 & 3.4 & 2.9 & 2.7 \\
Életút & INDEP & 9.0 & 5.7 & 3.7 & 2.4 & 1.8 & 1.9 & 1.8 \\
Évgyürük & INDEP & 11.3 & 8.7 & 5.1 & 4.3 & 3.3 & 3.1 & 2.6 \\
\hline Weighted Average & MKT & 12.7 & 7.0 & 4.5 & 3.8 & 3.2 & 3.1 & 2.9 \\
Weighted Average & EMP & 12.5 & 6.1 & 3.8 & 3.0 & 2.4 & 2.3 & 2.1 \\
Weighted Average & FIN & 12.9 & 7.0 & 4.6 & 3.9 & 3.2 & 3.2 & 2.9 \\
Weighted Average & INDEP & 11.1 & 7.6 & 4.6 & 3.9 & 3.3 & 3.0 & 2.6 \\
\hline Solre: HFSA & & & & & & & &
\end{tabular}

Source: HFSA raw data

44. Total fees in the Hungarian second pillar still compare favorably with most other systems with the same period of implementation, especially when expressed as a share of contributions. As shown in Figure 5, the ratio of total fees to contributions has increased but is still one of the lowest, with the exception of Bolivia. ${ }^{14}$ The ratio of total fees to assets is roughly equal to the average of other reforming countries, as shown in Figure 6. The difference between the two results reflects the mixed fee structure in Hungary, the low volume of assets, and the increasing dominance of the asset management fee. Fees in most other countries are defined as a share of contributions, and this ratio does not change dramatically over time. This implies a sharp decline in fees expressed as a share of assets over time. By contrast, the current mixed fee structure in Hungary implies rising fees as a share of contributions, and a ratio of fee to assets that may not decline as much as the other countries in the long-run.

\footnotetext{
${ }^{14}$ The comparison between Hungary and other Latin America countries should be controlled for differences in factors like coverage, contribution rates, and structure of the labor market.
} 
Figure 5: Total Fees over Contributions - Hungary and Other Countries (\%)

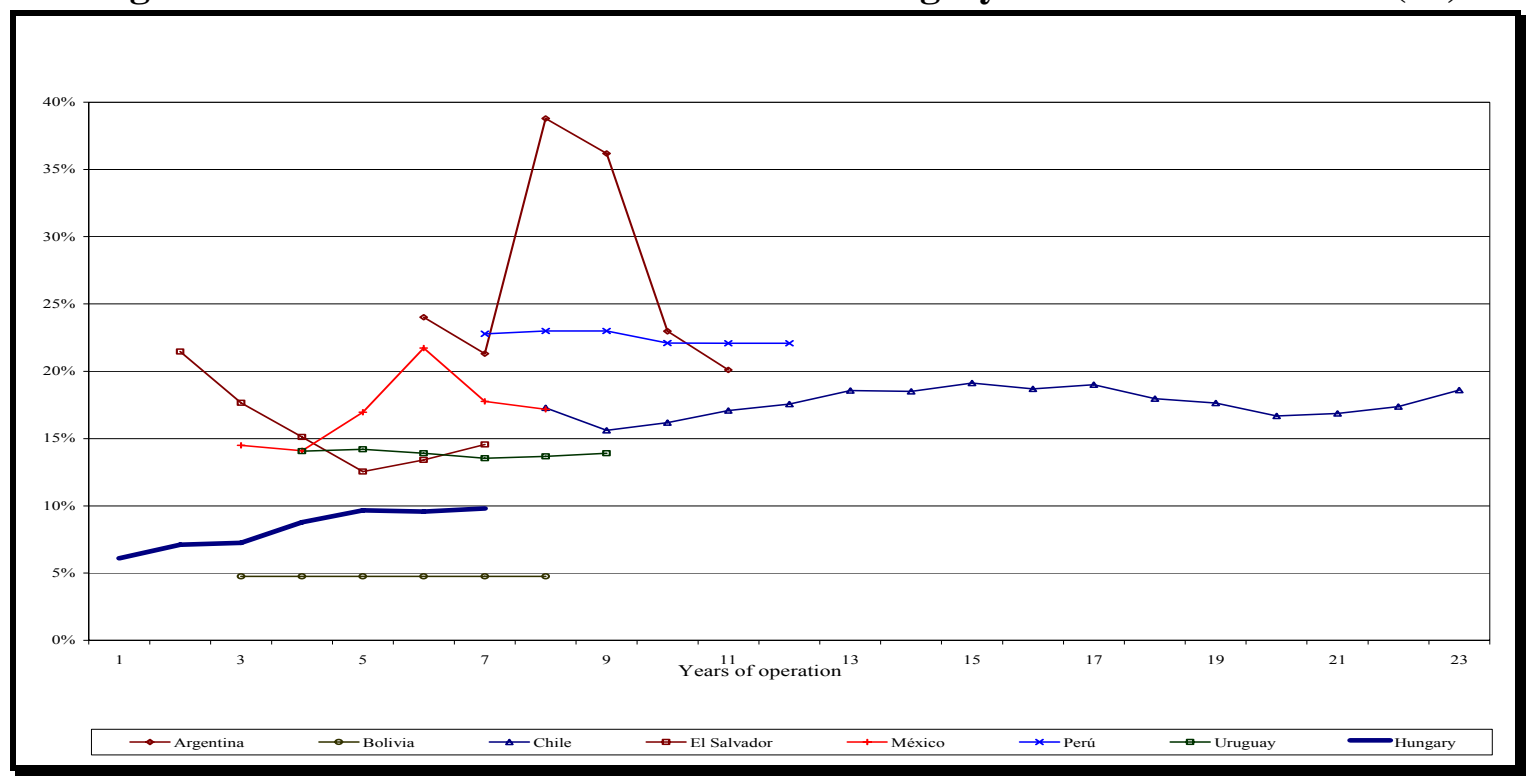

Note: Contributions and costs are net of death and disability insurance for Latin American countries

Source: AIOS and own calculations on HFSA raw data

Figure 6: Total Fees over Assets - Hungary and Other Countries (\%)

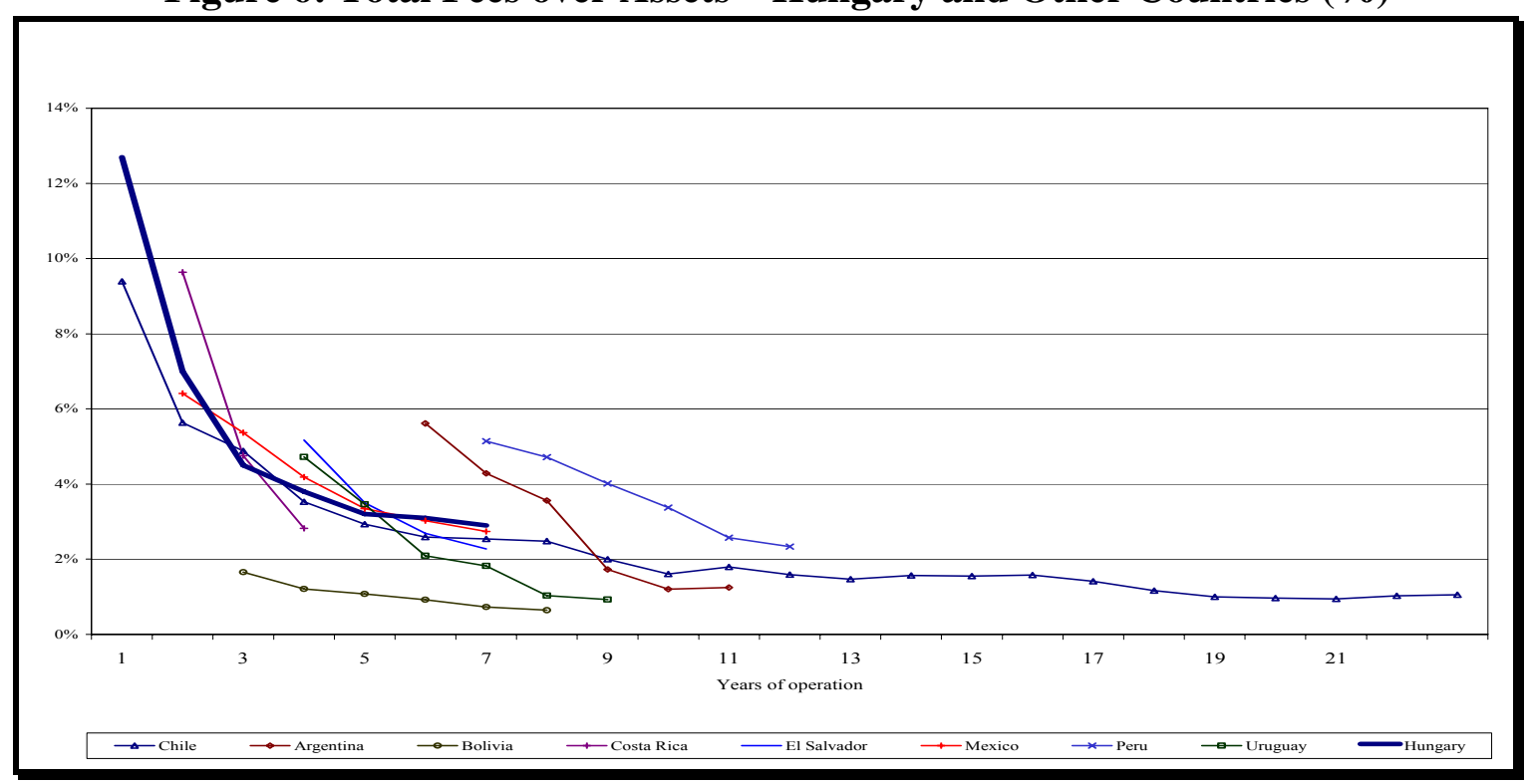

Note: Costs are net of death and disability insurance for Latin American countries

Source: AIOS and own calculations on HFSA raw data

45. If operating and asset management fees are kept at their current levels of 6.5 percent of contributions and 1 percent of assets, total fees in Hungary would compare unfavorably with other reforming countries in the long-run. As shown in Figure 7, total fees over contributions would increase to more than 35 percent in 30 years, driven primarily by the fixed asset management fee of 1 percent charged on the increasing assets. Total fees over assets would converge to about 1.2 percent, as shown in Figure 8, an excessive level for a mandatory system. Total fees over assets would not be much higher than the levels of fees in Chile today, but this comparison does not provide too much 
comfort, as the persistence of high fees has been one of the main criticisms of the Chilean system. These are the levels of fees charged by expensive active/high turnover equity mutual funds in the US. The fees charged by indexed (passive) equity mutual funds, bond funds, and money market mutual funds are much lower than 1 percent of assets, and so are the fees charged by occupational pension funds in most countries. ${ }^{15}$

Figure 7: Long Run Total Fees over Contributions for the Average MPF

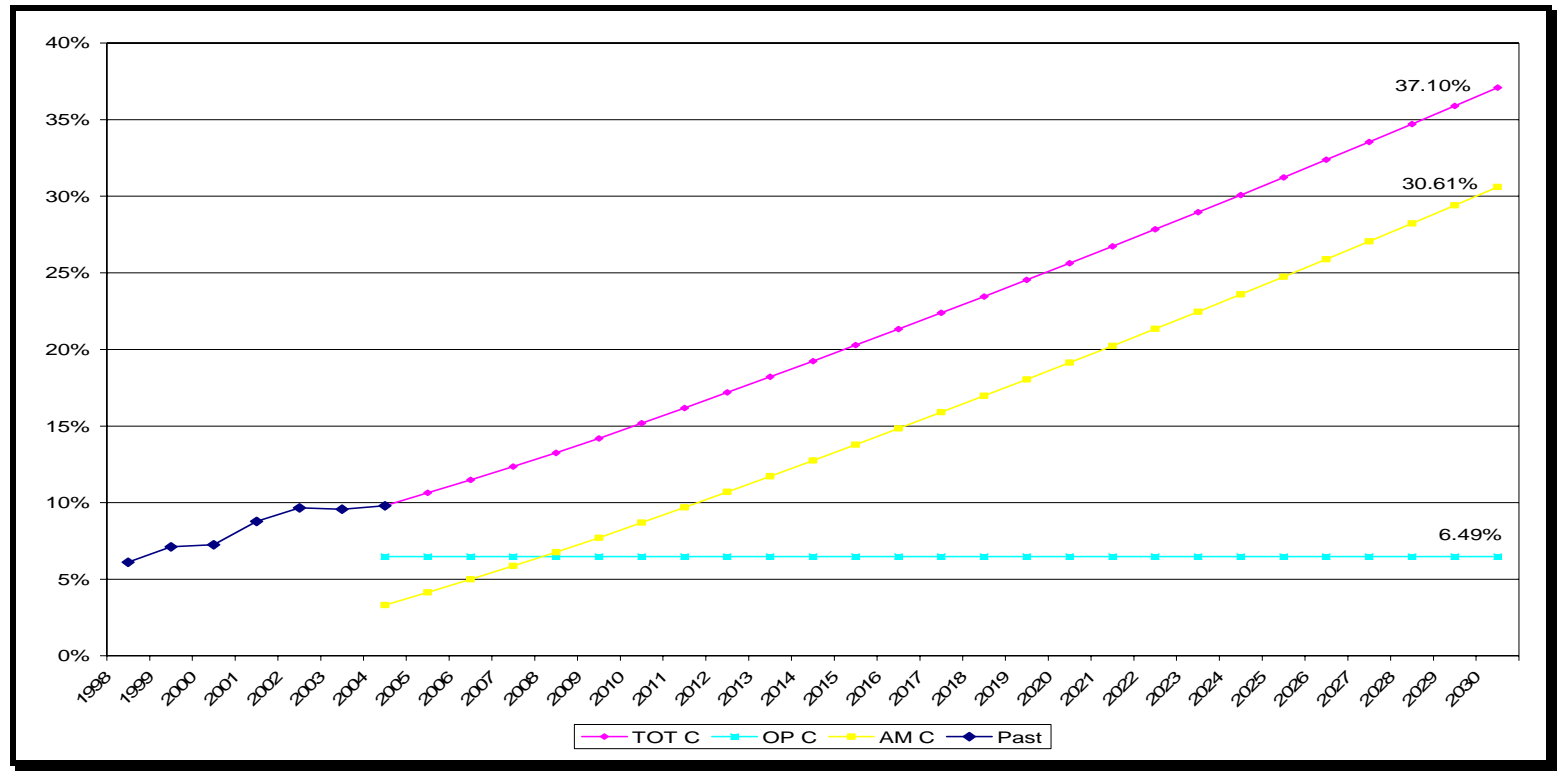

Note: real wage growth $=4 \%$, rate of return $=8 \%$, asset management fees $=0.97 \%$ of assets and operating fees: $6.49 \%$ of contributions.

Source: Own calculations on HFSA data.

Figure 8: Long Run Total Fees over Assets for the Average MPF

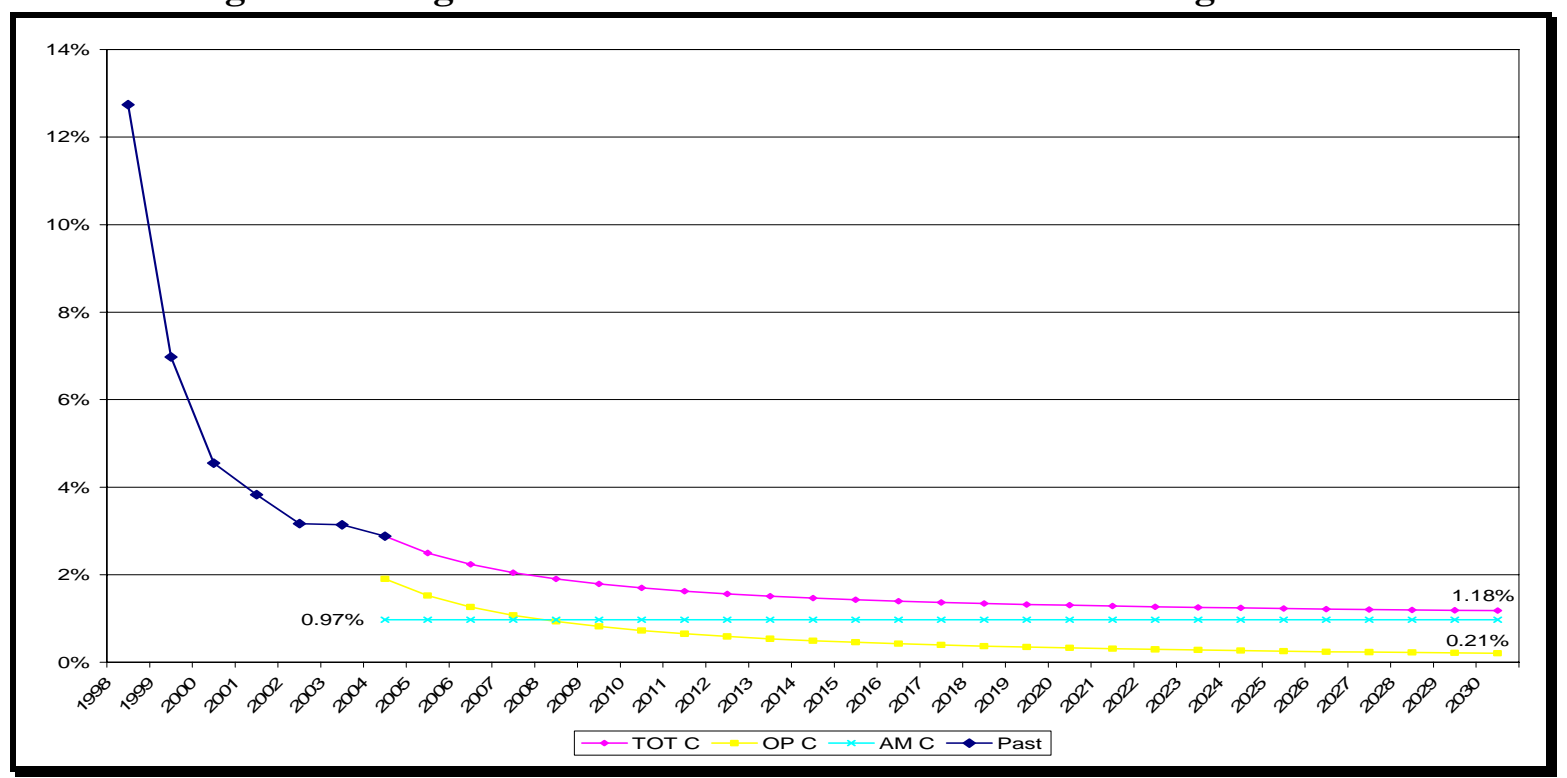

Note: Real wage growth $=4 \%$, rate of return $=8 \%$, asset management fees $=0.97 \%$ of assets, and operating fees $=$ $6.49 \%$ of contributions.

Source: Own calculations on HFSA data.

${ }^{15}$ See Colins (2003), Investment Company Institute (2003), and Rocha (2006). 
46. The exercise is admittedly mechanistic, and it is possible that both operating fees and asset management fees would be reduced over time, in line with asset growth.

However, the exercise also illustrates the potential problems that may be caused by the maintenance of the mixed fee structure, combined with the lack of transparency and competition in the pension system. If the system remains as segmented as it is in the present time, some members might be penalized and suffer from relatively low replacement ratios at the time of retirement.

47. Figure 9 and Figure 10 replicate the exercise for the two MPFs with the highest and lowest total fees over assets or over contributions in 2004 reported in Table 18 and Table 19. Results are also compared with and the results obtained before for the average MPF. Notice that total fees over contributions would converge to $51 \%$ and $16 \%$ for the highest and lowest cost MPFs, respectively. Similarly, total fees over average assets would converge to $1.66 \%$ and $0.49 \%$ for the highest and lowest fee MPFs, respectively. The exercise suggests that it should be possible to reduce long-run fees to about 50 basis points, which is also the level of fees charged by large occupational funds in the US. ${ }^{16}$

Figure 9: Long-Run Fees over Contributions for Average, Highest and Lowest Cost MPF

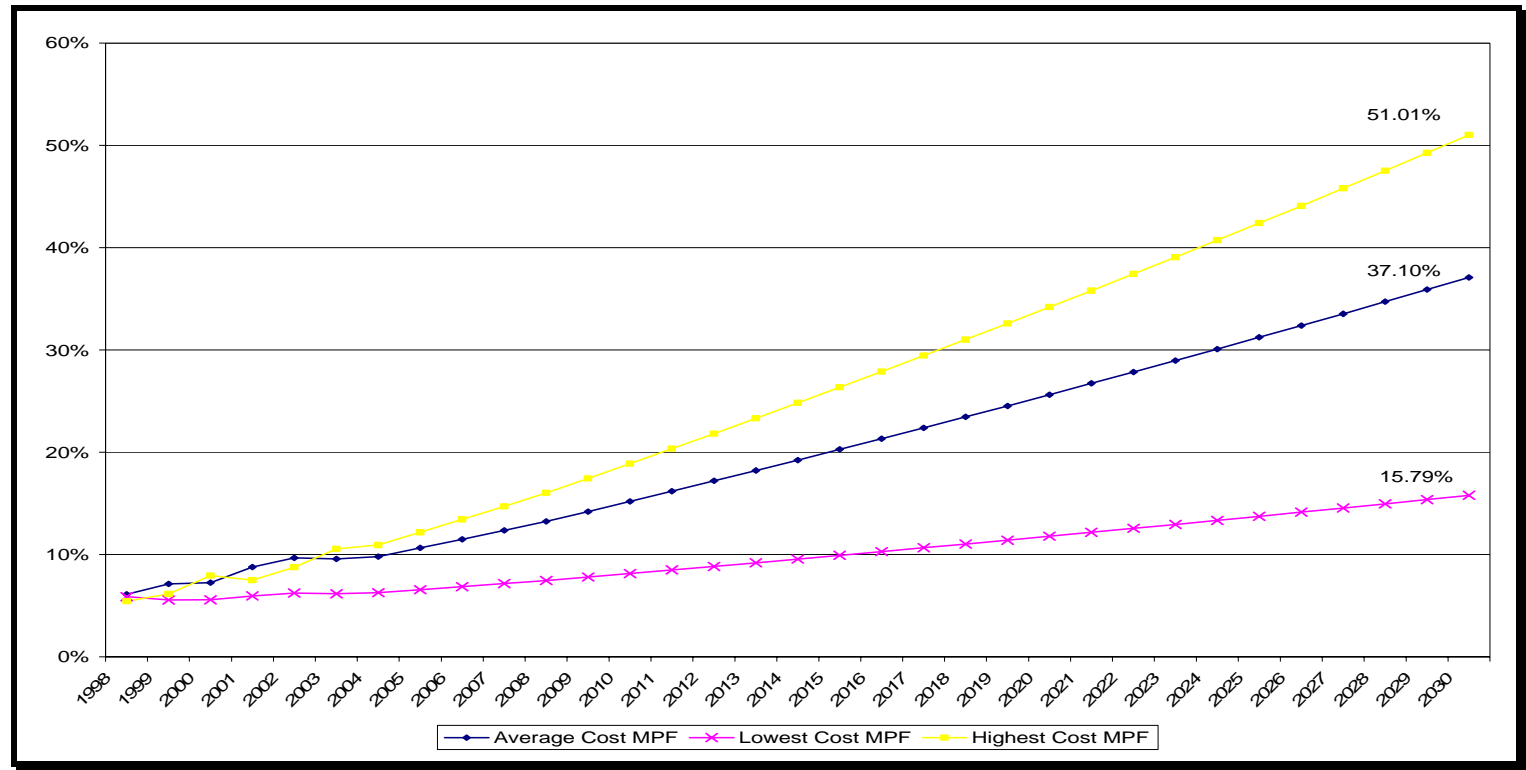

Note: real wage growth $=4 \%$, rate of return $=8 \%$.

Source: Own calculations on HFSA data.

\footnotetext{
${ }^{16}$ Colins (ibid) and Investment Company Institute (ibid).
} 
Figure 10: Long-run Fees over Assets for Average, Highest and Lowest Cost MPF

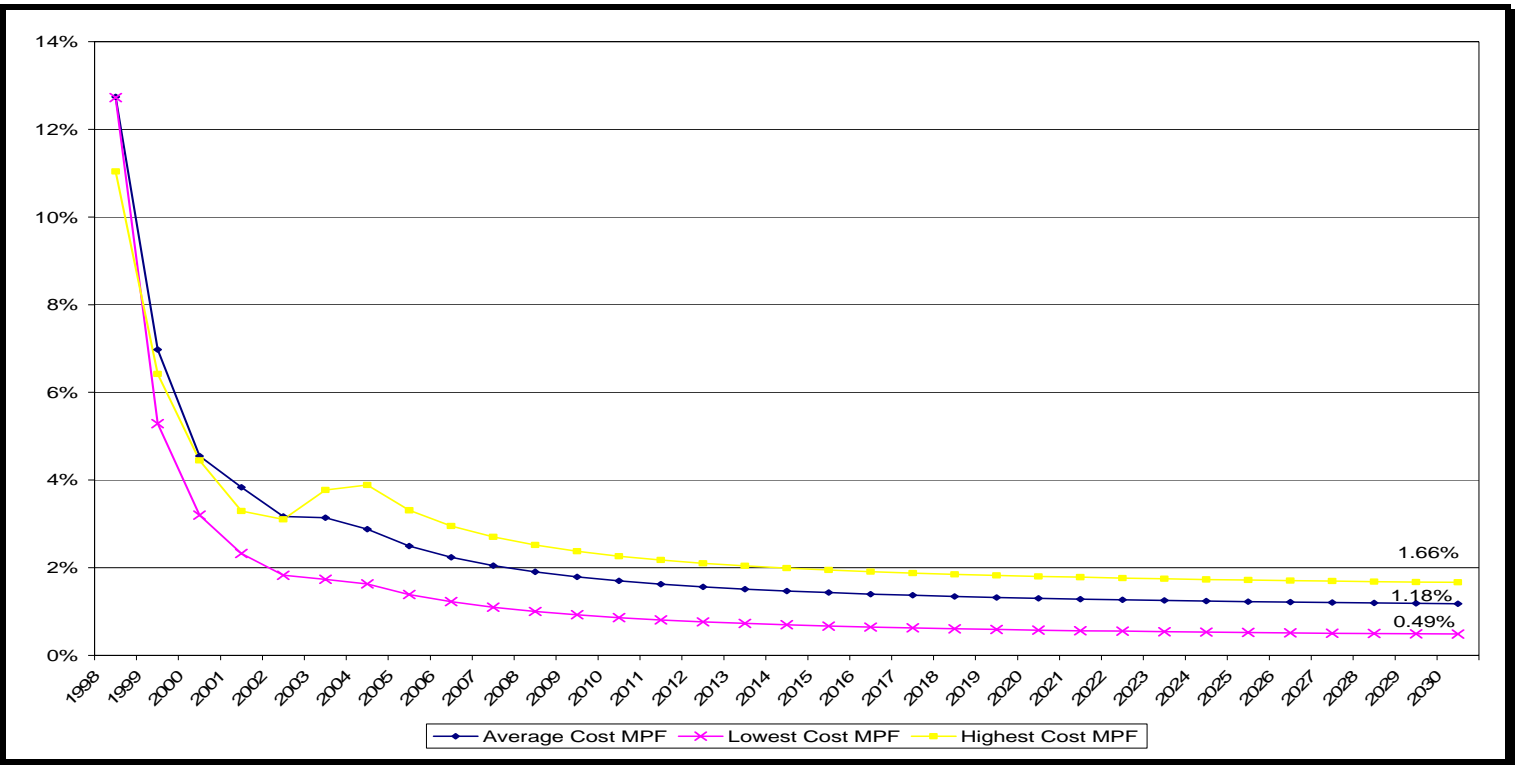

Note: Real wage growth $=4 \%$, rate of return $=8 \%$.

Source: Own calculations on HFSA data.

48. An alternative way to examine fees in Hungary entails the examination of the long-run equivalence of fees over contributions and assets, building on the general methodology developed in Diamond (2001). Figure 11 shows the compensating variation in fees of contributions that would be required to maintain the final balance constant if the fees on assets is set to 1 percent for an individual with a wage growth of 5\%, a working career of 40 years $(T=40)$, and no interruption in service $\left(T^{*}=40\right)$. It shows that fees on assets of 1 percent are equivalent to fees of 15 to 30 percent on contributions, depending on the net rate of return (gross rate minus fees). These results are consistent with the simulations shown in Figure 7 and Figure 8, and illustrate the long-run impact of asset fees charged during the whole accumulation phase. In particular, the long-run total fee over assets of 1.18 percent for the average MPF would translate in a long run contribution fee of $17-35$ percent. ${ }^{17}$

\footnotetext{
${ }^{17}$ The methodology is developed in Appendix B. Note that the projected fees on contributions in Figure 7 are higher because the average fees on assets charged during the accumulation phase are higher than 1 percent and wage growth assumption is lower.
} 
Figure 11: Long-Run Fees Over Contributions Equivalent to a 1\% Asset Management Fee

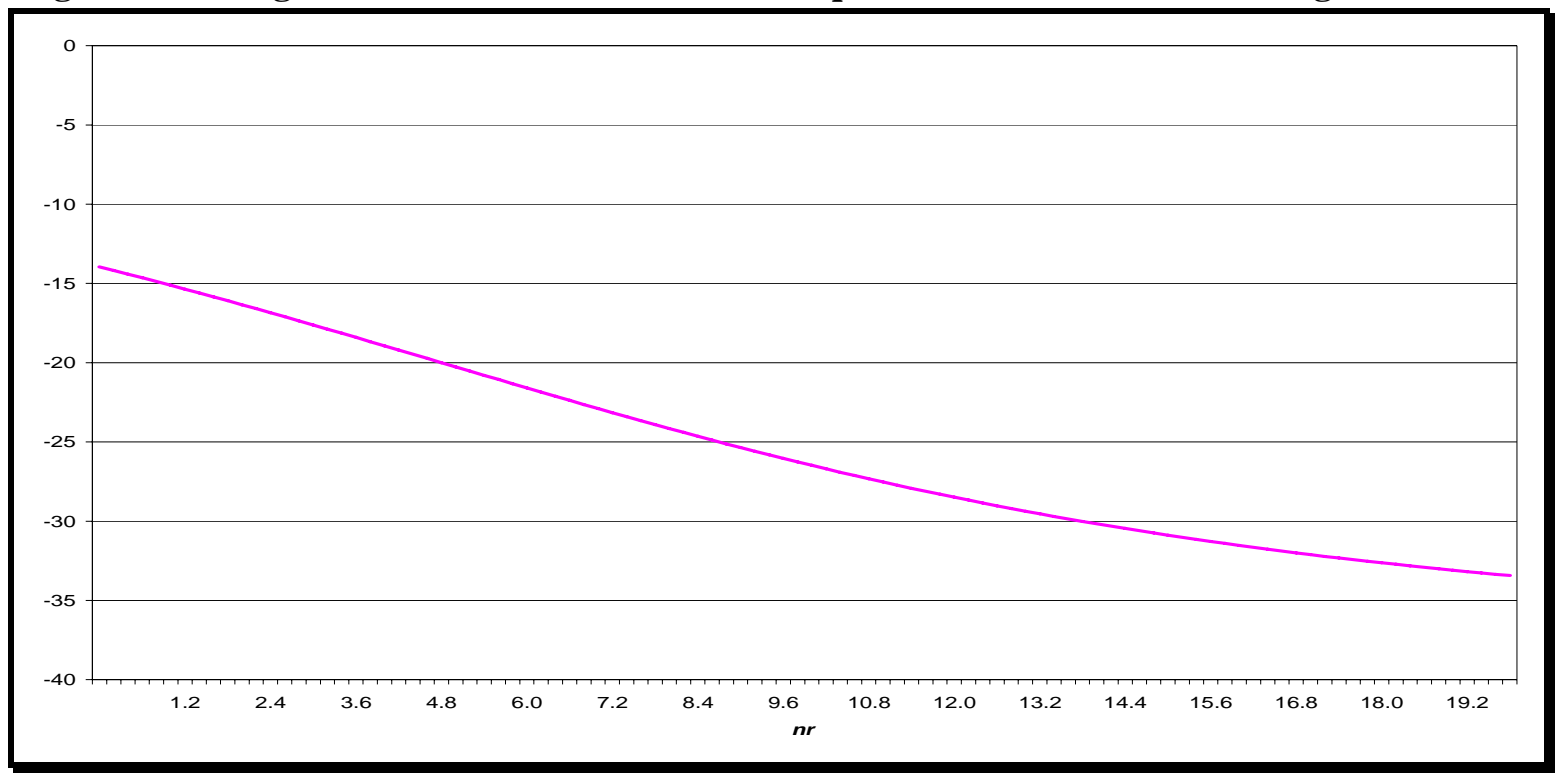

Note: The $\mathrm{Y}$ axis measures the long run fee over contribution required to compensate (hence, the negative sign) a $1 \%$ asset management fee for increasing asset net rate of return measured along the $\mathrm{X}$ axis. Other assumptions used: wage growth $=5 \%, T=40, T^{*}=40$.

49. Finally, the long-run impact of fees charged during the accumulation period can also be assessed through the computation of charge ratios. ${ }^{18}$ A charge ratio is defined as one minus the accumulation ratio. The accumulation ratio is the ratio of the final cash balance produced when fees are charged over the cash balance where fees are not charged. Table 20 reports the charge ratios for the average MPF in Hungary defined as the MPF that charges an operating fee of 6.49 percent of contributions and an asset management fee of 0.97 percent of assets. The ratio is calculated for different wage growth rates, rates of return, interruption in service $\left(T-T^{*}\right)$ assumptions, and for a 40 year career individual $(T=40)$.

Table 20: Charge ratios for the average MPF in Hungary, (\%)

\begin{tabular}{|ccc|c|c|c|}
\hline & & & \multicolumn{3}{|c|}{ Rate of return (\% p.a.) } \\
\hline \multirow{2}{*}{$T^{*}=\mathbf{3 0}$} & wage & $\mathbf{2}$ & 26.9 & $\mathbf{5}$ & $\mathbf{8}$ \\
& growth & $\mathbf{5}$ & 28.4 & 25.3 & 23.8 \\
& (\% p.a.) & $\mathbf{8}$ & 29.8 & 26.9 & 26.3 \\
\hline \multirow{2}{*}{$\mathbf{T}^{*}=\mathbf{3 5}$} & wage & $\mathbf{2}$ & 25.2 & 23.4 & 20.9 \\
& growth & $\mathbf{5}$ & 27.3 & 25.2 & 23.0 \\
& (\% p.a.) & $\mathbf{8}$ & 29.2 & 27.3 & 25.2 \\
\hline \multirow{2}{*}{$\mathbf{T}^{*}=\mathbf{4 0}$} & wage & $\mathbf{2}$ & 23.5 & 20.5 & 17.7 \\
& growth & $\mathbf{5}$ & 26.3 & 23.5 & 20.5 \\
& (\% p.a.) & $\mathbf{8}$ & 28.6 & 26.3 & 23.5 \\
\hline
\end{tabular}

Note: Contribution fee $=6.49 \%$, asset management fee $0.97 \%, T=40$

50. Note that the charge ratio increases with non-contributory periods (due to unemployment, for instance), as even if the contribution fee is not charged, the asset

\footnotetext{
${ }^{18}$ See Diamond (2000), Haukur, Trygvi, and Orszag (1999), Murthi, Orszag, and Orszag (2001 and 2001b), Rusconi (2004), and Whitehouse (2000).
} 
management fee is charged until retirement. There is a trade off between the rate of return and wage growth, as shown by the terms along the diagonals. Note also that the charge ratio increases with the rate of return and decreases with wage growth. When the rate of return increases the incidence of the asset management fee also increases, raising the charge ratio. When wage growth increases, the end of period cash balance without fees increases more quickly than in the case of no fees, lowering the charge ratio.

51. Mitchell and Bateman (2003) report charge ratios for Australia that vary from 5 to 15 percent for employer-sponsored defined contribution schemes, and that vary from 22 to 28 percent for the much more costly open, retail schemes. Whitehouse (2000) reports charge ratios that vary between 15 and 20 percent in most Latin American countries, but that can reach 28 and 35 percent in Argentina and Mexico, respectively. Therefore, the charge ratios for the average MPF in Hungary do not compare favorably with the ratios of most other second pillars.

52. Again, the exercise is admittedly mechanistic but it illustrates the problems that may arise if the current structure and levels of fees are maintained in the longer-run: even a mere total fee of 1 percent over assets would consume the equivalent of 15 to 30 percent of the final cash balance over a full career of contributions and average assumptions on inflation, wage growth and rate of return.

\section{Pension Reform and Capital Market DeVelopment}

53. Pension reforms involving the introduction of a second pillar are expected to contribute to capital market development by promoting the growth of institutions with a long investment horizon, such as pension funds and insurance companies. The presence of these institutions is expected, inter alia, to accelerate the development of several financial instruments with long maturities, improve access to finance and risk management to a wider range of investors, enhance competition in the financial sector, and promote better regulations and corporate governance.

54. The contribution of the second pillar to capital market development has been modest so far. As shown in Table 21, there has been some progress in expanding the market for traded government securities and starting a market for mortgage bonds, and institutional investors have made a contribution to these positive developments. However, indicators of liquidity and maturity suggest that the development of the market for government debt has been only moderate, and the stock of mortgage bonds is still very small. Moreover, other financial instruments such as corporate, municipal, and infrastructure bonds have not been developed, nor has private equity.

Table 21: Stocks of Major Financial Instruments (\% of GDP), 2000 and 2004

\begin{tabular}{lcccccc}
\hline & $\begin{array}{c}\text { Traded } \\
\text { Government } \\
\text { Securities }\end{array}$ & $\begin{array}{c}\text { Public } \\
\text { Equity }\end{array}$ & $\begin{array}{c}\text { Mortgage } \\
\text { and } \\
\text { Financ. Instit. } \\
\text { Bonds }\end{array}$ & $\begin{array}{c}\text { Corporate } \\
\text { and } \\
\text { Municipal } \\
\text { Bonds }\end{array}$ & $\begin{array}{c}\text { Private } \\
\text { Equity }\end{array}$ & $\begin{array}{c}\text { Infrastructure } \\
\text { Bonds }\end{array}$ \\
\hline 2000 & 30.0 & 21.0 & 0.0 & 0.0 & n.a. & 0.0 \\
2004 & 43.0 & 26.0 & 6.0 & 0.1 & n.a. & 0.0 \\
\hline Source: HFSA, BSE, MNB, AKK & & & &
\end{tabular}


55. The government debt market remains the centerpiece of Hungary's capital market and developed further during this period, as indicated by the increase in the share of traded securities from 53 to 74 percent of the total debt stock, and the corresponding increase in the stock of traded government securities from 30 to 43 percent of GDP between 2000 and 2004. Moreover, 15-year bonds have been introduced and all auctions for these bonds have been oversubscribed, revealing a strong demand for these instruments, while the share of short-term T-bills has declined from 35 to 24 percent between 2000 and 2004. Institutional investors contributed to these positive outcomes by holding an increasing share of the stock (Figure 12) and participating actively in the auctions of long-term securities.

56. At the same time, the issues of long-term securities are still a small share of total issues, as shown in Figure 13. As a result, the increase in the average maturity and duration of the stock has been modest, as shown in Figure 14. Moreover, the annual turnover of all government securities has dropped from 6-8 times the debt stock in 2000 to 3- 4 times the stock in 2004, and bid-ask spreads have increased in the same period. Therefore, whereas there has been progress in developing the market for government securities, this progress should not be exaggerated either.

Figure 12: Holders of government debt (\% of total), $1997-2004$

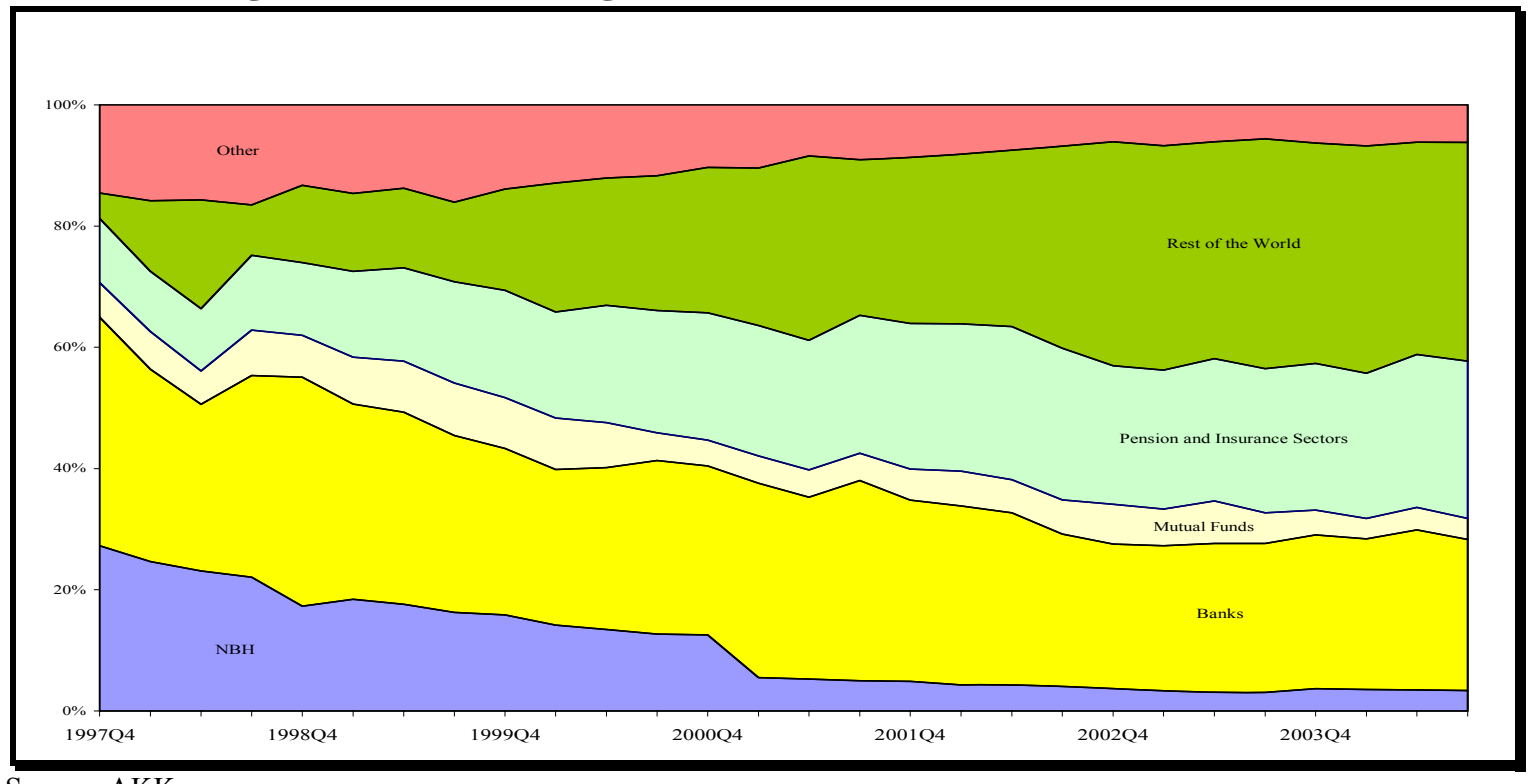

Source: AKK 
Figure 13: Stock Of government securities by maturity - HUF million, Dec. 2004

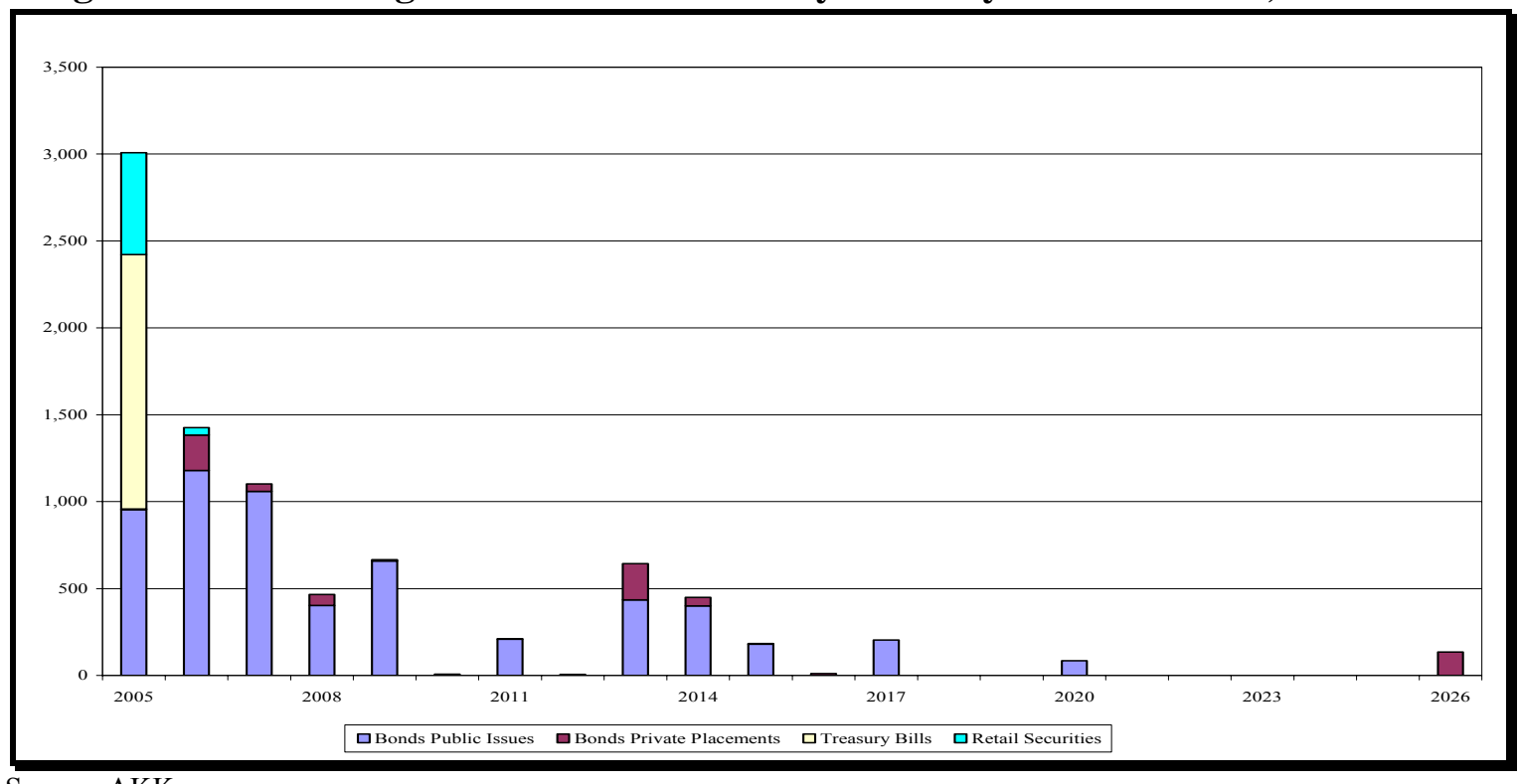

Source: AKK.

Figure 14: Average maturity and duration of government securities, 2002-2004

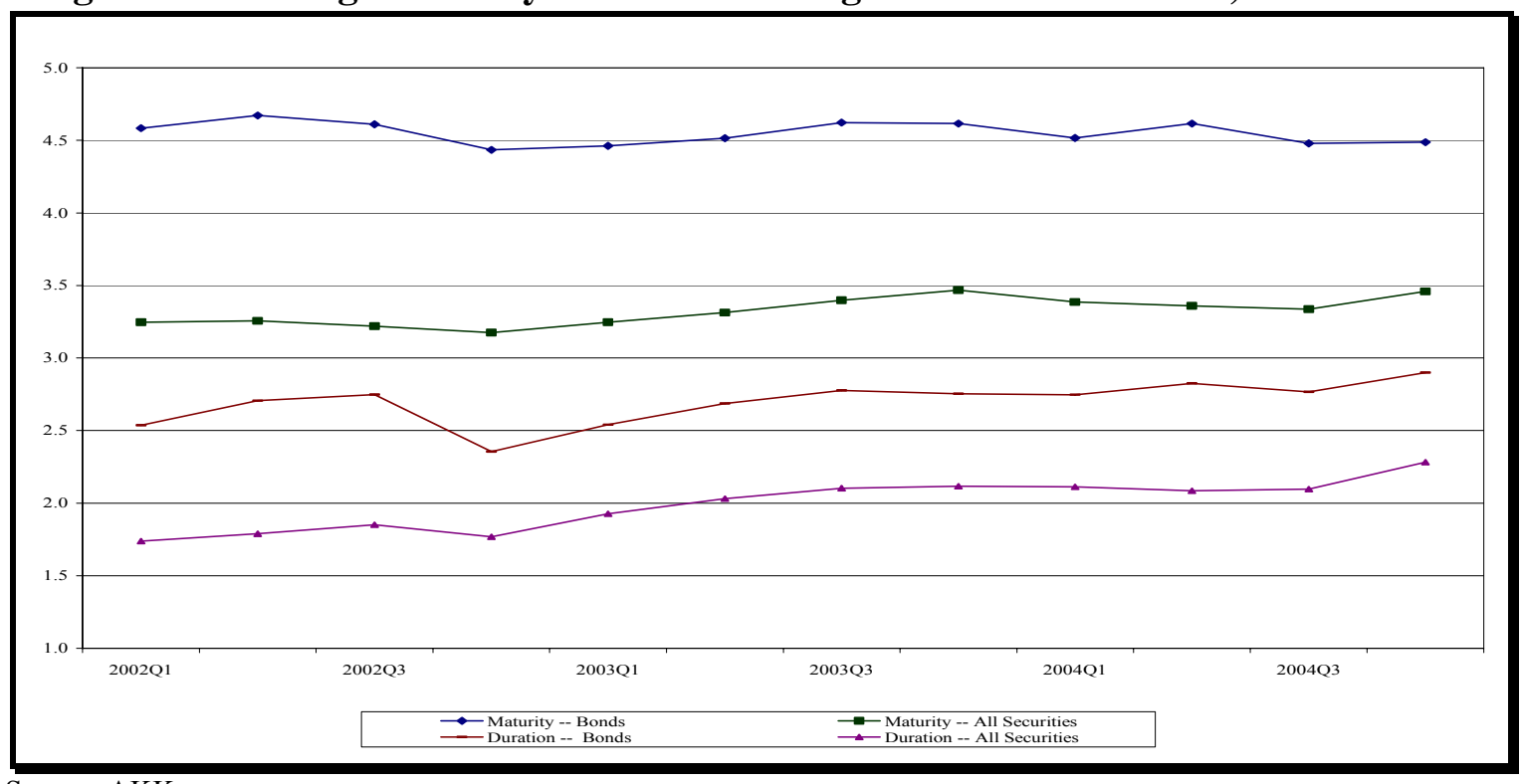

Source: AKK.

57. The short average maturity of the stock of government debt looks particularly disappointing, because the lengthening of the maturity of government debt is one of the first outcomes expected from a pension reform. A more pronounced increase in maturity and duration would indicate that the Government is succeeding in developing this key market and building a yield curve for government securities, which provides the benchmark and the necessary preconditions for the development of other fixed income instruments with long durations such as mortgage, corporate, and infrastructure bonds.

58. The short duration of Government debt may not reflect a failure of the pension reform, however, but a deliberate strategic decision by the Debt Management Agency 
(AKK), designed to avoid losses at the time of accession to the Euro zone, which is anticipated for 2010. Duration is apparently being maintained at 2.2 years to reduce the risk of losses from converting long-term liabilities denominated in HUFs into Euros at interest rates which are higher than those in the Euro zone. ${ }^{19}$ It would not make sense to lock in these higher interest rates for Euro-denominated contracts. Therefore, the short duration probably reflects a sound debt management decision, but it remains true that the short duration of instruments in this key market will tend to slow the development of other related fixed income instruments.

59. Regarding the development of the equity market, BSE market capitalization has remained roughly stable at relatively low levels. Moreover, as with many other regional exchanges, capitalization and trading are dominated by a small number of large national companies. The BSE is highly concentrated, with the top five companies accounting for 89 percent of market capitalization and 93 percent of turnover in 2004. A variety of fixed income instruments are also listed on the BSE, but trading in those instruments (chiefly government bonds) is primarily conducted in OTC markets. Institutional investors have contributed modestly to the development of Hungary's equity market, as indicated by their limited holdings of domestic equity, concentrated in very few issues.

60. The development of Hungary's equity market is being dominated by global trends towards equity migration. These trends are driving the recent acquisition of the BSE by a group of Austrian and Hungarian banks and financial institutions, including the Vienna Stock Exchange, and the merger of the BSE and Budapest Commodities Exchange (BCE). This group is now seeking a closer relationship with equity market players in Poland, as part of a regional strategy to integrate the stock market, the commodity market, and settlement and custody provision into one value chain. It is not clear what will be the role of the BSE as Hungary integrates more closely with the EU. On the one hand, it may continue to play a role as a provider of finance to second tier, medium-sized companies, but it could also become increasingly redundant in an integrated regional financial system.

61. The market for corporate bonds has not developed because of intense bank competition for prime borrowers and a high degree of foreign ownership, which facilitates access to loans from the foreign mother company. However, there may also be some regulatory glitches. While bank loans can be arranged in a few days with established creditors, the costs of preparing a new bond prospectus and the time required to obtain the necessary approvals can be significant. Moreover, if liabilities are greater than equity companies need to obtain a credit rating before issuing a bond. This creates a serious problem for potential issuers, because no credit rating agencies are active in Hungary and many of the largest blue-chip companies are not formally rated.

62. Developing a private equity industry has been a challenge in many countries, and in the case of Hungary inflexible regulations have aggravated this problem. The Venture Capital Act places requirements on fund investors to pay in capital before investments have been identified and limits the flexibility of fund managers regarding the timing of their investments and design of investment structures. Because of these restrictions, the

\footnotetext{
${ }^{19}$ Real interest rates on Government securities are lower in Hungary than in most other emerging countries, in good part because of Hungary's higher credit rating. However, Hungarian rates are still higher than rates on Government securities issued by developed countries in the Euro zone.
} 
private equity industry incorporates and maintains their capital outside of Hungary even though in many cases their operations are based in Budapest.

63. Infrastructure bonds have not developed either, partly due to market limitations and partly to some regulatory barriers to Public-Private Partnership (PPP). Several large highway projects are being considered as PPPs, but these will probably need to access external markets due to their large size. Smaller PPP projects would have the potential to be matched with domestic institutional investor capacity, and could include hospitals, housing, and sporting complexes. However, bond financing for smaller PPP projects is hindered by the lack of clear project frameworks, including clear ownership structures, methods for handling revenue, and risk mitigation. There are also some regulations that make it difficult for a newly formed PPP company to issue bonds, such as a clause in the Capital Market Act prohibiting newly formed companies from issuing bonds if they have been in operation for less than one year, unless guaranteed by the government or if the bond issue is backed by specific assets pledged as collateral. Special purpose companies set up for PPPs are generally new and raise money backed by contracts for revenue from assets under construction, so would not satisfy those requirements.

\section{Regulation of the Accumulation and Payout Phases}

64. This section analyses the regulatory framework of MPFs of the accumulation and payout phases. The main areas analyzed are: licensing, governance, investment regulation, accounting standards and valuation rules, auditing standards, disclosure rules,

\section{A. Main Regulatory Issues in the Accumulation Phase}

\section{Licensing}

65. Licensing criteria and procedures in Hungary are generally reasonable. The list of documents needed to obtain a license includes the deed of foundation, the financial plan of the fund, information on the members of the board of directors, the supervisory board and the auditor, internal controls and auditing systems, and outsourcing contracts with any service provider, including custodians and external asset managers.

66. The HFSA screens applications to ensure that MPFs are managed by reputable and qualified individuals and that it only employs reputable service providers. For instance, while in principle most functions can be outsourced, each MPF needs to have on payroll at least a managing director, a senior accounting officer, a manager responsible for investments and an internal controller. These professionals are subject to adequate fit and proper tests. However, the same sound procedures are not applied to board members. The Law requires only a higher education degree for the chairmen of the board of directors and the supervisory board, and imposes no requirements on other board members. The simple requirement of a higher degree does not ensure the qualifications, reputation and professional experience, needed to effectively govern a pension fund.

\section{Governance}

67. MPFs are legally structured as non-profit, open mutual benefit associations, following exactly the same legal structure of voluntary third pillar funds, which have existed since 1993. The governance structure of MPFs is also equal to the structure of 
voluntary funds. The maximum governing body of an MPF is the general assembly of the fund members. In large pension funds the delegates, elected to such position for a period of five years, are expected to represent members. The general assembly meets typically twice a year, to discuss and approve the annual report and the financial plan. It also approves modifications to the deed of foundation and fund regulations, elects and removes the members of the board of directors and the supervisory board, and elects and removes the external auditor. The general assembly does not approve the choice of external service providers like asset managers.

68. The board of directors is the managing body of the fund and is formed only by members of the fund. The powers and responsibilities of the board of directors include implementing the resolutions passed at the general meeting, ensuring that the fund's books are kept in accordance with regulatory requirements and the fund's by-laws, approving the fund's investment policy and the method of asset valuation, selecting the asset manager, and selecting other external service providers such as administrators.

69. The supervisory board is composed by a majority of fund members and regularly reviews and inspects the MPF's finances, accounting and management. The supervisory board also recommends the external auditor to the general assembly for approval, selected on the basis of an open and competitive application process. ${ }^{20}$

70. While in principle the governance structure is designed to grant decision powers to fund members, this outcome does not materialize in many funds. The open mutual association nature and the absence of capital requirements imply that in most cases the MPF needs a sponsor to meet the start-up costs. As shown in Section II, the industry is divided in three groups of MPFs: (i) MPFs sponsored by financial institutions; (ii) MPFs sponsored by large employers; and (iii) independent MPFs (in other words, MPFs without a sponsor). The third group consists of only three MPFs and accounts for less than 10 percent of the second pillar.

71. The boards of MPFs sponsored by financial institutions are de facto controlled by these institutions. Typically, the general assembly is dominated by the employees of these financial institutions, and vote on members of the board of directors and the supervisory board among pre-selected employees. The board of directors then outsources asset management and administration to the asset management and administration companies within the sponsoring financial group. Therefore, these MPFs tend to operate in practice like open pension funds in Chile and most other countries that followed the Chilean approach, in the sense that there is a one to one relationship between the pension fund and the profit-oriented asset manager and administrator within the financial group. A major difference with Chile, however, is the lack of transparency of this relationship and the weaker legal accountability of the sponsoring financial institution (evidenced, among other factors, by the lack of capital requirements on the fund manager).

\footnotetext{
${ }^{20}$ This two-board structure is relatively common in Continental Europe, although it was originally designed for joint-stock companies, not mutual associations. In Company Laws (or Commercial Codes) the supervisory board is expected to represent the interests of shareholders and neutralize any influence of management on the main board. It plays a role similar to that of independent, outside directors in the one board systems prevalent in Anglo-Saxon countries.
} 
72. The MPFs sponsored by large employers tend to operate in practice like nonprofit, occupational, defined contribution pension funds in high income OECD countries (such as Australia). There are some differences regarding the rules for board composition, and in the fact that these funds are typically closed, while the Hungarian employer-based funds are open to members without an employment relationship with the sponsor. However, the absence of a profit motive by the sponsor provides a similarity to occupational funds in the OECD. Independent MPFs are not related to any particular sponsor and operate like non-profit mutuals, following more closely the original design intended for third pillar funds.

73. Not surprisingly, the fees charged by MPFs sponsored by financial institutions are higher than the fees charged by the other two types of MPFs, as shown in Section V.

Since all funds are open, members of high cost funds can switch to lower cost funds, i.e., "vote with their feet", but very little switching has taken place since 1998. This inertia is due, at least to some extent, to weak disclosure requirements. The absence of readily available information on comparable fees makes it more difficult for members to realize that they could switch to lower cost funds yielding similar returns. The allocation of undecided new entrants to default funds which tend to be the higher cost funds may also explain the result. Finally, funds sponsored by financial institutions have a sales force and probably adopt more active marketing tactics than other types of funds.

74. It is important to note that the Hungarian construction may lead to situations where the boards may not act in the best interests of their members, especially in the case of the funds sponsored by financial institutions. For example, the supervisory board recommends an auditor to the general assembly on the basis of an open and competitive bidding process. If the board of directors followed a similar procedure for the selection of the asset manager and the administrator, it is possible that companies outside the sponsoring financial group would be selected. This would create an unusual and tense situation, because the employees of the sponsoring institutions (who are the board members) would be handing the pension business to a competitor.

75. One of the main questions faced by Hungarian regulators is whether the current market segmentation can be addressed by simply improving disclosure rules, marketing rules, consumer education, and the rules for allocation of new entrants, or whether more forceful measures are called for, changing the core incentives and decisions at the management and board levels. If stronger measures prove necessary to reduce fees and market segmentation, a related question is whether this could be achieved by simply enforcing the formal fiduciary obligations of boards, or whether other more structural legal changes would be necessary, such as the "demutualization" of pension funds (i.e., adopting the more typical Chilean-style legal structure), or the adoption of different institutional arrangements for the second pillar. It is likely that a gradual approach involving initially only the adoption of measures to improve transparency, performance comparability and promote migration to low cost funds would improve competition and reduce the current segmentation. These measures could be strengthened by the introduction of more concrete behavioral controls ${ }^{21}$ for current directors or by requiring

\footnotetext{
${ }^{21}$ See Hess and Impavido (2004) and Impavido (2005) for a discussion on governance mechanisms that pension funds can adopt to compensate for the weaknesses of representative governing bodies. See Clark
} 
independent directors to serve on the MPF boards in order to facilitate the enforcement of the fiduciary obligations of boards.

\section{Investment Regulation}

76. Hungary adopted initially an investment regime for the second pillar based on portfolio restrictions, as opposed to the prudent man rule adopted typically in AngloSaxon countries. However, the investment regime has not been overly restrictive and has been progressively relaxed over time. As shown in Table 22, the limits on instruments or asset classes are reasonable, and have been either relaxed or eliminated over time.

77. The initial restrictions on foreign assets have been relaxed and eliminated for EU/OECD countries. There is a restriction of 30 percent on foreign currency exposure, equal to that prevailing in most Western European countries before the adoption of the Euro. The previous 50 percent limit on equity holdings was eliminated for listed equity in January 2005. The strict limit on direct real estate holdings is justified for defined contribution funds that need to value portfolios on a mark-to-market basis and therefore need more liquid portfolios than defined benefit funds. The limits by individual issuers are reasonable and also exist in many countries, including countries that follow the prudent man rule. The rule that limits the use of derivatives for hedging purposes is appropriate. The limits that seem restrictive include the limits on mortgage-backed securities and private equity. 
Table 22: Statutory limits on asset holdings for MPFs.

\begin{tabular}{|c|c|c|}
\hline Cat. & Instrument & $\%$ \\
\hline A & Cash (Hungarian and foreign currencies) & \\
\hline B & Transaction account and investment account & \\
\hline $\mathrm{C}$ & Term deposits & \\
\hline $\mathrm{D}$ & Debt securities (bonds) & \\
\hline d1 & Hungarian government securities & \\
\hline $\mathrm{d} 2$ & Securities backed by the absolute guarantee of the Hungarian state & \\
\hline $\mathrm{d} 3$ & Foreign government securities & \\
\hline $\mathrm{d} 4$ & Securities backed by the absolute guarantee of a foreign state & \\
\hline d5 & Publicly traded bonds issued by a business organization registered in Hungary, excluding credit institutions ${ }^{1}$ & $10 \%$ \\
\hline d6 & Publicly traded bonds issued by a business organization registered abroad, excluding credit institutions ${ }^{1}$ & $10 \%$ \\
\hline d7 & Publicly traded bonds issued by a credit institution registered in Hungary & \\
\hline $\mathrm{d} 8$ & Publicly traded bonds issued by a credit institution registered abroad & \\
\hline d9 & Publicly traded bonds issued by a Hungarian municipality ${ }^{1}$ & $10 \%$ \\
\hline $\mathrm{d} 10$ & Publicly traded bonds issued by a foreign municipality ${ }^{1}$ & $10 \%$ \\
\hline $\mathrm{E}$ & Stocks & \\
\hline e1 & Stocks listed on the BSE or another recognized securities market and offered to the public in Hungary & \\
\hline e2 & $\begin{array}{l}\text { Stocks issued and offered to the public in Hungary, which the issuer has pledged to list on a stock exchange or a } \\
\text { recognized securities market within six months, and there is no statutory or other impediment to listing, or stocks for } \\
\text { which at least two brokerage firms publicly quote a price representing an irrevocable purchase obligation continuously } \\
\text { within } 30 \text { days prior to the purchase }{ }^{1}\end{array}$ & $10 \%$ \\
\hline e3 & $\begin{array}{l}\text { Stocks listed on a stock exchange or another recognized securities market and issued } \\
\text { and offered to the public abroad }\end{array}$ & \\
\hline e4 & $\begin{array}{l}\text { Stocks issued and offered to the public abroad, which the issuer has pledged to list on a stock exchange or a recognized } \\
\text { securities market within six months, and there is no statutory or other impediment to listing, } \\
\text { or stocks for which at least two brokerage firms publicly quote a price representing an irrevocable purchase obligation } \\
\text { continuously within } 30 \text { days prior to the purchase }{ }^{1}\end{array}$ & $10 \%$ \\
\hline $\mathrm{F}$ & Investment units $^{2}$ & $50 \%$ \\
\hline $\mathrm{fl}$ & Investment units of investment funds registered in Hungary, including real estate investment trusts ${ }^{3}$ & $10 \%$ \\
\hline $\mathrm{f} 2$ & Investment units of investment funds registered abroad, including real estate investment trusts ${ }^{3}$ & $10 \%$ \\
\hline $\mathrm{G}$ & Mortgage-backed certificates & $25 \%$ \\
\hline g1 & Mortgage-backed certificates issued by a mortgage lending institution registered in Hungary & \\
\hline g2 & Mortgage-backed certificates issued by a mortgage lending institution registered abroad & \\
\hline $\mathrm{H}$ & Exchange-traded futures ${ }^{4}$ & \\
\hline I & Exchange-traded options ${ }^{4}$ & \\
\hline $\mathrm{J}$ & Real estate & $5 \%$ \\
\hline
\end{tabular}

Notes: Investments from the same issuer limited to $10 \%, / 1$ All these investments together, $/ 2$ For all, but $10 \%$ for each fund, and $30 \%$ from the same issuer. $/ 3 \mathrm{fl}$ and $\mathrm{f} 2$ investing in real estate and $\mathrm{j}$ together, $/ 4$ Only for hedging.

78. In general, the investment regime allows substantial room for asset managers to operate, and has not constrained or influenced portfolio strategies to a meaningful extent. As discussed in Section IV, portfolio strategies have been determined by other factors, such as the fiscal and macroeconomic environment, the limited supply of financial instruments, and the MPF's internal approach to risk management. Therefore, even if the HFSA adopted a prudent man approach to investment regulation, as prescribed in the recent EU Pensions Directive, it is unlikely that portfolio strategies would change. ${ }^{22}$ Each pension fund is required to formulate and disclose an investment policy and its performance is monitored by the supervisor against this individual benchmark.

\footnotetext{
${ }^{22}$ The recent EU Pensions Directive prescribes the switch to a prudent man rule in the EU, but Hungarian MPFs are not subject to the Directive, due to their legal construction.
} 


\section{Minimum Return Guarantee}

79. The regulatory framework includes a minimum return guarantee that differs from the well known relative return guarantee adopted in Chile and the absolute return guarantee adopted in Switzerland. In Chile and most other countries that adopted the Chilean system, the minimum return guarantee is relative - defined in relation to a band around the average rate of return of all pension funds over a rolling 36 month period. If the rate of return is lower than the lower band, the asset manager needs to make up for the difference from its own minimum reserves. If the return is higher than the upper band, the difference is placed in a profitability reserve in the pension fund. The extreme herding by pension funds in Chile has led to very similar returns, implying that profitability reserves have not been built, nor asset managers have had to use their own minimum reserves to increase returns to the minimum.

80. The absolute guarantee in Switzerland ( 3 percent p.a.) is backed by an industrywide guarantee fund. This construction, similar to pension benefit guarantee schemes in defined benefit systems, and bank deposit insurance schemes prevalent in many countries, raises moral hazard issues that have not yet been satisfactorily addressed in Switzerland.

81. In Hungary, the benchmark is not the industry's average return, nor an absolute return, but a rate of return target that is determined primarily by a basket of long-term Government securities. If the rate of return exceeds the upper band the excess would need to be placed in the liquidity reserve. If the rate of return is lower than the lower band it should be increased to the minimum with transfers from the liquidity reserve. The liquidity reserve cannot be larger than 4 percent of total assets. Therefore, the rate of return guarantee in Hungary seems an internal smoothing device, designed to avoid extreme fluctuations relative to the benchmark.

82. The minimum return guarantee in Hungary does not seem to have affected investment policies in practice, possibly because there are questions of whether it can be legally enforced, and because the supervisor has set wide bands that make the guarantee effectively innocuous. This pragmatic approach by the supervisor has been appropriate, because this type of guarantee could lead asset managers to adopt defensive strategies and avoid entirely assets with higher risk-return characteristics, and could also lead to extreme herding behavior among pension funds, even when the asset manager does not have the formal obligation to back the minimum return with its own resources. ${ }^{23}$

\section{Accounting Standards and Valuation Rules}

83. Pension fund portfolios have been marked to market daily by the custodian, based on settlement prices during the trading day. The prices of listed and traded assets are provided by the Budapest Stock Exchange (BSE) and the Debt Management Agency (AKK). Apparently, the prices of assets traded in the over-the-counter (OTC) market are also reported. Assets which have not been traded for more than 30 days are valued by the lowest between the purchase price and the latest traded price. Real estate is valued once a year. It is not clear how other non-listed securities are valued, but exposure to these assets is very small. Capital gains and losses are split between realized and unrealized, but both

\footnotetext{
${ }^{23}$ Herding has also been observed in the UK, where pension funds do not need to meet formal minimum returns (Blake et al. 2002), but is probably intensified in the presence of formal guarantees.
} 
are reflected in the individual accounts. Until recently, custodians were required to submit this daily evaluation to the pension fund and the HFSA, but this requirement was recently abolished.

84. There are some rules that deviate from international accounting standards and distort the calculation and comparability of rates of return across different MPFs. Some of these problems are related to the division of pension contributions among 3 types of reserves: (i) the coverage reserve, constituting the sum of all individual accounts in the pension fund; (ii) the operational reserve, used to meet operational costs; and (iii) the liquidity reserve, used to smooth rates of return. Rate of return calculations are performed only on the coverage reserve and the portion of the operational reserve that is invested, i.e., only on a fraction of total contributions. This implies that the custodian has no oversight on the total assets of the pension fund and that return performance cannot be accurately compared. Although the operational reserve and, especially, the liquidity reserve, are relatively small, the methodology still implies some distortions.

85. Returns are calculated on a quarterly basis using a Dietz-modified type of formula (Appendix D). The methodology recognizes the shortcomings of ignoring the timing of the cash flows by proposing to day-weight cash flows. However, this is still an approximation of the true time weighted rate of return. Furthermore, the formula assumes that between the beginning and the end of the quarter the market value of the portfolio changes linearly, another rough approximation. The low frequency in calculating rates of return and the shortcomings in the methodology also hinder somewhat the comparability of rates of return across MPFs. For instance, two pension funds with the same portfolios could have different performances simply due to the different time and weight of cash flows between the pension fund and the asset manager.

86. There are some additional gaps in rules and procedures that also hinder the accurate comparison of investment performance. For example, performance evaluation against benchmarks is limited in Hungary, as there are no standards uniformly applied by the industry on how benchmarks should be re-balanced. For instance, two asset managers could have the same investment mandate and the same benchmarks but use different rebalancing frequencies. The different frequency translates in different benchmarks and therefore, in different performances. Also, no uniform rules exist for charging brokerage fees on equities. Some asset managers rightly charge the trading cost to the asset, while some other asset managers invoice the brokerage fees separately to the client, hence inflating their performance.

\section{Auditing Standards}

87. Auditing rules and practices in the second pillar are generally reasonable, although there are still some specific gaps that would merit attention from the regulatory authorities. All individual auditors of financial institutions need to be registered with the HFSA and licensed to audit a particular type of institutions. Individual auditors cannot audit more than five companies in the same sector and are subject to a maximum five year rotation rule, although the rotation requirement does not apply to the auditing firm employing the individual auditor.

88. Auditing rules do not specify in detail the scope of the audit, but in practice auditors review all financial statements, IT systems, internal controls, and the 
reconciliation of values with the custodian. Pension fund audits have included these elements because auditors believe they are necessary for a sound assessment of fair valuation. Therefore, the scope of the audit looks generally reasonable, and the HFSA has some influence on the scope through informal discussions with the industry. However, the Law does not empower the HFSA to change/broaden the scope, according to special needs.

89. The supervisors can call the auditors for clarifications without need for approval of the pension fund board or management. However, the HFSA does not have access to the auditors' working papers. Moreover, auditors have the legal obligation to report serious breaches of regulation and prudential guidelines directly to the supervisor, but the definition of what constitutes a "serious breach" is not specific and therefore open to interpretation. Reporting obligations are more specific only in the case of suspected money laundering activities. Finally, while the HFSA has formal sanctioning powers with respect to auditors, these sanctions seem to be ineffective due to the weak basis for determining liability in the auditing process.

\section{Disclosure Rules}

90. MPFs need to disclose once a year the net and gross rates of return based on a Dietz-modified type of formula (Appendix D), opening and closing asset values for the year, investment allocation, and changes in investment policy. Information to individual members should be disclosed at least once a year. The provisions are detailed but there are no requirements to disclose rates of returns for the individual accounts, nor requirements to compare returns and fees on a systematic basis.

91. Disclosure requirements in Hungary are generally weak, especially considering that the Hungarian second pillar is based on open pension funds, and that the efficiency of this type of system requires high levels of disclosure and transparency. The flaws in this area include not only the absence of standardized indicators that can be easily understood and compared by members, but also the lack of sufficient dissemination of the information and lack of efforts to educate consumers.

92. The fees of different pension funds cannot be easily compared because of their mixed structure. Operational fees are charged on contributions while asset management fees are charged on assets, and members do not have access to information summarizing these two fees in a single indicator. Furthermore, there are no efforts to project these fees in the long-run and provide estimates of their impact on replacement ratios.

93. Regulatory practices also impair the accurate comparison of returns across funds. This is because the current methodology, not based on unit accounting, produces indicators that are affected by the size and timing of the cash flows between the pension fund and the asset manager, as noted above. Finally, comparability of rates of return is undermined by the absence of uniform performance standards, as also noted above. The HFSA is discussing with the industry the adoption of Global Investment Performance Standards (GIPS).

\section{Supervision}

94. Hungary was the first CEE country to create an integrated supervision agency -the HFSA - with supervision powers over the whole financial sector, except for credit 
cooperatives. The current legal provisions provide a reasonable degree of independence and resources to the HFSA, as well as adequate enforcement powers, although the HFSA does not have the formal power to issue binding regulations, and there are some specific reporting obligations to the Government that have raised some concerns.

95. The HFSA has a board responsible for supervision strategy and a management responsible for its implementation in day-to-day operations. The Chairman of the Board is appointed by Parliament for a term of six years, and cannot be easily removed. The other members of the board are appointed by the President of the Republic by indication of the Prime Minister. The General Manager is appointed by the Prime Minister. The separate responsibility of the Legislative and Executive powers in appointing the highest governing positions at HFSA could potentially create situations of friction within the leadership of HSFA and undermine the smooth development of operations in the future.

96. The HFSA has no formal regulatory powers outside the area of anti-money laundering. Secondary regulations are only issued in two forms: (i) Government decrees issued by the Council of Ministers, or (ii) Ministerial decrees. The HFSA can draft regulation, but this regulation needs to be proposed to the Ministry of Finance, and issued by the Ministry or the Cabinet. The Ministry has generally issued regulations proposed by the HFSA, but this arrangement is still sub-optimal, as it opens the possibility for delays and external interference in regulation.

97. The risks related to the lack of formal regulatory powers are partly mitigated by the issuance of resolutions and guidelines. Strictly speaking, resolutions are enforcement decisions applying to individual institutions, while guidelines are non-binding interpretations of laws and regulations. However, resolutions and guidelines have constituted de facto a body of binding secondary regulations applicable to all supervised entities. This outcome has been in good part due to a large number of court rulings favoring the supervisory authority in legal disputes, and using previously issued resolutions and guidelines as the basis for the ruling. Therefore, both HFSA staff and market participants consider that these resolutions and guidelines have, at least to some extent, offset the deficiencies caused by the lack of formal regulatory powers.

98. The HFSA is financed through the imposition of supervisory fees on market participants, which gives the agency considerable financial independence. The Ministry of Finance approves the budget proposed by the HFSA, but the approval is not conditioned on a detailed allocation of resources. The Law requires only that overall limits on personnel, development and operations, be included in the budget. Moreover, the HFSA can carry over its surpluses to the next fiscal period. The agency has been able to offer competitive salaries and to attract and retain qualified staff.

99. The Chairman of the HFSA needs to report quarterly to the Minister of Finance and annually to Parliament. The Chairman of the HFSA has used the quarterly reports as a vehicle for proposing regulation, and has also disseminated these reports. This initiative, combined with the practice of more frequent consultations with the industry, has been well received by officials and market participants, as they reflect a policy of greater transparency in the formulation and enforcement of regulations. However, one particular legal provision that has raised concern relates to the Finance Minister's power to interfere 
in HFSA decisions. Although this power has not been exercised, it still opens the possibility for political interference in supervisory actions.

100. The HFSA has made progress in moving towards consolidated supervision and is also making efforts to move from a compliance approach to a more modern risk-based approach. There are currently 23 professionals supervising pension funds, out of a total staff of 530. These supervisors perform both off-site and on-site supervision, but there is a lead supervisor for each of the major funds.

101. The supervision of pension funds has adopted elements of risk-based supervision. The off-site unit collects relevant information from many different sources, builds a variety of indicators, and tries to compile an overall risk rating reflecting its assessment of market, operational, and personnel risks that should be used to determine priorities and allocate supervisory resources. The on-site inspection program also seems to follow a risk-based approach. Besides the obvious market risks associated with the investment activity of pension funds, the on-site manual directs inspectors to assess risks related to the membership base of the funds, risks related to external service providers, and risks associated with management and governance structures. The manual provides some description of the internal procedures and controls that are expected to be in place for all these risks to be adequately identified and monitored by the supervised entities.

\section{B. Main Regulatory Issues in the Payout Phase}

\section{Review of Main Payout Regulations}

102. The pension reform approved in July 1997 and implemented in January 1998 included a rule allowing retirees fifteen years to choose between lump-sums and annuities, but mandating annuities after this transition period, i.e., from 2013 on. ${ }^{24}$ After that date, retiring members will be able to choose from four types of annuities, namely, (i) a single life annuity; (ii) a joint life annuity; (iii) the combination of a fixed term joint annuity (covering the spouse or other beneficiary for a fixed period) with a single life annuity; and (iv) the combination of a single life annuity with a fixed term annuity, covering the spouse or other beneficiary for a fixed period after the main beneficiary's death.

103. All annuities are fixed (i.e., not linked to market returns) and indexed to a basket of prices and wages with equal weights - the Swiss indexation formula - the same formula used to adjust first pillar benefits. Annuities need to be calculated from unisex mortality tables, i.e., there can be no differentiation of annuity payouts by gender. Married members do not need to contract joint life annuities. Therefore, survivors (spouses and young children) are not necessarily insured against the risk of death, although they still get a benefit from the first pillar.

104. Annuities can be provided by MPFs themselves, provided that they meet a number of conditions and are licensed by the HFSA to offer these products. The conditions include a minimum size of 25,000 members (although smaller funds can still apply), the elaboration of benefit regulations, the preparation of specific mortality tables, the

\footnotetext{
${ }^{24}$ This period of 15 years was originally related to the concession of a minimum benefit guarantee to switching members until the age of 47 , and to the minimum retirement age of 62 . The guarantee was subsequently eliminated.
} 
constitution of some reserves (examined below), and the employment of an actuary. Alternatively, the pension fund may offer annuities to its members through a collective contract with a life insurance company. Finally, any individual member has the right to buy an annuity from any licensed life insurance company, if he or she is not satisfied with the annuity offered by his pension fund or with the annuity offered by the contracted life insurance company.

105. Pension funds that decide to offer annuities may price them freely (subject to the constraints mentioned above, including the indexation formula and the unisex table) but need to disclose to the supervisor all the assumptions and factors utilized in the pricing decision. Members that become annuitants have their individual balances transferred to a service account, which is the liability of the pension fund to the retired member. The collection of service accounts is called the service reserves of the pension fund (technical reserves in most jurisdictions). The assets backing the service reserves are not subject to a different investment regime from that applying to the accumulation phase.

106. When the member retires and the annuity contract is issued, the pension fund should not only create a service account but also add 0.3 percent of the value of the account to a demographic reserve, presumably intended to cover longevity risk. The law specifies rules for transferring funds from the service accounts to the demographic reserves, depending on the actual mortality experience. If mortality proves higher than projected there can be a transfer from the demographic reserve to the service reserve-i.e., the adjustment of benefits may exceed the Swiss formula. If mortality proves lower than projected there is a transfer from the demographic reserve to the service reserve, and the demographic reserve is replenished from the operating reserve, which is formed from the flow of contributions. The law also specifies the possibility for transfers from the liquidity reserve. In an attempt to avoid the deliberate underestimation of annuity liabilities, the law limits the technical interest rate to a rate of 1.5 percent above the Swiss indexation rate in the same year. The law does not explicitly require reserves to cover investment risk, especially the mismatches that may occur between the structure of assets and liabilities.

\section{The Main Deficiencies in the Payout Phase}

107. The regulatory framework for the payout phase contains several deficiencies that need to be addressed in the coming years. The Government is aware of these flaws and has created a working group that is expected to redesign the framework and prepare the ground for the development of an efficient market for retirement products. The working group will need to revise all aspects of the regulatory framework, including the menu of retirement products, the design of each individual instrument, and the regulation of intermediaries licensed to offer these products.

108. The menu of retirement products is probably too restricted and unable to meet the needs of retirees with different characteristics and degrees of risk aversion. The existence of a first pillar benefit providing a replacement ratio of roughly 45 percent for full career workers allows regulators to consider a more flexible menu, including partial lump-sums subject to restrictions, phased withdrawals and a wider range of annuities. At the same time, survivors may not be sufficiently protected in the new system, as the survivor 
benefit in the reduced first pillar is smaller than the one in the former system and possibly not adequate and married members are not forced to buy joint life annuities. ${ }^{25}$

109. The Swiss indexation formula was possibly imposed on the second pillar because of the perception that price indexation would imply a less generous benefit for the annuitant. This is a wrong perception caused by the failure to differentiate between unfunded and funded systems. Different indexation formulas in a defined benefit (DB), PAYG system do imply different levels of generosity for the individual retiree. More specifically, the net present value (NPV) of DB-PAYG benefits adjusted by a wage indexation formula is larger than the NPV of benefits adjusted by a Swiss formula, and the latter is larger than the NPV of benefits adjusted by a pure price indexation formula. Of course, the other side of the coin is larger PAYG deficits generated by the more generous indexation formulas, and a larger implicit pension debt of the public sector. The intertemporal budget constraint implies that some cohorts will pay for the larger implicit pension debt generated by a generous formula, most typically the young cohorts and future generations.

110. In a fully-funded second pillar, the final balance that generates the annuity payment is the same, whether the benefits are adjusted by wages, prices, or any combination of the two. If the risk for the provider is the same, the net present value of annuities adjusted by different indexation formulas should also be the same. This means that annuities adjusted by the Swiss formula would need to start at a lower level than annuities indexed to prices, because they are expected to increase at higher rates during the retirement period (assuming that real wages will grow during this period).

111. However, annuities indexed to the Swiss formula imply more risk to the provider, because the provider is exposed to movements of two stochastic variables, prices and wages, and probably will not have the instruments to hedge this risk. While many countries have developed price indexed financial instruments that allow providers to hedge inflation risk, there are no instruments allowing providers to hedge wage risk. ${ }^{26}$ This implies that providers would either charge a very high risk premium to cover themselves against this risk (i.e., very low annuities) or avoid offering annuities altogether.

112. The rules allowing annuities to be offered by pension funds, or by insurance companies through collective arrangements, or by individual search, were apparently designed with the objective of enhancing competition and protecting the consumer. However, the rules allowing pension funds to offer annuities were poorly designed and may ultimately lead to insolvency and/or unintended transfers across cohorts, ultimately harming contributing workers and retirees.

\footnotetext{
${ }^{25}$ Disability and survivorship insurance in the contribution/accumulation phase is also restricted to the first pillar. The design of this type of insurance in the new mixed system also merits a review by policy-makers. ${ }^{26}$ Many defined benefit pension funds hold equity to match the increase in wages during the accumulation phase. This strategy is frequently justified with the argument that the shares of labor and capital income in GDP are stable and, therefore, equity returns accumulated for long periods of time should not be too different from wage growth accumulated over the same period. This argument bears some relation to the hypothesis that stock returns are mean-reverting. However, this strategy may still expose pension funds to extreme drops in equity prices and to under-funding.
} 
113. The current regulatory framework for the payout phase does not address effectively the complex risks involved in the provision of contracts with very long durations such as fixed annuities, particularly the longevity and investment risks. The demographic reserve that pension funds would have to build is too small and unrelated to the size of the risk pool. This is aggravated by the lack of sound cohort mortality tables for the population that will start retiring in 2013.

114. The situation is even worse with respect to investment risk. Pension funds would not need to build reserves to address this particular risk, a serious regulatory flaw, especially considering that the absence of appropriate hedging instruments would imply severe mismatches between assets and liabilities and substantial exposure to this risk. The need to adjust annuities according to the Swiss formula would prove particularly problematic, due to the absence of appropriate hedging instruments in Hungary or any other country in the EU. The rule that imposes a maximum value for the technical rate used to value liabilities is also problematic - the technical rate would be linked to a variable (wage growth) that is unrelated to market returns, and that could increase sharply in some periods due to political considerations (such as the early 2000s), leading to a severe underestimation of liabilities.

115. The regulatory framework contains some risk-sharing clauses apparently designed to prevent insolvency, but that will imply unintended and undesirable transfers across cohorts. For example, the rule that allows the modest demographic reserve to be replenished from the operating reserve would imply transfers from newly retired members and, especially, members in the accumulation phase. There are examples of risk-sharing schemes that address longevity risks well, such as the scheme employed by the TIAACREF in the US, but the rules of this type of scheme are better designed and transparent, and do not imply transfers from members in the accumulation phase to cover imbalances in the payout phase.

\section{CONCLUSIONS AND REFORM AgENDA}

\section{A. Review of Main Findings}

116. The structure of the Hungarian second pillar is unique among reforming countries. MPFs have been structured as open mutual benefit associations operating under a two board structure. The members of these boards are elected among fund members and should represent their interests. In practice, most MPFs are controlled by the sponsors that incurred the start up costs. This resulted in a hybrid second pillar, with most MPFs controlled by financial institutions, some MPFs sponsored by large employers, and only three independent MPFs. The first group of MPFs account for the bulk of the second pillar's members and assets, despite charging higher fees.

117. The second pillar has had a mixed performance since its introduction in 1988. In 2004 total assets amounted to only 4 percent of GDP, a low ratio by comparison with other second pillars with the same period of implementation. The slow growth of assets has been due to the slow growth of contributions and the weak average return performance. The slow growth of contributions was due to a good extent to the policies followed during 1998-2002, a period characterized by lack of political support for the reform. The weak average return performance was due to an undiversified portfolio, 
consisting primarily of relatively low yield Government securities, and to the weak performance of equity markets during most of the implementation period.

118. Since 2003 there has been an improvement in the system's performance. Contributions have increased again, reflecting the return of the reformist socialist government and the adoption of supportive policies towards the second pillar. Return performance improved considerably in 2004 and remained strong in the first half of 2005, boding well for the future of the system. Despite the recent improvement in performance, the historical performance of the Hungarian second pillar still does not compare favorably with the performance of the first pillar due to a particularly lax wage policy until 2003. While nominal wage growth has stabilized at around 6 percent in the last two years and nominal net returns have been more than double that figure, the 1998 - 2005 annualized average real net rate of return of MPFs is still only 3.9 percent compared to a real wage growth of 5.3 percent over the same period.

119. Average fees in the Hungarian second pillar compare favorably with fees charged in most other reforming countries with the same period of implementation, especially when expressed as a share of contributions. The absence of any meaningful marketing expenses in the case of Hungary would explain the favorable comparison with other reforming countries. Fees charged by independent MPFs and MPFs sponsored by employers look particularly low. However, if the current segmentation and fee structure are maintained, the costs of the Hungarian system would become more evident in the future, particularly in the case of MPFs sponsored by financial institutions. It is difficult to predict how the system will evolve, but positive outcomes may depend on improving transparency and consumer awareness, enhancing competition and reducing the high level of fragmentation.

120. The pension reform has so far contributed only modestly to the development of Hungary's capital market. This has been due to several factors, including the modest growth of the second pillar, the sharp growth of bank lending in the first half of the 2000s, after a period of restructuring and privatization in the 1990s, the Government debt management strategies that have been adopted in the pre-Euro period, and some remaining regulatory glitches. It is probable that the stronger growth of the second pillar and the slower growth of bank lending will tend to induce a stronger development of domestic capital market instruments in the future. The accession into the Euro zone may have some mixed effects - the reduction in some risks and the lengthening of time horizons will tend to favor the development of domestic instruments with longer durations, but access to these instruments elsewhere in the EU will tend to reduce the need for their development domestically. In any case, the development of the capital market will also depend on the removal of all remaining regulatory impediments.

121. Regulators face even more important challenges in the payout phase. The regulatory framework for the payout phase is very deficient and needs to be overhauled. The range of retirement instruments is limited, survivors may not be adequately protected, and pension funds are allowed to offer annuities subject to weak investment and capital regulations, and without access to instruments to hedge investment and longevity risk. Fortunately, regulators have some time to improve the framework and promote the development of financial instruments, as pension funds are only required to offer annuities 
from 2013 on. The recent creation of a task force to review the whole regulatory framework for the payout phase has been an important positive initial step.

122. The menu of regulatory measures that should be considered to ensure that the second pillar performs its expected role includes those that would apply to the accumulation phase and those that would apply to the payout phase. Regarding the accumulation phase, the set of measures that should be considered includes those that would primarily strengthen its stability and resiliency, and those that would improve market structure and performance. Regarding the payout phase, the set of measures would need to be comprehensive, amounting to a redesign of the regulatory framework. Finally, progress in developing a wider range of financial instruments and risk management tools would improve the performance of both the accumulation and payout phases of the new pension system.

\section{B. Improving the Regulatory Framework for the Accumulation Phase}

123. The first years of implementation of the new second pillar were affected by lack of support to the reform, resulting in slower growth of contributions and assets and uncertainty among institutions and contributors. This has not benefited any of the involved parties, because the performance of the second pillar and its contribution to capital market development depend to a good extent on its size. In order to ensure a steady growth of the system in coming years, it would be necessary to keep the contribution rate at its current level of 8 percent, maintain the rules of the transition from the old to the new pension system, and also maintain the contribution ceiling stable in relation to the average covered wage.

124. In addition to pension policy measures designed to ensure a steady growth of the system, there are specific regulatory measures that would also contribute to a more stable and resilient second pillar. For example, licensing and governance rules could be improved through the extension of fit and proper tests to all board members. Also, the external audit function could be more integrated into the supervisory process, by empowering the HFSA to change/broaden the scope of the audit, if the circumstances justify this action, providing access to all audit results, including working papers, clarifying the concept of "serious breach" of regulations and the reporting obligations of auditors to supervisors, and strengthening sanctions.

125. Regarding the structure and performance of the second pillar, one of the main challenges faced by Hungarian regulators is to ensure that costs and fees are contained and remain reasonable during the whole period of accumulation. In order to achieve this goal, a number of policy measures may be considered.

126. One possibility to reduce costs associated with revenue collection (one of the major cost items) involves the introduction of an agency charged with the responsibility of collecting contributions and transferring them to MPFs. The agency could be owned by the industry or be an independent and reputable service provider selected through bidding on a periodical basis. The agency would need to be regulated along the lines of a private monopoly regulation. Particular care would be needed in designing its governance structure due to the sensitive information on individual accounts managed by such an agency. If the provider is owned by the industry (a possibility that is being seriously 
considered by one of the association of MPFs) the HFSA would need to pay particular attention to the fee structure, to avoid discrimination against small MPFs and to ensure the contestability of the market.

127. In order to ensure that fees charged by MPFs are contained at reasonable levels, especially the MPFs sponsored by financial institutions, a number of policy measures could be considered, including a substantial strengthening of disclosure requirements, efforts to improve consumer education, changes in the rules for the allocation of undecided new members, and changes in fee regulations.

128. An open pension system that relies on informed choices by consumers to operate efficiently should provide information on critical indicators of fund performance, especially returns and fees. Disclosure requirements in Hungary are deficient, not providing consumers the means to make informed decisions, "vote with their feet", and select better performing funds. The problems in disclosure include not only the confusion caused by the mixed fee structure but also the lack of easy access to essential information and clear comparisons across pension funds.

129. One of the first measures that should be considered involves the systematic computation of indicators summarizing all the fees charged by the MPFs, and expressing total fees as a share of contributions and assets. The information on fees should be combined with information on returns to form a coherent picture that is easily understood by members and that can be used to compare fund performance. In a second stage, regulators may consider computing other supplementary indicators, such as the estimation of ranges of replacement ratios under reasonable and transparent assumptions, ${ }^{27}$ and even charge ratios.

130. The information on returns and fees charged by each MPF should be provided at least on a quarterly basis in the HFSA's website. In each quarter the HFSA could produce a press release highlighting the results and the differences and encouraging the publication of this information in the main newspapers, magazines, and other media. The annual report sent by MPFs to members should contain not only information on the individual MPF's performance but also simple tables comparing performance with the rest of the industry.

131. Regulators are sometimes concerned that systematic comparisons will lead consumers to adopt a short-term horizon or "chase returns" (i.e., switch to pension funds that may have had a better return performance recently but not on a systematic basis). This concern is generally more valid for returns than for fees, as the former variable is more volatile than the latter, and could be addressed by the computation of average accumulated rates of return over relevant periods. Moreover, the segmented structure of the Hungarian second pillar and the typical herding behavior suggests that on average there will probably be larger differences in fees than returns.

132. In addition to improvements in disclosure, regulators may also consider changes in the rules for allocating new members, especially undecided new members. In Hungary, new entrants that do not select a fund are usually assigned to a fund chosen by the employer. Currently, the employer has an incentive to induce new entrants to choose the

\footnotetext{
${ }^{27}$ This type of exercise is already being performed by the pension fund supervision in Chile, the SAFP.
} 
same fund selected by the majority of employees, in order to reduce his own administrative paperwork. However, this fund is rarely one of the funds charging low fees. If the new entrant does not make a formal selection, he or she is allocated to a default fund on a regional basis, which also tends to be one of the funds charging high fees.

133. If larger numbers of new entrants started selecting the low fee funds, this could increase the overall degree of competition and lead the other funds to decrease their fees as well. In order to achieve this outcome, employers should be directed to show a table comparing cost and return performance of all funds to new entrants, in order to ensure better informed choices. New employees should sign a form indicating their awareness about the alternatives to the fund preferred by the employer. An alternative and more assertive policy measure designed to reduce consumer inertia, enhance competition and reduce fees, would entail allocating new undecided members to one of the three funds (or other relevant percentile) charging the lowest fees in the preceding twelve months.

134. In addition to changes in the rules for new entrants, regulators could also consider rules facilitating switching to lower cost funds. For example, members could be allowed to switch by simply using the internet. Another measure involves allowing the target fund to process the relevant paperwork on behalf of workers, to prevent the origin fund from creating administrative obstacles to workers wishing to switch funds. A more assertive policy measure would entail allowing switching only to lower cost funds.

135. Some of these solutions may seem excessively intrusive, but the concern with high fees and consumer inertia has led regulators in other countries to implement several of them. For example, Mexican regulators have adopted a very assertive set of policies since 2002, designed to reduce the very high level of commissions. These have included much better disclosure rules, the allocation of undecided new entrants to the lowest fee funds, ${ }^{28}$ and the prohibition for members to switch funds more than once a year, unless they switch to a lower fee fund.

136. Although it is still early to quantify the full impact of these new regulations in Mexico, they have succeeded in reducing projected average long-run fees from 1.1 percent of assets to 0.7 percent of assets, as noted in Figure 15. It is noteworthy that the decline in the average fee was caused both by reductions in fees by individual incumbents and the entry of new companies charging low fees. It is difficult to associate the decline in the average fee over this period to specific policy measures, but the decline undoubtedly reflects the market response to a credible commitment by the regulator to lower fees in the second pillar.

\footnotetext{
${ }^{28}$ Workers who have not elected a pension fund are assigned every year to the bottom quartile of the cost distribution and inversely proportionally to the costs charged by each pension fund. In other words, the least costly fund within the bottom quartile receives the largest share of members while the most costly fund within the bottom quartile receives the lowest share.
} 
Figure 15: Decrease in Long-Run Average Fee over Assets in Mexico

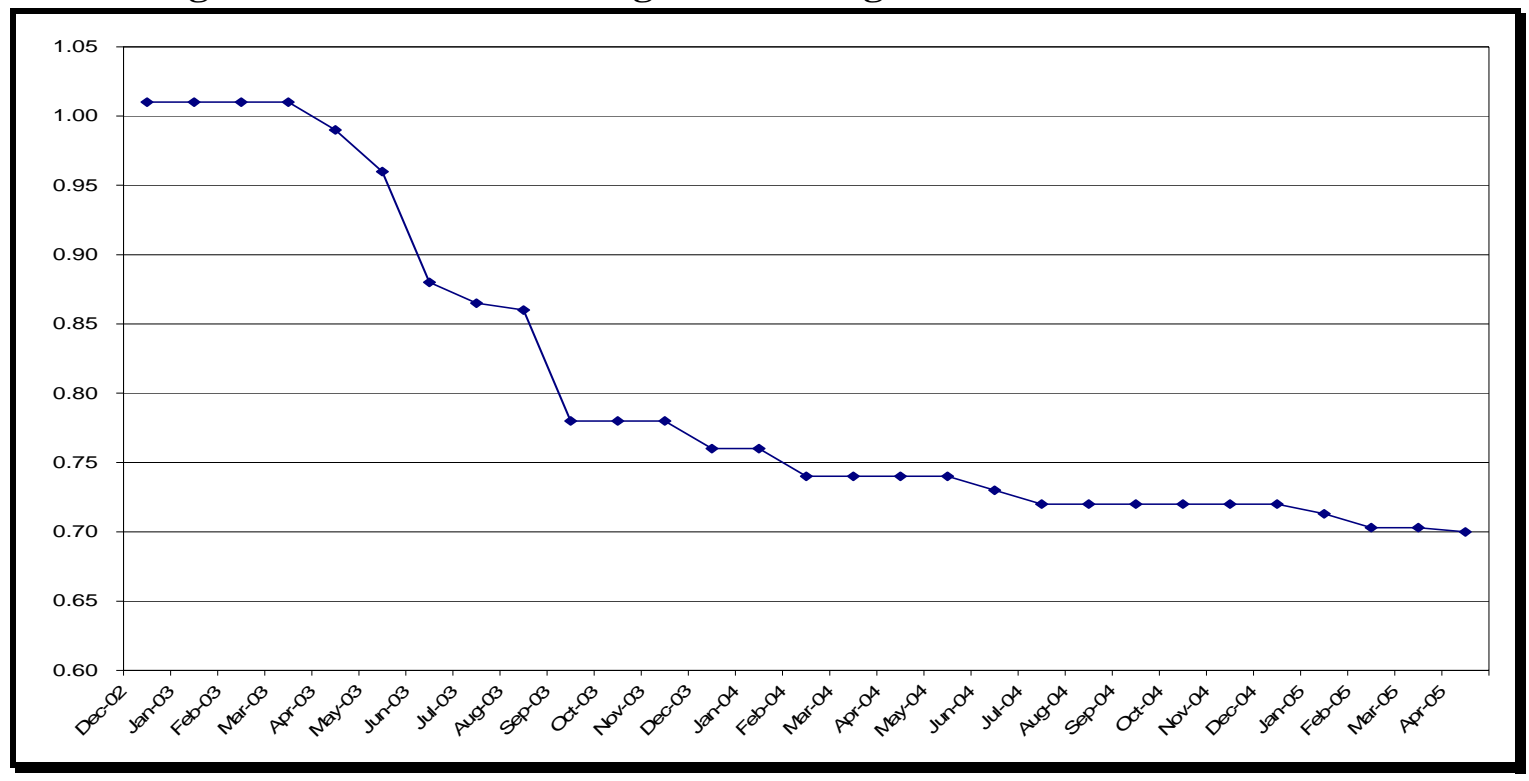

Source: CONSAR

137. The problems related to the comparability of rates of return are not as severe as those related to the comparability of fees, but there is scope for improvements in this area as well. The HFSA might consider requiring MPFs to calculate true time weighted rate of return similarly to what done by mutual funds. The HFSA may also consider unifying the coverage, operational, and liquidity reserves (or at least the first two) and require MPFs to calculate rates of return on total contributions. Finally, the HFSA may promote the diffusion of Global Performance Investment Standards (GIPS) and require asset managers for MPFs to be GIPS certified. The adoption of GIPS by all asset managers would greatly improve the comparability of performance evaluations across asset managers. ${ }^{29}$

138. Another measure that is frequently used to monitor performance and contain excessive fees, involves the publication of returns on equity and other indicators of profitability of asset managers and other financial institutions. Asset management companies provide a valuable service and are entitled to earn profits in a competitive financial sector. However, asset management companies operating in second pillars sometimes generate much higher returns on equity than other financial institutions such as banks and insurance companies, while taking much lower risks. Disclosing these indicators on a systematic basis would enhance the awareness of regulators, policymakers, and the public at large of the existence of market inefficiencies leading to excessive profits, increasing the pressure for policy corrections.

139. Before embarking on a major effort to improve disclosure and consumer awareness and change key regulations, it would be important to assess whether the low cost funds have the capacity to absorb a larger number of members. Several of these funds indicate that they would be interested in absorbing more members, even in the absence of a profit motive, because a larger membership would reduce their fixed costs. Some managers may also benefit from a larger membership in terms of bonuses and

\footnotetext{
${ }^{29}$ GIPS can be downloaded at http://www.cfainstitute.org/standards/pps/gips.html.
} 
prestige. However, some of these funds may not have the IT infrastructure and the organizational capacity to absorb a large number of members in a short period of time. Therefore, efforts to promote switching to the lower cost funds should be preceded by efforts to encourage the build up of their administrative capacity and ensure the continuity of fund operations.

140. It is possible that the combination of all these measures would be sufficient to address the problem of consumer inertia and market segmentation, reducing fees and benefiting all second pillar members. However, regulators should also consider more forceful policy actions if these measures fail to produce meaningful effects.

141. One possibility would involve enforcing more explicit and transparent procedures for the selection of asset managers and administrators by MPF boards, especially MPFs sponsored by financial institutions. This type of action would amount to enforcing the fiduciary obligation of board members, and would also seem consistent with reforms being proposed in Chile and other reforming countries, involving the adoption of bidding schemes designed to strengthen price competition and reduce fees. ${ }^{30}$

142. Performing a fiduciary obligation that already exists under the law would seem to be an obvious duty of both members and regulators. In Hungary this would expose the inconsistencies in the construction of the second pillar, and could lead to very tense and unusual situations. Indeed, enforcing this rule could result in situations where the board members of the MPF, who are employees of the sponsoring financial institution, would be effectively forced to hand the profitable pension business of that MPF to a competitor that did not incur the initial costs, and also put their own jobs at risk. This measure would effectively represent a major structural change hurting the interests of several incumbents, and for this reason would not be easily implemented.

143. Former debates in Hungary on how to improve the system's structure have focused on the "demutualization" of the MPFs. This would entail their legal transformation into pension funds without boards and managed by a single pension fund management company, along the lines of the second pillar in Chile and most other reforming countries, including neighboring countries such as Poland. This type of reform could generate benefits, such as greater transparency and accountability of the management company, but would not necessarily improve competition and reduce fees. Moreover, if the MPFs sponsored by employers were also "demutualized", lower cost alternatives could be removed entirely, not contributing to competition and efficiency.

144. It is possible that efforts to improve disclosure and consumer awareness, combined with new rules for allocating new entrants, will lead to some switching to the lower cost MPFs, and lead the other MPFs to reduce their fees to avoid further loss of membership and market share. If this positive outcome materializes, regulators may not need to consider other measures. However, if these measures fail to reduce market segmentation and fees charged by some MPFs become excessive in the future, regulators may consider more radical reforms. This could include the "demutualization" of MPFs, but combined with bidding arrangements, or combined with the move to a Swedish type of arrangement, involving a single basic service provider charged with the collection of revenues and the

\footnotetext{
${ }^{30}$ See Valdés -Prieto (2005).
} 
management of blind individual accounts, and the licensing of a larger number of asset managers. This type of arrangement was designed to maximize economies of scale and competition in small financial systems and could prove a feasible alternative for Hungary.

\section{Overhauling the Regulatory Framework for the Payout Phase}

145. The 1997 pension law created a grace period for policy-makers and regulators to review and improve the design of the payout phase, and the creation of a task force to deal with the problem is a positive and commendable step. Given the weak regulatory framework for the payout phase, the task force will need to consider a complete overhaul of the regulatory and institutional framework. The following options might be considered during such a review.

146. As mentioned before, the existence of a first pillar benefit providing a replacement ratio of roughly 40-45 percent of the final wage provides room for a more flexible menu of retirement products. Partial lump-sums could be allowed with restrictions. For example, the partial lump-sum could be restricted through a rule imposing a minimum second pillar pension equal to a multiple of the minimum pension, or other relevant benchmark. Phased withdrawals could be introduced, also with some restrictions, designed to prevent a rapid depletion of the second pillar balance. This could be achieved by a formula including life expectancy, such as the formula applied in Chile.

147. Other types of annuities could be considered, especially guaranteed annuities that provide protection against longevity risk and also some room for bequests upon the death of the beneficiary during the guaranteed period. They have proved popular in countries with a high degree of annuitization such as Chile. There are constructions that allow annuitants some room to deal with the annuity rate risk (i.e. the risk of a drop in interest rates and annuity rates at the time of retirement). These include the staggered purchase of fixed annuities in the period preceding retirement and adjustable annuities (fixed annuities that are changed every three or five years according to the movements of long-run interest rates). Adjustable annuities also imply less investment risk for the provider, allowing the provider to offer a higher initial annuity payment. Variable annuities linked with a riskier portfolio could also be considered, although they would need to be restricted to higher income consumers.

148. Regulators could consider allowing phased withdrawals and non-fixed annuities, but only through a combination of these products and a fixed annuity, in order to enhance insurance against longevity and investment risk in the second pillar. However, the greater flexibility in the range of products allowed might need to be accompanied by more stringent conditions in other areas. For example, married retirees might need to buy joint life annuities or withdrawals in order to provide greater protection for their spouses.

149. One of the most important changes that will need to be introduced in instrument design is the removal of the Swiss indexation formula in the second pillar benefit, and its replacement by a price indexation formula. As mentioned before, the move from Swiss to price indexation does not imply a reduction in the level of generosity of the second pillar benefit, relative to the first pillar benefit, as the net present value of the second pillar annuity would be roughly the same. In fact, the move to price indexation might increase the net present value of the annuity due to the sharp reduction of the risks for the provider. 
Some providers may simply refuse to offer annuities indexed to the Swiss formula, leading to a collapse of the annuities market.

150. If regulators believe that it would be important to offer a product similar to a Swiss-indexed annuity, they could consider a price-indexed annuity with an escalating clause, say, 1 percent above CPI inflation. Providers would find this liability more acceptable, because they would not be exposed to wage growth risk, a risk that cannot be easily hedged. However, the initial level of this escalating real annuity would be lower than a simple price-indexed annuity, and most consumers might not find it attractive for this reason.

151. Pension funds should not be allowed to offer annuities but only phased withdrawals. An alternative but maybe less preferable solution would entail allowing pension funds to offer annuities provided that they adopt sound and transparent risksharing rules, that adjust annuity payments to unexpected improvements in longevity, impose a sound investment regime for the payout phase, impose substantial reserves to cover investment risk, and also tie benefits to imbalances between assets and liabilities resulting from investment losses. The rules would not allow non-transparent and unintended transfers from members in the accumulation phase.

152. Fixed annuities exposing the provider to longevity and investment risks should only be offered by licensed life insurance companies subject to proper regulation and supervision. However, this would still require strengthening investment and capital regulations in the insurance sector, preparing the sector to deal with the specific risks involved in this type of product.

\section{Promoting the Development of Financial Instruments}

153. Looking beyond debt management in the pre-Euro accession period, the authorities need to develop a strategy to build a market in long-term government bonds, including indexed bonds that would serve as an inflation hedge for annuities providers during the payout phase of the pension system. This phase will begin for mandatory members of the system in 2013 but may begin for voluntary members before that date.

154. It is true that governments in several EU countries have been issuing very longterm bonds, including indexed bonds, and Hungarian institutional investors would have access to these instruments without exposing themselves to currency risk after Hungary joins the Euro. ${ }^{31}$ However, over reliance on foreign debt issues in the EU to meet the needs of domestic institutional investors may not be an appropriate strategy. Foreign governments frequently tailor their long-term issues to the needs of their own institutional investors, typically defined benefit pension funds, which face a matching problem that may be different from that of annuity providers. Moreover, these issues could be infrequent, irregular, and generally insufficient. Furthermore, local inflation rates could be different, even inside the same currency area, exposing local annuity providers to basis risk (i.e., an imperfect hedge against local inflation risk). Finally, if Hungarian institutional investors go systematically to other EU countries to meet their hedging requirements, this could complicate Hungary's own debt management program.

\footnotetext{
${ }^{31}$ See de Haan and Wolswijk (2005) and G10 (2005).
} 
155. Therefore, the development of a domestic Government debt market may remain an essential condition for the development of sound and healthy pension and insurance sectors, and especially important for the development of an annuities market. Moreover, progress in developing further the Government debt market may also determine the future development of other domestic fixed income markets, such as mortgage, corporate, and infrastructure bonds.

156. The mortgage bond market could be developed further through a number of measures, including: (i) increasing the investment limit in pension fund portfolios; (ii) reducing the risk-weighting applied to well-rated mortgage bonds for capital adequacy purposes (iii) reviewing the current methodology for rating mortgage bonds adopted by rating agencies. Due to their novelty, mortgage bonds were granted only one maximum notch above unsecured bonds, but rating agencies might be willing to revise rating criteria to better differentiate the impact of a high-quality cover pool.

157. The corporate bond market will probably develop slowly, as large companies in Hungary have had easy access to bank and inter-company loans at very favorable rates. However, the attractiveness of this instrument will probably increase over time, as many companies will probably feel the need to diversify their liabilities and increase their duration. To encourage the first issues and facilitate the development of this market, the Government may consider completing the implementation of the EU Prospectus Directive, and also consider removing the requirement that the company should be rated before issuing a bond if liabilities are greater than equity.

158. Regarding infrastructure bonds, the government may consider the development of a "Structured Finance Act", along the lines of the model adopted in Chile and more recently Brazil, which creates the legal framework for tools commonly used in PPP and municipal finance. These tools can include revenue intercepts, third-party custody of revenues, the securing of bond payments with specific revenue flows, and bond pooling intermediaries to consolidate smaller issues into larger ones. The government may also consider removing the requirement in the Capital Markets Act that companies can only issue bonds if they have been in operation one full year, unless guaranteed by the government or if the bond issue is backed by specific assets pledged as collateral.

159. Regarding private equity, the government may consider adding a section to the Capital Markets Act (CMA) to govern venture capital and private equity which provides for governance and appropriate consumer protection, but does not overly limit the flexibility of fund managers. This section of the CMA can then replace the Venture Capital Act in its entirety. Developing this instrument may also require coordinated efforts with regulators in other CEE countries, designed to promote regional private equity funds, as Hungary's small size may limit the development of attractive funds offering sufficient risk diversification and exit possibilities.

160. Last but not least, the development of a wider menu of domestic financial instruments will also depend on the maintenance of a more supportive fiscal policy. The sharp expansion of fiscal deficits in the early 2000s, above and beyond the revenue losses to the second pillar, has contributed to a decline in national savings and investment, hindering private issues of instruments designed to finance private capital formation. This has contributed, in turn, to a number of combined negative effects, including slower 
economic growth, undiversified pension portfolios, and lower rates of return for all participants. Therefore, success in generating the potential positive effects of a pension reform on savings, investment, and capital market development, will also depend on efforts to reduce fiscal deficits and move away from debt financing of the transition. 


\section{REFERENCES}

Bateman, Hazel and Olivia S. Mitchell, 2004, New Evidence on Pension Plan Design and Administrative Expenses, Journal of Pension Finance and Economics, vol. 3(1): 63-76.

Benediktsson, Haukur C \& Herbertsson, Thor Tryggvi and J. Michael Orszag, 2001, The Charge Ratio on Individual Accounts and Investment Plans in Iceland, Applied Economics, vol. 33(8): 979-87.

Blake, David, Bruce Lehmann and Allan Timmermann, 2002, Performance Clustering and Incentives in the UK Pension Industry, Journal of Asset Management, 3, 2002, 173 194.

Clark, Gordon L., 2005, Pension Fund Governance: Expertise and Organizational Form, in John Piggott ed, Shortchanged? Pension Fund Governance and Retirement Provision (Edgar), forthcoming.

Collins, Sean, 2003, The Expenses of Defined Benefit pension Plans and Mutual Funds, ICI Perspectives, vol. 9, No 6.

Corbo, Vittorio and Klaus Schmidt-Hebbel, Efectos macroeconómicos de la Reforma de Pensiones en Chile, in CIEDESS, ed, Resultados y Desafíos de las Reformas a las Pensiones.

De Haan, Jacob and Guido Wolswijk, 2005, Government Management in the Euro Area, Recent Theoretical Development and Changes in Practices, ECB Occasional Paper Series, No 25.

Diamond, Peter, 2000, Administrative Costs and Equilibrium Charges with Individual Accounts, in John B. Shoven, ed: Administrative Aspects of Investment-Based Social Security Reform, NBER Conference Report, University of Chicago Press, Chicago, Ill.

Dietz, Peter O. and Jeannette R. Kirschman, 1983, Evaluating Portfolio Performance, in John L. Maginn and Donald L. Tuttle, Warren, eds.: Managing Investment Portfolios-A Dynamic Process (Gorham \& Lamont).

Dobrogonov, Anton, and Mamta Murthi, 2005, Administrative Fees and Costs of mandatory Private Pensions in Transition Economies, Journal of Pension Economics and Finance 4(1): 31-55.

G10, 2005, Ageing and pension system reform: implications for financial markets and economic policies. Mimeo.

Hess, David and Gregorio Impavido, 2004, Governance of Public Pension Funds: Lessons from Corporate Governance and International Evidence, in Alberto R. Musalem and Robert J. Palacios, eds, Public Pension Fund Management, Governance, Accountability and Investment Policies, The World Bank, Washington, DC.

Impavido, Gregorio, 2005, Governance of Public Pension Plans: the Importance of Residual Claimants. Mimeo. 
Matits, Agnes, 2002, Practical Experience with the Second Pillar of the Hungarian Mandatory Pension System, in Elaine Fultz, ed.: Pension Reform in Central and Eastern Europe, Vol. 1, ILO, Geneva, Switzerland.

Matits, Agnes, 2004, Supplementary Pension Funds in Hungary, Project on Intergenerational Equity, Discussion Paper, March 2004.

MNB, 2005, The operation of private pension funds in Hungary. Mimeo.

Murthi, Mamta, J. Michael Orszag, and Peter R. Orszag, 2001, Administrative Costs and the Organization of Individual Account Systems: a Comparative Perspective, in Robert Holzmann and Joseph Stiglitz, eds: New Ideas about Old Age Security, The World Bank, Washington DC.

Murthi, Mamta, J. Michael Orszag, and Peter R. Orszag, 2001b, The Maturity Structure of Administrative Costs: Theory and the UK Experience, Private Pensions Systems, No 2, OECD, Paris.

OECD, 2005, Pension Markets in Focus, Issue No 1.

Orbán, Gábor and Dániel Palotai, 2005, The Sustainability of the Hungarian Pension System: a Reassessment, NMB Occasional Papers, No 40.

Otermin , Marcelo, 2004, Latin American Investment Instruments Available for Pension Funds and Supply Response in Developing Instruments to Meet Pension Funds Demand. Processed.

Palacios, Roberto, and Roberto Rocha, 1998, The Hungarian Pension System in Transition, The World Bank Social Protection Discussion Paper Series, No 9805.

Párniczky, Tibor, 2005, Overview of the Hungarian private pension system and possibilities of development. Summary of original study prepared for the National Pension Strategy of Hungary.

Rocha, Roberto de Rezende, Fernando Saldanha, 1995, Fiscal and quasi-fiscal deficits, nominal and real: measurement and policy issues. Revista Brasileira de Economia, vol. 49, no. 3 .

Rocha, Roberto, 2006, The Chilean Second Pillar: Performance and Future Challenges. The World Bank, Washington DC.

Rocha, Roberto, and Dimitri Vittas, 2002, The Hungarian Pension Reform: a Preliminary Assessment, in Martin Feldstein and Horst Siebert, eds, Social Security Pension Reform in Europe. NBER and The University of Chicago Press, Chicago, Ill.

Rusconi, Rob, 2004, Costs Saving for Retirement: Options for South Africa, paper presented at the ASSA convention, Oct. 2004, Cape Town South Africa.

Valdés-Prieto, Salvador, 2004, Market-based Social Security as a Better Means of RiskSharing, Pension Research Council Working Paper, No 2005-16.

Whitehouse, Edward, 2001, Administrative Charges for Funded Pensions: Comparison and Assessment of 13 Countries, Private Pensions Systems, No 2, OECD, Paris. 


\section{APPENDIX A}

\section{Methodology for Estimating the Sources of Growth of Pension Fund Assets}

In the absence of detailed information on the cash flow of mandatory pension funds, the sources of the growth of pension fund assets relative to GDP were estimated through information on asset stocks, rates of return, and fees. ${ }^{32}$

Equation (1) shows the changes in the ratio of mandatory pension fund assets, A, to GDP, Y:

(1) $\left(\frac{\dot{A}}{Y}\right)=\frac{1}{Y}(\dot{A}-A \hat{Y})$, where: $\left(\frac{\dot{A}}{Y}\right)=\frac{d\left(\frac{A}{Y}\right)}{d t} ; \dot{A}=\frac{d A}{d t}$ and $\hat{Y}=\frac{1}{Y} \frac{d Y}{d t}$

Moreover, $\dot{A}=\mathrm{cwM}+\mathrm{rA}-\mathrm{fA}$, where $\mathrm{c}$ is the rate of contribution to the second pillar, $w$ is the average covered wage, $M$ is the number of contributors to the second pillar, $r$ is the nominal rate of return, and $f$ captures total fees expressed as a share of assets. Ideally, these components would be directly obtained through the consolidated cash-flow of second pillar pension funds, but this is not available in Hungary. There is information on the flows of contributions to the second pillar but not on the other components. These components were estimated through information on stocks, rates of return, and fees.

The methodology involves computing the integral of the terms between parentheses on the right hand side of (1) assuming constant fees and exponential growth rates of assets, rates of return and GDP during the period ${ }^{33}$ :

(2) $\int_{0}^{1} \dot{A} d t=c w M+\int_{0}^{1} \mathrm{r}(\mathrm{t}) \mathrm{A}(\mathrm{t}) \mathrm{dt}-\int_{0}^{1} \mathrm{fA}(\mathrm{t}) \mathrm{dt}$

(3) $\mathrm{A}(\mathrm{t})=\mathrm{A}(0) \mathrm{e}^{\hat{\mathrm{A} t}} ;$ and $\mathrm{r}(\mathrm{t})=\mathrm{r}(0) \mathrm{e}^{\hat{\mathrm{r}} \mathrm{t}}$

(4) $\int_{0}^{1} \mathrm{fA}(\mathrm{t}) \mathrm{dt}=\frac{\mathrm{f}}{\hat{\mathrm{A}}}(\mathrm{A}(1)-\mathrm{A}(0))$

A

(5) $\int_{0}^{1} \mathrm{r}(\mathrm{t}) \mathrm{A}(\mathrm{t}) \mathrm{dt}=\frac{1}{\hat{\mathrm{r}}+\hat{\mathrm{A}}}(\mathrm{A}(1)-\mathrm{A}(0))$

\footnotetext{
32 The methodology for estimating flows from data on stocks, interest rates, fees and other relevant variables is explained in more detail in Rocha and Saldanha (1995).

${ }^{33}$ Rates of return were initially assumed to be constant, but this resulted in some differences with the actual changes in the ratio of pension assets to GDP, especially in 2004. These differences were probably due to the sharp changes in rates of return in some years, particularly from 2003 to 2004.
} 
(6) $\int_{0}^{1} \hat{\mathrm{Y}} \mathrm{A}(\mathrm{t}) \mathrm{dt}=\frac{\mathrm{Y}}{\hat{\mathrm{A}}}(\mathrm{A}(1)-\mathrm{A}(0))$

(7) where $\hat{A}=\operatorname{Ln}(\mathrm{A}(1) / \mathrm{A}(0)) ; \mathrm{r}=\operatorname{Ln}(\mathrm{r}(1) / \mathrm{r}(0))$; and $\mathrm{Y}=\operatorname{Ln}(\mathrm{Y}(1) / \mathrm{Y}(0))$; 


\section{APPENDIX B}

\section{A General Framework for Comparing Fees During the Accumulation Phase}

This appendix provides a general framework for comparing 5 different types of fees during the accumulation phase in individual accounts in terms of compensating variations. We will present the simpler case with no interruption in service and simulate later the more general case with interruptions in service.

\section{The General Set-up}

Take an individual with wage $w_{0}$ at the start of his career and constant (for simplicity) wage growth $w g$ for the rest of his career until retirement age $T$. In continuous time, his wage trajectory is given by:

$$
w_{s}=w_{0} e^{w g s}
$$

The contribution rate on these earnings is $c$ and two different types of front load fees are charged: a fee $f_{1}$, proportional to gross contributions and a flat dollar fee $f_{2}$. Net contributions at time $t$ are therefore given by:

$$
n c_{s}=w_{s} c\left(1-f_{1}\right)-f_{2}
$$

which we assume to be positive all the time. Net contributions accumulate at a gross rate of return of $r$ minus two types of fees: an asset manager performance fee $f_{3}$, proportional to the gross rate of return, and an asset management fee $f_{4}$, proportional to total assets under management. Hence, contributions accumulate until retirement time $T$ at a net rate of return $n r=r\left(1-f_{3}\right)-f_{4}$. Finally, an exit fee $f_{5}$, proportional to the accumulated balances at retirement, is also charged.

\section{No Interruptions in Service}

With no interruptions in service the individual accumulation is given by:

$$
A(F, c, T)=\left(1-f_{5}\right) \int_{0}^{T} n c_{s} e^{n r(T-s)} d s
$$

The substitution for (B.1) and (B.2) into (B.3) yields:

$$
A=\left(1-f_{5}\right) \int_{0}^{T}\left[w_{0} e^{w g s} c\left(1-f_{1}\right)-f_{2}\right] e^{\left[r\left(1-f_{3}\right)-f_{4}\right](T-s)} d s
$$

that can be re-arranged into:

$$
A=\left(1-f_{5}\right) \int_{0}^{T}\left\{w_{0} c\left(1-f_{1}\right) e^{w g s+\left[r\left(1-f_{3}\right)-f_{4}\right](T-s)}-f_{2} e^{\left[r\left(1-f_{3}\right)-f_{4}\right](T-s)}\right\} d s
$$


And further into:

$$
A=\left(1-f_{5}\right)\left\{e^{\left[r\left(1-f_{3}\right)-f_{4}\right] T} \int_{0}^{T} w_{0} c\left(1-f_{1}\right) e^{\left[w g-r\left(1-f_{3}\right)+f_{4}\right] s} d s-\int_{0}^{T} f_{2} e^{\left[r\left(1-f_{3}\right)-f_{4}\right](T-s)} d s\right\}
$$

This form has the intuitive interpretation that with no interruption of service both the flat fee and the contribution fee are collected during the whole career of an individual.

The solution of the integral yields:

$$
A= \begin{cases}\left(1-f_{5}\right)\left[e^{n r T} w_{0} c\left(1-f_{1}\right) \frac{e^{(w g-n r) T}-1}{w g-n r}-f_{2} \frac{e^{n r T}-1}{n r}\right] & w g \neq n r>0 \\ \left(1-f_{5}\right)\left[e^{n r T} w_{0} c\left(1-f_{1}\right) T-f_{2} \frac{e^{n r T}-1}{n r}\right] & w g=n r>0 \\ \left(1-f_{5}\right)\left[w_{0} c\left(1-f_{1}\right) \frac{e^{w g T}-1}{w g}-f_{2} T\right] & w g \neq n r=0 \\ \left(1-f_{5}\right)\left[w_{0} c\left(1-f_{1}\right) T-f_{2} T\right] & w g=n r=0\end{cases}
$$

We will exclude the possibility of the trivial zero net rate of return (the third and fourth cases) and focus only on the first two cases in (B.7).

\section{Total Differential of A(F,c,T) with no Interruption in Service.}

In order analyze the relative impact of the five types of fee on final cash balance we calculate the total differential for the first two cases in (B.7). Here, the relevant equation is:

$$
A=\left(1-f_{5}\right)\left[e^{n r T} w_{0} c\left(1-f_{1}\right) \frac{e^{(w g-n r) T}-1}{w g-n r}-f_{2} \frac{e^{n r T}-1}{n r}\right]
$$

The total differential is given by:

$$
d A=\frac{\partial A}{\partial f_{1}} d f_{1}+\frac{\partial A}{\partial f_{2}} d f_{2}+\frac{\partial A}{\partial f_{3}} d f_{3}+\frac{\partial A}{\partial f_{4}} d f_{4}+\frac{\partial A}{\partial f_{5}} d f_{5}
$$

when $w g \neq n r>0$ the total differential is given by: 


$$
\begin{aligned}
& d A=-\left(1-f_{5}\right) e^{n r T} w_{0} c \frac{e^{(w g-n r) T}-1}{w g-n r} d f_{1}-\left(1-f_{5}\right) \frac{e^{n r T}-1}{n r} d f_{2} \\
& -\left(1-f_{5}\right) r e^{n r T}\left\{w_{0} c\left(1-f_{1}\right)\left[\frac{e^{(w g-n r) T}-1}{(w g-n r)^{2}}-\frac{T}{w g-n r}\right]-f_{2}\left[\frac{e^{-n r T}-1}{n r^{2}}+\frac{T}{n r}\right]\right\} d f_{3} \\
& -\left(1-f_{5}\right) e^{n r T}\left\{w_{0} c\left(1-f_{1}\right)\left[\frac{e^{(w g-n r) T}-1}{(w g-n r)^{2}}-\frac{T}{w g-n r}\right]-f_{2}\left[\frac{e^{-n r T}-1}{n r^{2}}+\frac{T}{n r}\right]\right\} d f_{4} \\
& -\left[e^{n r T} w_{0} c\left(1-f_{1}\right) \frac{e^{(w g-n r) T}-1}{w g-n r}-f_{2} \frac{e^{n r T}-1}{n r}\right] d f_{5}
\end{aligned}
$$

When $w g=n r>0$ we use l'Hôpital's rule on (B.10) and the total differential is given by:

$$
\begin{aligned}
& d A=-\left(1-f_{5}\right) e^{n r T} w_{0} c T d f_{1}-\left(1-f_{5}\right) \frac{e^{n r T}-1}{n r} d f_{2} \\
& -\left(1-f_{5}\right) r e^{n r T}\left\{w_{0} c\left(1-f_{1}\right) T-f_{2}\left[\frac{e^{-n r T}-1}{n r^{2}}+\frac{T}{n r}\right]\right\} d f_{3} \\
& -\left(1-f_{5}\right) e^{n r T}\left\{w_{0} c\left(1-f_{1}\right) T-f_{2}\left[\frac{e^{-n r T}-1}{n r^{2}}+\frac{T}{n r}\right]\right\} d f_{4} \\
& -\left[e^{n r T} w_{0} c\left(1-f_{1}\right) T-f_{2} \frac{e^{n r T}-1}{n r}\right] d f_{5}
\end{aligned}
$$

Notice that $\frac{\partial A}{\partial f_{i}}<0 \forall i$ since $\frac{e^{(w g-n r) T}-1}{w g-n r}>0$ and we know that $e^{x}-1>x \forall x \neq 0$. This is reassuring: fees indeed reduce accumulated balances.

Equation (B.10) allows us to compare the five different types of fee in the case of no interruption in service. In order to allow for more flexibility, we will first expand the setup to the case of interruption in service and compare fees in that more general framework. The case of no interruption in service will be a sub-case of the more general set-up where the length of the contribution phase coincides with the length career history of the individual.

\section{Interruption in Service}

The easiest way to model interruption in service is by assuming that all time spend outside the labor force takes place before or after contribution phase but before retirement. The assumption that all leisure time takes place before the contribution phase is trivial. If $T=40$ (say) for a full career individual, the assumption that all leisure time takes place before the contribution phase simply implies that $T<40$ in (B.7) and our results would not change. The assumption that all leisure time takes place after the contribution phase but before retirement is more interesting as it allows for accumulation of account balances over a period with zero contributions. The assumption overestimates the value of final cash balances compared to a situation where interruption of services are scattered along the contribution phase. This distorts the relationship between fees by an order of 
magnitude that is proportional to the difference in accumulated balances between the assumed scenario and the true state of the world.

For sake of simplicity we will consider only the case where all leisure time (interruption of service) takes place after the contribution phase: i.e., after $0<T^{*}<T$. The final cash balance at retirement $T$ has two components: 1$)$ the cash balance $A^{*}=A\left(F, c, T^{*}\right)$ at the end of the contribution phase $\left[0, T^{*}\right]$ with the accrued interests on such cash balance during the off service period $\left[T^{*}, T\right]$; and the flat fee $f_{2}$ charged during the off service period $\left[T^{*}, T\right]$ :

$$
A^{*}\left(F, c, T^{*}, T\right)=\left(1-f_{5}\right)\left\{\left\{\int_{0}^{T^{*}}\left[w_{0} c\left(1-f_{1}\right) e^{w g s}-f_{2} e^{n r\left(T^{*}-s\right)} d s\right\} e^{n r\left(T-T^{*}\right)}-\int_{T^{*}}^{T} f_{2} e^{n r(T-s)} d s\right\}\right.
$$

which can be re-arranged into the more intuitive:

$$
A^{*}=\left(1-f_{5}\right)\left\{\left[\int_{0}^{T^{*}} w_{0} c\left(1-f_{1}\right) e^{w g s+n r\left(T^{*}-s\right)} d s\right] e^{n r\left(T-T^{*}\right)}-\int_{0}^{T} f_{2} e^{n r(T-s)} d s\right\}
$$

This rearrangement highlights the fact that the flat fee $f_{2}$ is levied during the full career of the individual and irrespectively on whether the individual contributes or not to his individual account.

The solution for $A^{*}$ is:

$$
A^{*}= \begin{cases}\left(1-f_{5}\right)\left[e^{n r T} w_{0} c\left(1-f_{1}\right) \frac{e^{(w g-n r) T^{*}}-1}{w g-n r}-f_{2} \frac{e^{n r T}-1}{n r}\right] & w g \neq n r>0 \\ \left(1-f_{5}\right)\left[e^{n r T} w_{0} c\left(1-f_{1}\right) T^{*}-f_{2} \frac{e^{n r T}-1}{n r}\right] & w g=n r>0 \\ \left(1-f_{5}\right)\left[w_{0} c\left(1-f_{1}\right) \frac{e^{w g T^{*}}-1}{w g}-f_{2} T\right] & w g>n r=0 \\ \left(1-f_{5}\right)\left[w_{0} c\left(1-f_{1}\right) T^{*}-f_{2} T\right] & w g=n r=0\end{cases}
$$

Notice that $A^{*} \leq A \forall T^{*} \leq T$. We will again exclude the possibility of the trivial zero net rate of return (the third and fourth cases) and focus only on the first two cases.

\section{Total Differential of $A^{*}\left(\mathbf{F}, c, T^{*}, T\right)$ with Interruption in Service}

Similarly to the previous section, we calculate the total differential for the first two cases in (B.14). Here, the relevant equation is:

$$
A^{*}=\left(1-f_{5}\right)\left[e^{n r T} w_{0} c\left(1-f_{1}\right) \frac{e^{(w g-n r) T^{*}}-1}{w g-n r}-f_{2} \frac{e^{n r T}-1}{n r}\right]
$$

When $w g \neq n r>0$ the total differential is given by: 


$$
\begin{aligned}
& d A^{*}=-\left(1-f_{5}\right) e^{n r T} w_{0} c \frac{e^{(w g-n r) T^{*}}-1}{w g-n r} d f_{1}-\left(1-f_{5}\right) \frac{e^{n r T}-1}{n r} d f_{2} \\
& -\left(1-f_{5}\right) r e^{n r T}\left\{w_{0} c\left(1-f_{1}\right)\left[\frac{e^{(w g-n r) T^{*}}-1}{(w g-n r)^{2}}+\frac{\left(T-T^{*}\right) e^{(w g-n r) T^{*}}-T}{w g-n r}\right]-f_{2}\left[\frac{e^{-n r T}-1}{n r^{2}}+\frac{T}{n r}\right]\right\} d f_{3} \\
& -\left(1-f_{5}\right) e^{n r T}\left\{w_{0} c\left(1-f_{1}\right)\left[\frac{e^{(w g-n r) T^{*}}-1}{(w g-n r)^{2}}+\frac{\left(T-T^{*}\right) e^{(w g-n r) T^{*}}-T}{w g-n r}\right]-f_{2}\left[\frac{e^{-n r T}-1}{n r^{2}}+\frac{T}{n r}\right]\right\} d f_{4} \\
& \left.-\left[e^{n r T} w_{0} c\left(1-f_{1}\right) \frac{e^{(w g-n r) T^{*}}-1}{w g-n r}-f_{2} \frac{e^{n r T}-1}{n r}\right] d f_{5}\right]
\end{aligned}
$$

Notice that $\frac{\partial A^{*}}{\partial f_{i}} \leq \frac{\partial A}{\partial f_{i}} \forall T^{*} \leq T$ and $i \neq 2$. In other words, with interruptions in service fees have a smaller impact on the final cash balance as: either fees are not paid while individuals are not in service, or proportional fees are levied on smaller balances. The flat fee has the same impact on cash balances, whether there are interruptions or not, as it is levied irrespectively on whether the individual contributes or not until retirement.

When $w g=n r>0$ we use l'Hôpital's rule on (B.16) and the total differential is given by:

$$
\begin{aligned}
& d A^{*}=-\left(1-f_{5}\right) e^{n r T} w_{0} c T^{*} d f_{1}-\left(1-f_{5}\right) \frac{e^{n r T}-1}{n r} d f_{2} \\
& -\left(1-f_{5}\right) r e^{n r T}\left\{w_{0} c\left(1-f_{1}\right)\left[\frac{T^{* 2}}{2}+\left(T-T^{*}\right) T^{*}\right]-f_{2}\left[\frac{e^{-n r T}-1}{n r^{2}}+\frac{T}{n r}\right]\right\} d f_{3} \\
& -\left(1-f_{5}\right) e^{n r T}\left\{w_{0} c\left(1-f_{1}\right)\left[\frac{T^{* 2}}{2}+\left(T-T^{*}\right) T^{*}\right]-f_{2}\left[\frac{e^{-n r T}-1}{n r^{2}}+\frac{T}{n r}\right]\right\} d f_{4} \\
& -\left[e^{n r T} w_{0} c\left(1-f_{1}\right) T^{*}-f_{2} \frac{e^{n r T}-1}{n r}\right] d f_{5}
\end{aligned}
$$

\section{Simulating the Relationship Among Fees}

From what developed earlier, it is clear that the relationship among different types of fees will depend on a series of factors like wage growth, years of contribution, contribution rate, gross rate of return and initial salary levels. Furthermore, the relationship will also depend on the level of each fee. Hence, for sake of simplicity, we analyze here the relationship between two individual fees at a time assuming that all remaining fees are set to zero and for a given plausible set of the other parameters.

The following table simulates the percentage change in the fees listed in the top row that is required to keep the cash balance constant when the fees listed in the first column increase by one percent, when the net rate of return on assets is allowed to vary up to 20 . As we have assumed that all fees are set to zero, the net rate of return coincides with the gross rate of return. In the simulations we also assumed an initial wage $w_{0}$ of 1 , a 
contribution charge $c$ of $15 \%$, a wage growth $w g$ of $5 \%$, a career history $T$ of 40 years and a contribution period $T^{*}$ of 35 years.

Several interesting observations can be made in Table 23 which we analyze top to bottom, starting with the first column.

The relationship between a fee on contributions $\left(f_{1}\right)$ and a flat fee $\left(f_{2}\right)$ is depicted in the first cell of the first column of Table 23. An increase in one cent in the flat fee is compensated by a decrease of the contribution fee that varies in our specific case between 2 and 5. The compensating variation is larger the higher is the interest rate. The intuition behind this is that the future value of the flat fee is only a function of the retirement age and the rate of return. However, the future value of the contributions to the fund is also a function of the wage growth. The higher the interest rate the larger the compensating change in the contribution fee needs to be. However, the higher the wage growth, the lower the compensating variation needs to be. The relationship between the two fees when wage growth and interest rates are allowed to change is reported in Table 24 . Notice also that the relationship between the two fees is also a function of the initial wage and the contribution rate. In the simpler case where $T^{*}=T$; the relationship simplifies to:

$$
-\frac{d f_{1}}{d f_{2}}=-\frac{w g-r}{r} \frac{e^{r T}-1}{\left[e^{(w g-r) T}-1\right] w_{0} c}
$$

The higher the initial wage or the contribution rate the lower is the required compensating variation. The same intuition can be used to explain the impact of wage growth, initial wage and contribution rate: for a given increase in the flat fee a progressively smaller compensating variation in the contribution fee is required if the contribution base is allowed to increase. Notice that all relationships involving the flat fee will be function of the specific initial wage chosen. Hence, contrary to the relationships not involving the flat fee, they cannot be easily generalized.

The relationship between the contribution fee $\left(f_{1}\right)$ and the performance fee $\left(f_{3}\right)$ is depicted in the second cell of the first column of Table 23. An increase in 1 in the contribution fee can be compensated in our specific case with a decrease in the performance fee that is directly proportional to the interest rate. Obviously, when rates are zero, there is no need to compensate any change in the performance fee: any chosen level in the performance fee would not have any effect on final cash balances. However, the higher the interest rate, the stronger the impact of an increase in the performance fee, and therefore, the larger is the required compensating variation in the contribution fee. Table 24 reports data on the relationship between the two fees when both wage growth and interest rates are allowed to change. It is easy to see that wage growth essentially compensates for interest rate increases. For any given level of interest rates, an increase in wage growth would reduce the required magnitude of the compensating variation in the contribution fee.

To see this, simply take the simpler case where $T^{*}=T$; the relationship simplifies to:

$$
-\frac{d f_{1}}{d f_{3}}=-\frac{r}{w g-r}+\frac{r T}{e^{(w g-r) T}-1}
$$


The relationship between the contribution fee $\left(f_{1}\right)$ and the asset management fee $\left(f_{4}\right)$ is depicted in the third cell of the first column of Table 23. It is often quoted that a 1 asset management fee is more or less equivalent to a 20 contribution fee over for a full career individual. The next two tables provide further insight on this statement. The compensating variation in the contribution fee is a positive function of the interest rate. The intuition is simple: the higher the interest rate the higher is the impact on final cash balances of an increase in the asset management fee and therefore, the higher is the required compensating variation in the contribution fee. Table 24 reports data on the relationship between the two fees when both wage growth and interest rates are allowed to change. The higher the wage growth the smaller is the required compensating variation in the contribution fee for any given increase in the asset management fee. For a full career individual $\left(T^{*}=T\right)$ this varies from minus 13 in a high wage growth and low interest rate environment to minus 28 in a low wage growth and a high interest rate environment. What is interesting is that wage growth and interest rate have an identical but opposite impact on the compensating variation. This can be inferred from the constant elements on the diagonal of the relevant matrices in Table 24 or by casual inspection of the compensating variation:

$$
\frac{d f_{1}}{d f_{4}}=-\left[\frac{1}{w g-r}+\frac{\left(T-T^{*}\right) e^{(w g-r) T^{*}}-T}{e^{(w g-r) T^{*}}-1}\right]
$$

The relationship between the contribution fee $\left(f_{1}\right)$ and the end of period fee $\left(f_{5}\right)$ is constant and always takes the form of:

$$
\frac{d f_{1}}{d f_{5}}=-1
$$

The rationale for this is that the present value of the end of period fee is equal to the present value of the contribution fees levied each year during the contributing history of an individual. Alternatively, the future value of the contribution fees levied each year during the contributing history of an individual is the end of period fee. In other words $d f_{1}=d f_{5}$. Notice that this is true only in the absence of a flat fee. This particular relationship will facilitate the analysis of the relationships of all other fees with the end of the period fee in the last paragraph of this section. 
Table 23: Comparative statics of fee relationship when net rate of return is allowed to change

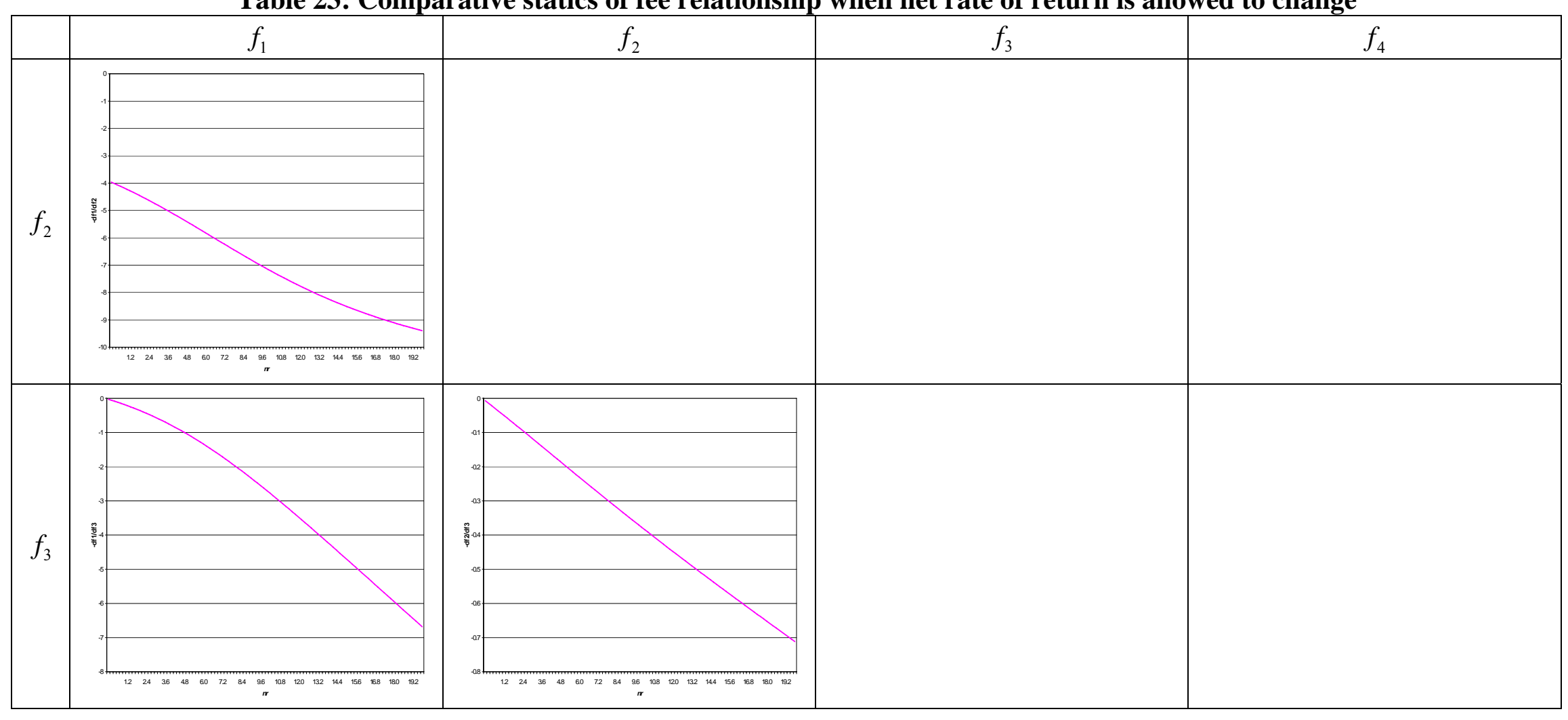




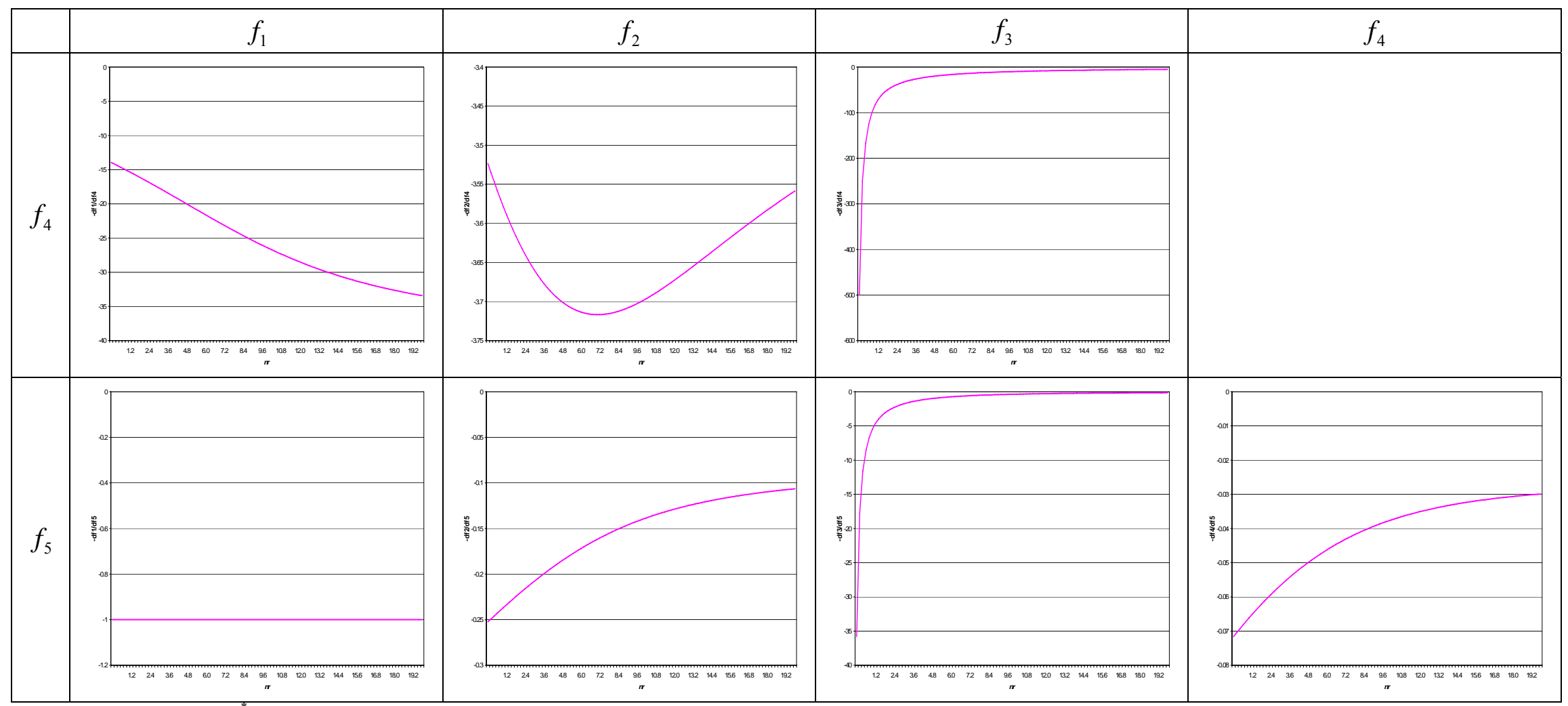

Note: $w g=5 \%, T=40, T^{*}=35, c=15 \%, w_{0}=1, F=0$ which implies that $n r=r$. 
The relationship between the flat fee $\left(f_{2}\right)$ and the performance fee $\left(f_{3}\right)$ is depicted in the second cell of the second column of Table 23 and it is similar to the relationship between the flat fee and the contribution fee previously described. The future value of the flat fee is only a function of the retirement age and the rate of return. However, the future value of the contributions to the fund is also a function of the wage growth, contribution rate and initial wage. For zero interest rate, no matter what performance fee is charged, its impact will be null and therefore the compensating variation is zero. For higher levels of interest rate the compensating variation will increase proportionally and it will be higher the higher is the contribution base (initial wage, wage growth, and contribution rate). The joint effect of interest rate and wage growth is reported in Table 24.

The relationship between the flat fee $\left(f_{2}\right)$ and the asset management fee $\left(f_{4}\right)$ is depicted in the third cell of the second column of Table 23. For low levels of net rate of return the relationship is negative: i.e., higher levels of asset management fee can be compensated with higher levels (in absolute terms) of flat fee. For high levels of net rate of return the relationship is positive: i.e., higher levels of asset management fee can be compensated with lower levels (in absolute terms) of flat fee.

Table 24: Comparative statics of fee relationship

\begin{tabular}{|c|c|c|c|c|c|c|c|c|c|c|c|}
\hline & & \multirow[b]{3}{*}{ () } & \multicolumn{3}{|c|}{$T^{*}=30$} & \multicolumn{3}{|c|}{$T^{*}=35$} & \multicolumn{3}{|c|}{$T^{*}=40$} \\
\hline & & & & $r$ & & & $r$ & & & $r$ & \\
\hline & & & 3 & 6 & 9 & 3 & 6 & 9 & 3 & 6 & 9 \\
\hline \multirow{3}{*}{$A^{*}$} & \multirow{3}{*}{$w g$} & 2 & 12.91 & 28.89 & 68.82 & 14.71 & 31.14 & 71.66 & 16.42 & 32.99 & 73.66 \\
\hline & & 5 & 20.47 & 42.86 & 95.91 & 25.24 & 48.83 & 103.40 & 30.52 & 54.51 & 109.53 \\
\hline & & 8 & 34.68 & 67.97 & 142.28 & 47.36 & 83.81 & 162.12 & 63.64 & 101.32 & 180.99 \\
\hline \multirow{3}{*}{$-\mathrm{df} 1 / \mathrm{df} 2$} & \multirow{3}{*}{$w g$} & 2 & $\begin{array}{c}-5.99 \\
\end{array}$ & $\begin{array}{l}-5.78 \\
\end{array}$ & -5.75 & -5.26 & -5.36 & -5.52 & -4.71 & -5.06 & -5.37 \\
\hline & & 5 & -3.78 & -3.90 & -4.12 & -3.06 & -3.42 & -3.83 & -2.53 & -3.06 & -3.61 \\
\hline & & 8 & -2.23 & -2.46 & -2.78 & -1.63 & -1.99 & -2.44 & -1.22 & -1.65 & -2.19 \\
\hline \multirow{3}{*}{$-\mathrm{df1} / \mathrm{df3}$} & \multirow{3}{*}{$w g$} & 2 & $\begin{array}{l}-0.77 \\
\end{array}$ & -1.68 & -2.69 & -0.71 & -1.59 & -2.61 & $\begin{array}{l}-0.64 \\
\end{array}$ & -1.51 & -2.55 \\
\hline & & 5 & -0.71 & -1.54 & -2.51 & -0.61 & -1.41 & -2.38 & -0.52 & -1.28 & -2.26 \\
\hline & & 8 & -0.64 & -1.41 & -2.32 & -0.53 & -1.23 & -2.12 & -0.41 & -1.04 & -1.92 \\
\hline \multirow{3}{*}{$-\mathrm{dfl} 1 \mathrm{df4}$} & \multirow{3}{*}{$w g$} & 2 & -25.75 & -27.93 & -29.90 & -23.52 & -26.46 & -29.02 & -21.33 & -25.12 & -28.30 \\
\hline & & 5 & -23.51 & -25.75 & -27.93 & -20.47 & -23.52 & -26.46 & -17.36 & -21.33 & -25.12 \\
\hline & & 8 & -21.38 & -23.51 & -25.75 & -17.64 & -20.47 & -23.52 & -13.74 & -17.36 & -21.33 \\
\hline \multirow{3}{*}{$-\mathrm{df} 1 / \mathrm{df5}$} & \multirow{3}{*}{$w g$} & 2 & -1.00 & -1.00 & -1.00 & -1.00 & -1.00 & -1.00 & -1.00 & -1.00 & -1.00 \\
\hline & & 5 & -1.00 & -1.00 & -1.00 & -1.00 & -1.00 & -1.00 & -1.00 & -1.00 & -1.00 \\
\hline & & 8 & -1.00 & -1.00 & -1.00 & -1.00 & -1.00 & -1.00 & -1.00 & -1.00 & -1.00 \\
\hline \multirow{3}{*}{$-\mathrm{df} 2 / \mathrm{df} 3$} & \multirow{3}{*}{$w g$} & 2 & -0.13 & -0.29 & -0.47 & -0.13 & -0.30 & -0.47 & -0.14 & -0.30 & -0.47 \\
\hline & & 5 & -0.19 & -0.40 & -0.61 & -0.20 & -0.41 & -0.62 & -0.21 & -0.42 & -0.63 \\
\hline & & 8 & -0.29 & -0.57 & -0.83 & -0.32 & -0.62 & -0.87 & -0.34 & -0.63 & -0.88 \\
\hline \multirow{3}{*}{$-\mathrm{df} 2 / \mathrm{df} 4$} & \multirow{3}{*}{$w g$} & 2 & -4.30 & -4.83 & -5.20 & -4.47 & -4.93 & -5.26 & -4.53 & -4.96 & -5.27 \\
\hline & & 5 & -6.22 & -6.61 & -6.77 & -6.68 & -6.87 & -6.92 & -6.85 & -6.96 & -6.96 \\
\hline & & 8 & -9.59 & -9.56 & -9.26 & -10.80 & -10.27 & -9.64 & -11.31 & -10.53 & -9.76 \\
\hline \multirow{3}{*}{$-\mathrm{df3} / \mathrm{df} 4$} & \multirow{3}{*}{$w g$} & 2 & -33.33 & -16.67 & -11.11 & -33.33 & -16.67 & -11.11 & -33.33 & -16.67 & -11.11 \\
\hline & & 5 & -33.33 & -16.67 & -11.11 & -33.33 & -16.67 & -11.11 & -33.33 & -16.67 & -11.11 \\
\hline & & 8 & -33.33 & -16.67 & -11.11 & -33.33 & -16.67 & -11.11 & -33.33 & -16.67 & -11.11 \\
\hline
\end{tabular}

Note: $w_{0}=1, c=15, F=0, T=40$.

Finally, the relationship between the performance fee $\left(f_{3}\right)$ and the asset management fee $\left(f_{4}\right)$ is depicted in the third cell of the third column of Table 23. A one percent increase in the asset management fee corresponds to a percentage change in the performance fee that is equal to the inverse of the interest rate. Like all other relationships not involving the flat fee this specific relationship is not affected by the level of initial wage or contribution rate. In addition, it is not affected by wage growth. The intuition behind this is easy to explain by noticing that the two fees affect the net rate of return $n r$ only. The compensating variation of one fee w.r.t. the other fee needs to keep $n r$ constant in order 
to have a neutral impact on the end of period cash balance. Therefore, the compensating variation in the performance fee will always take the form of:

$$
\frac{d f_{3}}{d f_{4}}=-\frac{1}{r}
$$

Notice we have not discussed the any relationship involving the end of period fee $\left(f_{5}\right)$ with the exception of the relationship between the end of period fee and the contribution fee. It is easy to see that, since $d f_{1}=d f_{5}$, it must be the case that $\frac{d f_{i}}{d f_{5}}=\frac{d f_{i}}{d f_{1}} \forall i$ and hence, the inverse of what discussed above applies to the relationship between any of the fees here presented and the end of period fee. 


\section{APPENDIX C}

\section{The Charge Ratio}

This appendix details the calculations of the charge ratio. It uses the notation developed in APPENDIX B.

For $w g$ unequal to both $r$ and $n r$ the accumulated balance without fees is given by:

$$
A^{*}\left(0, c, T^{*}, T\right)=e^{r T} w_{0} c \frac{e^{(w g-r) T^{*}}-1}{w g-r}
$$

The accumulation ratio is given by:

$$
A R\left(F, c, T^{*}, T\right)=\frac{A^{*}\left(F, c, T^{*}, T\right)}{A^{*}\left(0, c, T^{*}, T\right)}=
$$

The charge ratio is given by:

$$
C R\left(F, c, T^{*}, T\right)=1-A R\left(F, c, T^{*}, T\right)
$$




\section{APPENDIX D}

return calculations as measures of performance.

\section{Dollar Weighted Rate of Return}

The dollar weighted rate of return, or internal rate of return (IRR), is a methodology widely used until some thirty years ago to calculate performance. The IRR is related to the present value of a future stream of income: indeed it is the value of the discount rate that equates present value with future values of cash flows at different point in time. When cash flows are present the solution to the following equation yields the IRR:

$$
V_{0}+\sum_{i=1}^{n} C_{s} e^{-r t_{i}}-V_{n+1} e^{-r t_{n+1}}=0
$$

where $V_{0}$ is the value of the fund at the beginning of the period, $C_{i}$ is the $i$-th cash flow (positive or negative) in or out of the fund during the period, $V_{n+1}$ is the value of the fund at the end of the period, $t_{i}$ is the time in years from the beginning of the period until the $i$ th cash flow, and $r$ is the IRR.

Notice that since the end of period portfolio value $V_{n+1}$ is a function of $C_{i}$, the IRR will also be a function of $C_{i}$. In other words, the IRR has the problem that it is affected by the value, number and timing of cash flows that should have nothing to do with performance of the asset or the manager managing it.

\section{Time Weighted Rates of Return}

Due to this major shortcoming of the IRR a move towards time weighted measures of rate of return was put forward by the Bank Administration Institute (BAI) in 1968. While the IRR reconciles the present value with future values, including cash flows, time weighted returns ignore cash flows and only consider the money in the fund during the period. Here different methods have been proposed:

\section{The Linked IRR}

The Linked IRR calls 1) for dividing the period for which the rate of return is to be calculated into sub-periods where cash flows serve as sub-period boundaries, 2) valuing the portfolio in each sub-period; 3) compute the IRR for each sub-period; and 4) geometrically link the IRRs for each sub-period to obtain a time weighted rate of return for the whole period. Although, technically correct, this method has the disadvantage that the portfolio market value at the beginning and the ending of each sub-period has to be known, as well as the timing and value of each cash flow.

\section{The ICAA RR}

The Investment Counsel Association of America ICAA rate of return simplifies the process of treating cash flows by focusing only on the beginning and end of the period 
values of the portfolio, net total cash flows including income and reinvested income. The formula proposed by the ICAA is:

$$
r=\frac{E M V+I-\frac{N C}{2}}{B M V+\frac{N C}{2}}-1
$$

where $B M V$ is the value of the portfolio at the beginning of the period, $E M V$ is the value of the portfolio at the end of the period, $\mathrm{NC}$ is the net cash flow within the period (from any source including reinvestment income), $I$ is the total income within the period and $\mathrm{r}$ is the ICAA rate of return. The formula has the following three obvious shortcomings.

The formula assumes that between the beginning and the end of the period the market value of the portfolio changes linearly, clearly an approximation.

The formula ignores the timing of cash flows and therefore it is only an approximation of the true time weighted rate of return. In fact $N C / 2$ in the formula has the effect of "allocating" cash flows equally to the beginning and the end of the period. In other words, the formula assumes that all cash flows take place in the middle of the period under valuation. Hence, irrespectively of when contributions to a pension funds are made, these are assumed to be in the fund only 15 days per month (say).

The formula also treats reinvested income as a cash flow when this is not the case. Indeed, unless income is redistributed, it remains in the fund and should be considered appreciation of the end of period value of the portfolio. In other words, while cash flows should not affect performance, appreciation should. In the formula 50 of the income "appreciates" the end of the period value of the portfolio while re-invested income appreciates the beginning of the period value of the portfolio. This approximation is acceptable only when reinvested income is in the neighborhood of zero. In order to see this re-write (D.2) as:

$$
r=\frac{E M V+I-\frac{I+\overline{N C}}{2}}{B M V+\frac{I+\overline{N C}}{2}}-1
$$

where $\overline{N C}$ is now the true net cash flow for the period excluding reinvested income and where all the income is reinvested. The first derivative of $r$ w.r.t. I yields:

$$
\frac{\partial r}{\partial I}=(B M V-E M V)\left(B M V+\frac{I+\overline{N C}}{2}\right)^{-2}
$$

the sign of which is determined by the first factor. When $E M V>B M V$ the formula underestimates the rate of return and when $E M V<B M V$ the formula overestimates the 
rate of return. Furthermore, the error increases with the value of total income within the period as $\frac{\partial^{2} r}{\partial I^{2}}=<0$.

\section{The Dietz RR}

The Dietz rate of return (Kirschman and Dietz, 1983) addresses the second shortcoming above mentioned: i.e., the lack of separation between cash flows and reinvested income. In their paper, Kirschman and Dietz (1983) propose the following formula:

$$
r=\frac{E M V+\frac{\overline{N C}}{2}}{B M V+\frac{\overline{N C}}{2}}-1
$$

which still assumes that cash flows occur at the middle of the period and does not address the problem of the linear change in the market value of the portfolio.

\section{The Modified Dietz RR}

Kirschman and Dietz recognize the shortcoming of ignoring the timing of the cash flows by proposing to day-weight cash flows to address the problem of all midpoint methods. In other words:

$$
r=\frac{E M V-\sum_{i=1}^{n}\left(1-w_{i}\right) C_{i}}{B M V+\sum_{i=1}^{n} w_{i} C_{i}}-1
$$

where $C_{i}$ is the cash flow (positive or negative) in or out of the portfolio and $w_{i}$ is the proportion of days in the period that the cash flow has been in or out of the portfolio.

Day weighting has an ambiguous impact on the rate of return relatively to what produced by the Dietz formula. When $E M V>B M V$, (D.6) will be higher (lower) than (D.5) if $w_{i}$ is lower (higher) than 0.5. When $E M V<B M V$, (D.6) will be lower (higher) than (D.5) if $w_{i}$ is lower (higher) than 0.5. Furthermore, the differences increases with the value of $w_{i}$ as $\frac{\partial^{2} r}{\partial w^{2}}=<0$. The intuition behind this is that when $E M V>B M V$, by ignoring the extra amount of time that the money has spent in (out) of the fund, (D.5) underestimates (overestimates) performance.

The modified Dietz RR still assumes that the market value of the fund changes linearly within the period.

\section{The Unit Value Method}

The unit value method allows us to obtain true time weighted rate of returns. With this method the value of the fund at the beginning of the period is used as a base for all the calculations. Cash flows and changes in asset value are reflected in changes in the base value. Performance is then calculated by geometrically chain linking the rate of return 
calculated for any change in the base value. In order to adopt this methodology, the fund needs to be revalued before and after every cash flow. Furthermore, since the base value at any time is a function of all the changes in the base value since the beginning of the period, any adjustment made to early entries would require a re-calculation of all rates of return after the adjustment is made.

The calculation of the rate of return using the unit value method is simply the ratio of the end of period base value over the beginning of period base value:

$$
r=\frac{E B V}{B B V}-1
$$

\section{Comparing the Different Methodologies}

A simple example (which we call "Case A", for simplicity), reported in the following table, allows us to compare the different methodologies presented before.

Table 25: Comparing RR methodologies - Case A

\begin{tabular}{rrrrrrr}
\hline $\begin{array}{c}\text { Number } \\
\text { of Days }\end{array}$ & Mkt. Value & $\begin{array}{c}\text { Change in } \\
\text { Mkt. Value }\end{array}$ & Income & Cash Flow & $\begin{array}{c}\text { Number } \\
\text { of Units }\end{array}$ & Base Value \\
\hline 1 & $\$ 250,000$ & & & & 1000.00 & 250.000 \\
5 & $\$ 276,000$ & $\$ 25,000$ & $\$ 1,000$ & & 1000.00 & 276.000 \\
7 & $\$ 326,000$ & & & $\$ 50,000$ & 1181.16 & 276.000 \\
15 & $\$ 327,000$ & $\$ 1,000$ & & & 1181.16 & 276.847 \\
20 & $\$ 321,500$ & $-\$ 500$ & & $-\$ 5,000$ & 1163.10 & 276.417 \\
30 & $\$ 320,500$ & $-\$ 1,000$ & & 1163.10 & 275.557 \\
\hline
\end{tabular}

The fund has an initial position of US $\$ 250$ thousand which corresponds to 1000 units and a base value of 250 . After five days there is a change in market value of US\$25 thousand, due to revaluation of underlying assets (say), and income of US\$1000. The number of units does not change and the base value changes as the market value has appreciated. After 7 days there is a positive cash flow (contribution) of US\$50 thousand. This does not change the base value but increases the number of units by around 181, bought at the most recent available price 276. (Alternatively one can imagine that valuation is made on a daily basis and that the market value has not changed between day 5 and 6). After 15 days we have another market value appreciation that has the same impact of US\$1 thousand. This has no impact on the number of units but it increases the base value. After day 20 we have a minor depreciation and a negative cash flow of US\$5 thousand. These reduce both the number of units and the base value. A final depreciation of US\$1 thousand on the last day of the period further reduces the base value. The following table reports the result of the different rate of return calculations.

Table 26: Comparing RR methodologies - Case A

\begin{tabular}{ccccc}
\hline IRR & ICAA & Dietz & MDietz & Unit Value \\
\hline $8.531 \%$ & $9.725 \%$ & $9.358 \%$ & $9.871 \%$ & $10.223 \%$ \\
\hline
\end{tabular}


The calculated rate is around $10.2 \%$ given essentially by the US $\$ 25$ thousand realized in day 5 but the approximations of the true time weighted rate of return (TWRR) method can deviate substantially from the $10.2 \%$ due to the presence of large cash flows.

It is then interesting to investigate how large the cash flows need to be in order to make the TWRR approximations too inferior w.r.t. the unit value method. For such a purpose we have set up the following 4 artificial cases, a simplified version of "Case A" before described.

- Case B: Price appreciation of $10 \%$ on day 15 (mid month) and large (>10\%) cash flow at the beginning of the month.

- Case C: Price appreciation of $10 \%$ on day 15 (mid month) and large (>10\%) cash flow at the end of the month.

- Case D: Price appreciation of $10 \%$ on day 15 (mid month) and small $(<10 \%)$ cash flow at the beginning of the month.

- Case E: Price appreciation of $10 \%$ on day 15 (mid month) and small $(<10 \%)$ cash flow at the end of the month.

The data for these cases are reported in the next 4 tables.

Table 27: Comparing RR methodologies - Case B

\begin{tabular}{|c|c|c|c|c|c|c|}
\hline $\begin{array}{l}\text { Number } \\
\text { of Days }\end{array}$ & Mkt. Value & $\begin{array}{l}\text { Change in } \\
\text { Mkt. Value }\end{array}$ & Income & Cash Flow & $\begin{array}{l}\text { Number } \\
\text { of Units }\end{array}$ & Base Value \\
\hline 1 & $\$ 250,000$ & & & & 1000.00 & 250.000 \\
\hline 2 & $\$ 330,000$ & & & $\$ 80,000$ & 1320.00 & 250.000 \\
\hline 7 & $\$ 330,000$ & & & & 1320.00 & 250.000 \\
\hline 15 & $\$ 363,000$ & $\$ 33,000$ & & & 1320.00 & 275.000 \\
\hline 29 & $\$ 363,000$ & & & & 1320.00 & 275.000 \\
\hline 30 & $\$ 363,000$ & & & & 1320.00 & 275.000 \\
\hline
\end{tabular}

Table 28: Comparing RR methodologies - Case C

\begin{tabular}{|c|c|c|c|c|c|c|}
\hline $\begin{array}{c}\text { Number } \\
\text { of Days }\end{array}$ & Mkt. Value & $\begin{array}{l}\text { Change in } \\
\text { Mkt. Value }\end{array}$ & Income & Cash Flow & $\begin{array}{l}\text { Number } \\
\text { of Units }\end{array}$ & Base Value \\
\hline 1 & $\$ 250,000$ & & & & 1000.00 & 250.000 \\
\hline 2 & $\$ 250,000$ & & & & 1000.00 & 250.000 \\
\hline 7 & $\$ 250,000$ & & & & 1000.00 & 250.000 \\
\hline 15 & $\$ 275,000$ & $\$ 25,000$ & & & 1000.00 & 275.000 \\
\hline 29 & $\$ 355,000$ & & & $\$ 80,000$ & 1290.91 & 275.000 \\
\hline 30 & $\$ 355,000$ & & & & 1290.91 & 275.000 \\
\hline
\end{tabular}

Table 29: Comparing RR methodologies - Case D

\begin{tabular}{|c|c|c|c|c|c|c|}
\hline $\begin{array}{l}\text { Number } \\
\text { of Days }\end{array}$ & Mkt. Value & $\begin{array}{l}\text { Change in } \\
\text { Mkt. Value }\end{array}$ & Income & Cash Flow & $\begin{array}{l}\text { Number } \\
\text { of Units }\end{array}$ & Base Value \\
\hline 1 & $\$ 250,000$ & & & & 1000.00 & 250.000 \\
\hline 2 & $\$ 262,000$ & & & $\$ 12,000$ & 1048.00 & 250.000 \\
\hline 7 & $\$ 262,000$ & & & & 1048.00 & 250.000 \\
\hline 15 & $\$ 288,200$ & $\$ 26,200$ & & & 1048.00 & 275.000 \\
\hline 29 & $\$ 288,200$ & & & & 1048.00 & 275.000 \\
\hline 30 & $\$ 288,200$ & & & & 1048.00 & 275.000 \\
\hline
\end{tabular}


Table 30: Comparing RR methodologies - Case E

\begin{tabular}{rrrrrrr}
\hline $\begin{array}{c}\text { Number } \\
\text { of Days }\end{array}$ & Mkt. Value & $\begin{array}{c}\text { Change in } \\
\text { Mkt. Value }\end{array}$ & Income & Cash Flow & $\begin{array}{c}\text { Number } \\
\text { of Units }\end{array}$ & Base Value \\
\hline 1 & $\$ 250,000$ & & & 1000.00 & 250.000 \\
2 & $\$ 250,000$ & & & 1000.00 & 250.000 \\
7 & $\$ 250,000$ & & & 1000.00 & 250.000 \\
15 & $\$ 275,000$ & $\$ 25,000$ & $\$ 12,000$ & 1000.00 & 275.000 \\
29 & $\$ 287,000$ & & & 1043.64 & 275.000 \\
30 & $\$ 287,000$ & & & & \\
\hline
\end{tabular}

The following table compares the rate of return calculations in these four cases.

Table 31: Comparing RR methodologies - Case B - E

\begin{tabular}{cccccc}
\hline Case & IRR & ICAA & Dietz & MDietz & Unit Value \\
\hline B & $9.687 \%$ & $11.379 \%$ & $11.379 \%$ & $12.924 \%$ & $10.000 \%$ \\
C & $9.439 \%$ & $8.621 \%$ & $8.621 \%$ & $7.637 \%$ & $10.000 \%$ \\
D & $9.560 \%$ & $10.234 \%$ & $10.234 \%$ & $10.447 \%$ & $10.000 \%$ \\
E & $9.517 \%$ & $9.766 \%$ & $9.766 \%$ & $9.557 \%$ & $10.000 \%$ \\
\hline
\end{tabular}

When net cash flows are large and take place before the (positive) change in asset value, the true TWRR approximations substantially overestimate the unit value method. In Case B the cash flow is $32 \%$ the market value of the portfolio and the overestimation of the Dietz modified formula is around 300 basis points. When net cash flows are large and take place after the (positive) change in asset value, the true TWRR approximations substantially underestimates the unit value method. When cash flows are small and take place before the (positive) change in asset value, the true TWRR approximations only marginally overestimates the unit value method. In Case D the cash flow is $4.8 \%$ of the market value of the portfolio and the overestimation is of the Dietz modified formula is around 44 basis points.

In general, the error made in using approximations of the unit value method increases with the distance in time between the cash flow and the realization of the change in asset value. It is smallest when the two events coincide. Finally the error tends to zero when the asset base increases relatively to the size of cash flows. 